\title{
Where Next? A Study of Work and Life Experiences of Mature Students (incl. Disadvantaged) in Three Higher Education Institutions
}

\author{
Aidan Kenny \\ Technological University Dublin, aidan.kenny@tudublin.ie \\ Ted Fleming \\ National University of Ireland, Maynooth, ted.fleming@nuim.ie \\ Andrew Loxley \\ Trinity College Dublin, loxleya@tcd.ie
}

See next page for additional authors

Follow this and additional works at: https://arrow.tudublin.ie/beschreoth

Part of the Adult and Continuing Education Administration Commons, Community College Education Administration Commons, Community College Leadership Commons, Disability and Equity in Education Commons, Higher Education Administration Commons, and the Special Education Administration Commons

\section{Recommended Citation}

Kenny, A., Fleming, T., Loxley A., Finnegan F.: Where Next? A Study of Work and Life Experiences of Mature Students (incl. Disadvantaged) in Three Higher Education Institutions. Combat Poverty Agency, Working Paper 10/02, Ireland. ISBN: 978-0-9565660-0-3 April 2010. doi:10.21427/8rkr-z084

This Working Paper is brought to you for free and open access by the School of Surveying and Construction Management at ARROW@TU Dublin. It has been accepted for inclusion in Other Resources by an authorized administrator of ARROW@TU Dublin. For more information, please contact arrow.admin@tudublin.ie, aisling.coyne@tudublin.ie, gerard.connolly@tudublin.ie. 


\section{Authors}

Aidan Kenny, Ted Fleming, Andrew Loxley, and Fergal Finnegan

This working paper is available at ARROW@TU Dublin: https://arrow.tudublin.ie/beschreoth/42 


\title{
Where Next?
}

\section{A Study of Work and Life Experiences of Mature Students (incl. Disadvantaged) in Three Higher Education Institutions}

\author{
Ted Fleming, Andrew Loxley, Aidan Kenny \\ \& Fergal Finnegan
}

Combat Poverty Agency

Working Paper 10/02

ISBN: 978-0-9565660-0-3

April 2010

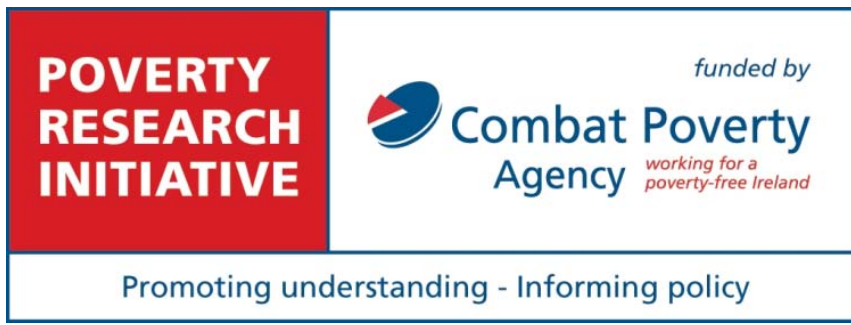




\section{Acknowledgements}

The researchers would like to acknowledge the always generous and enthusiastic engagement of the graduates of the three colleges who were interviewed for this research. Without them there could be no report and we hope to have faithfully carried their stories and experiences into this policy arena.

In all the three Higher Education institutions of National University of Ireland Maynooth, Trinity College Dublin and Dublin Institute of Technology we relied heavily on the goodwill and support of colleagues both in the administration and student support areas. Their willingness to co-operate and give access to information was welcome and allowed us to also experience the kind of response the students talk about so warmly.

The project team is hugely appreciative of the support we received from Ekaterina Kozina (TCD) whose work was invaluable on the project. We wish to thank The Alumni Office, Community Links, Prof. Frank McMahon, Dr Thomas Duff, Dr Anne Murphy, Dr Thomas Cooke, Dave Kilmartin, and a number of other people from the administrative units in DIT who kindly assisted this project. We would like to thank Fiona McKibben of TCD for once again entering yet more questionnaire data into the computer analysis system. At NUIM we are particularly indebted to Ann O'Brien, Emer Sheerin and Loretta Jennings for their generous help.

Finally, as research colleagues we wish to thank Combat Poverty Agency for supporting the project. 


\section{Abstract}

This study explores how graduates who entered college as mature students, and 'disadvantaged' mature students, view and value Higher Education after graduating with a primary degree. The study highlighted the limited usefulness of the concept of disadvantaged mature student and the findings of the research were not significantly different whether one was a mature student or a disadvantaged mature student. The rationale given by the state for supporting mature students in Higher Education (HE) is that it will yield economic and social benefits for both the students and society. As a consequence a wide range of access policies has been developed to support the entry of 'non-traditional' students. However, to date there is very little research on what happens to such students while in HE and after graduation. This research gathered quantitative and qualitative data from the graduates of NUI Maynooth, Trinity College Dublin and the Dublin Institute of Technology. The economic, social and personal benefits of participation in Higher Education were examined as were barriers to further career and career progression. Although most students valued their educational experience very highly the monetary benefits were more modest than expected. But the educational qualifications enabled many graduates to move away from routine work often with low levels of autonomy, status and pay. Overall, the research shows that for working-class mature students, students with disabilities and ethnic minorities HE is a highly valued transitional space that affords a greater level of career choice and opportunities to renegotiate aspects of personal identities.

Key Words: mature students; access; Higher Education

\section{Disclaimer}

This report was funded by the Combat Poverty Agency under its Poverty Research Initiative. The views, opinions, findings, conclusions and/or recommendations expressed here are strictly those of the author(s). They do not necessarily reflect the views of the Combat Poverty Agency, which takes no responsibility for any errors or omissions in, or for the accuracy of, the information contained in this Working Paper. It is presented to inform and stimulate wider debate among the policy community and among academics and practitioners in the field.

(c) Ted Fleming (2009) 

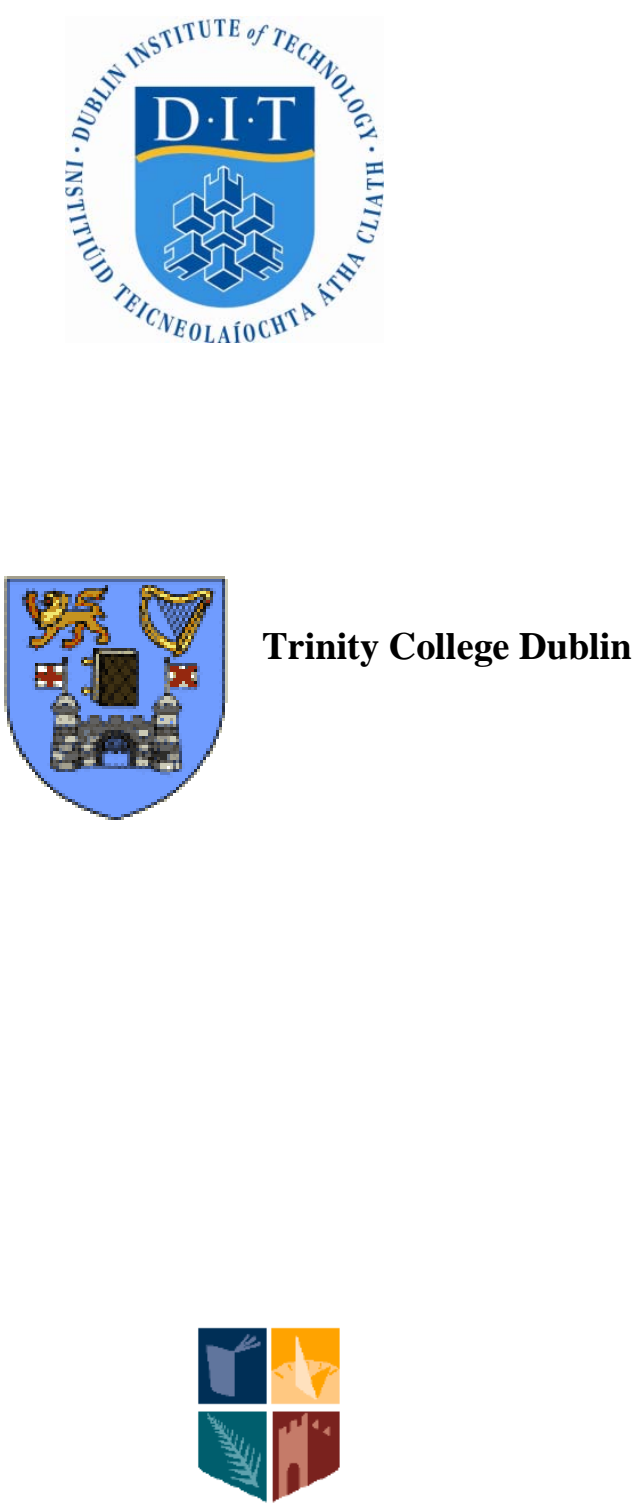

NUI MAYNOOTH

Ollscoil na hÉireann Má Nuad 


\section{Contents}

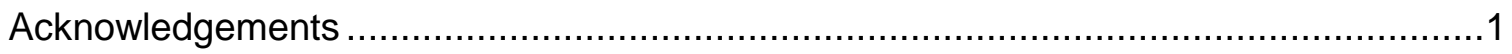

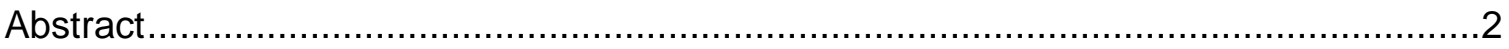

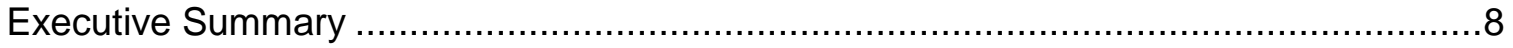

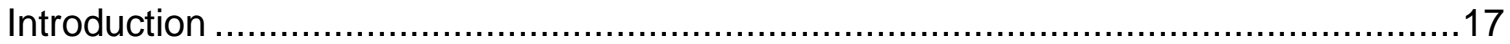

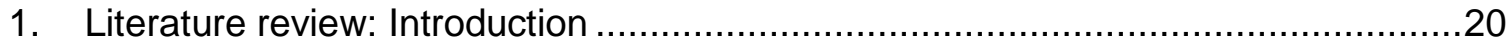

1.1 The context for the research: Mature students in educational and social policy

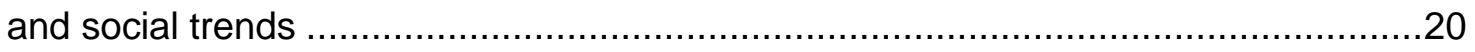

1.2 Issues and problems in assessing the impact of access policies...................25

1.3 Access to what? Graduate outcomes and post-degree destinations ..............28

1.4 Human capital, cultural capital and lifelong learning: Theoretical considerations 31

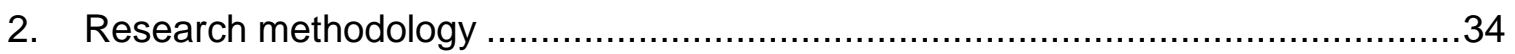

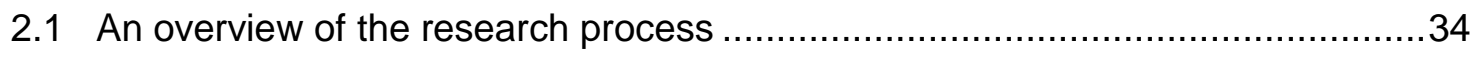

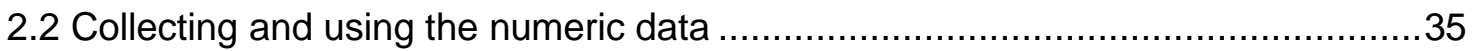

3. Brief Information on the Three Higher Education Institutions ...........................42

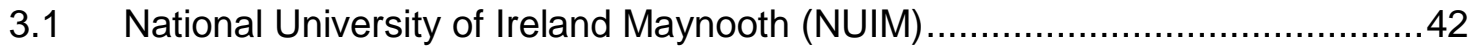

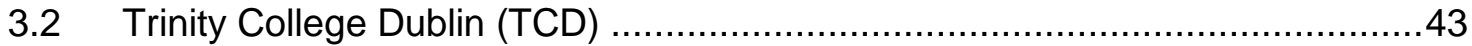

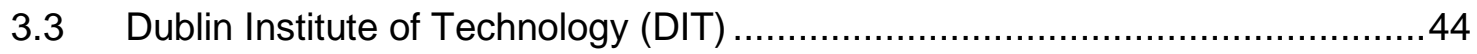

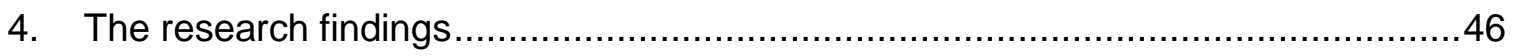

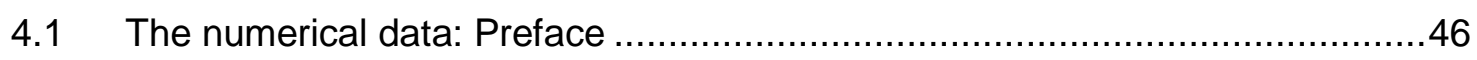

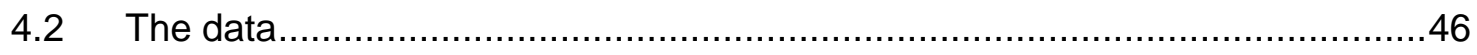

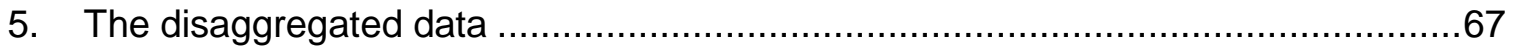

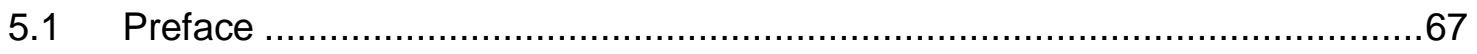

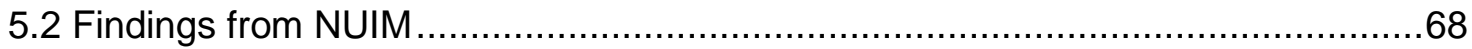

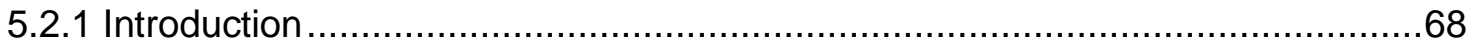

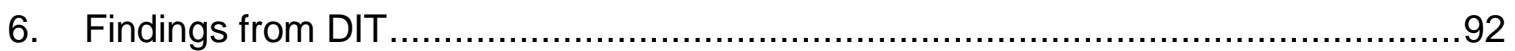

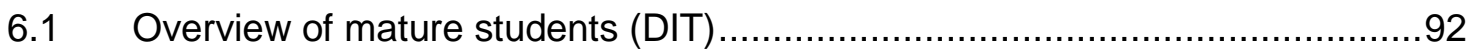

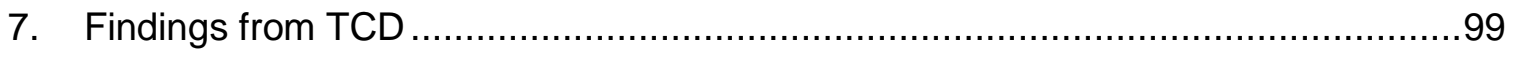

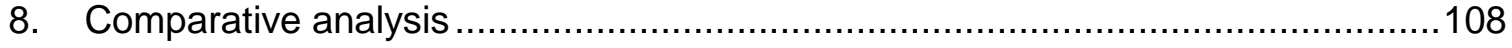

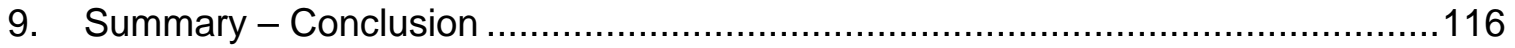

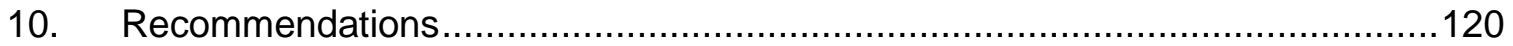

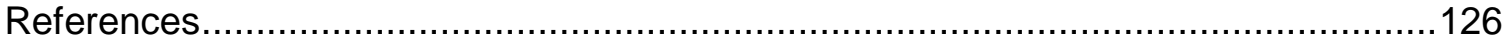




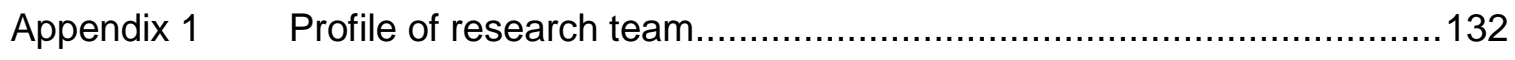

Appendix 2 The Interview Schedule for Students ..................................... 134

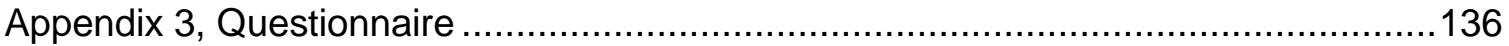




\section{LIST OF TABLES AND FIGURES}

Figure 1 Total number of persons in full-time third level education

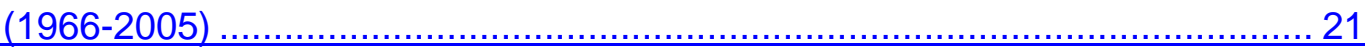

Figure 2 Projected growth in higher education 2003-2015.......................... 22

Figure $3 \quad$ Average Salaries by age of level 8 bachelors degree graduates ..... 29

Figure $4 \quad$ Unemployment rate of persons aged 25-64 …………………….... 30

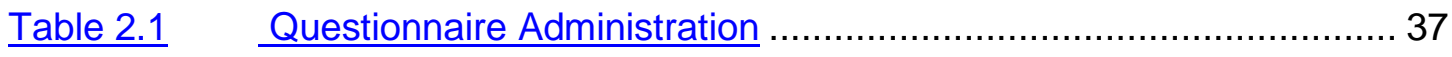

Table 2.2 Interview Sample Sizes and Methods Utilised ................................ 41

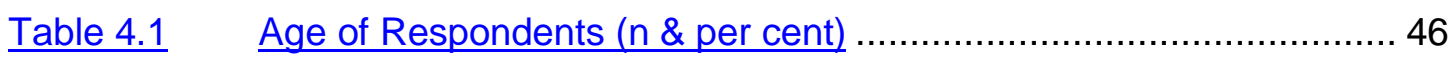

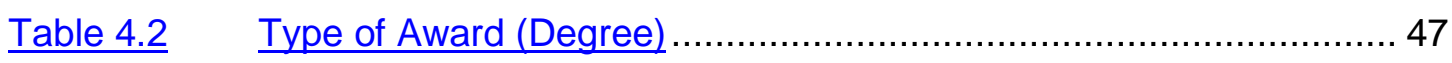

Table 4.3 Socioeconomic Groups Prior to Studying ....................................... 48

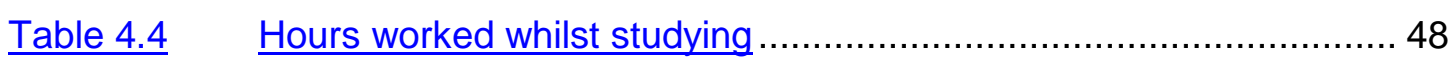

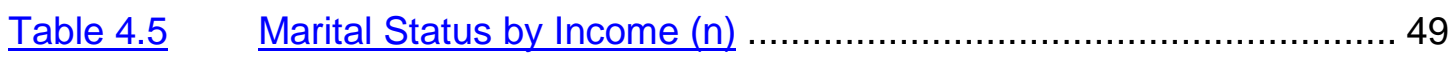

Table 4.6 Paid Employment by Social Welfare and Grant Status (per cent)..... 50

Table 4.7 Reported Average Hours Worked Whilst Studying ……................... 50

Table 4.8 Mean hours worked by social welfare status ……........................... 51

Table 4.9 Importance of Social Welfare Support (per cent) ……..................... 52

Table 4.10 Size of Debt Incurred whilst Studying ............................................ 52

Table 4.11 Debts incurred by worked whilst studying (per cent)..........................5 53

Table 4.12 Debts incurred by Financial Support (per cent) …….......................... 53

Table 4.13 Selected Items Asking about Students' Experience

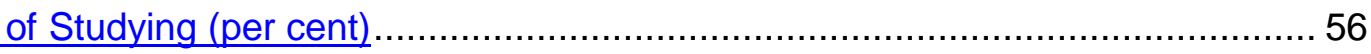

Table 4.14 Selected Items about Students' Work \& Employment

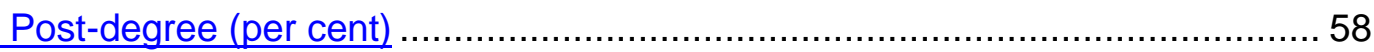

Table 4.15 Non-paid Work Destinations (per cent)_............................................ 59

Chart 2.1 Distribution of current (2008) gross income in €K (per cent) ............. 60

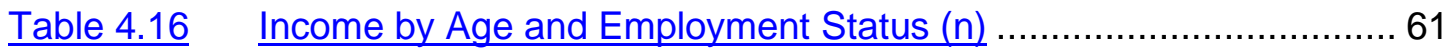

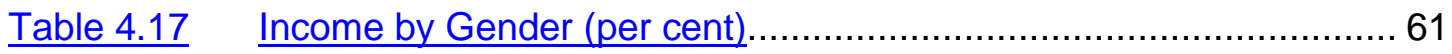

Table 4.18 Expected v Actual Earnings Post-Degree (per cent).......................... 61

Table 4.19 Income Post-degree by Actual Increase .......................................... 62

Table 4.20 Social Class 'Now' by Social Class 'Then' (n) ................................... 63

Table 4.21 Type of Postgraduate Programme Completed ................................ 64

Table 4.22 Income post-degree: Disadvantaaged ............................................65 
Table 8.1 Reported Hours Worked as Student (n) .................................. 106

Table 8.2 Financial Support by Institutions (n) …................................. 107

Table 8.3 Reported Level of Student Debt by Institutions (per cent)................ 107

Table 8.4 Responses to the statement: Studying for a degree

has changed me personally ............................................................ 109

Table 8.5 Response to the statement: Having a degree makes me

feel confident about my career prospects.............................................. 109

Table 8.6 Responses to the statement: It was necessary for me

to have degree for the job I wanted ................................................... 109

Table 8.7 Participants reported Gross Annual Income (2008) ...................... 110

Table 8.8 Reported increase in earning post-degree.................................. 110

Table 8.9 Response to the question: Did you expect your earning

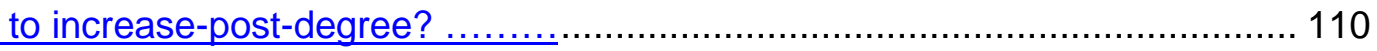

$\underline{\text { Table } 8.10}$ Completion of Postgraduate Qualifications ............................... 111

Table 8.11 Reasons for Undertaking Postgraduate Qualifications (n) ............. 111

Table 8.12 Comparative Matrix of Interview Data ..................................... 112 


\section{Executive Summary}

The study explored the post first-degree destinations (employment, postgraduate education or otherwise) of mature students in three Irish Higher Education institutions: National University of Ireland Maynooth (NUIM), Trinity College Dublin (TCD) and Dublin Institute of Technology (DIT). The report utilises a concept of destination that is broader than employment and salary. It is a finding of the report that destination, from the perspective of the students who graduated, includes a broader range of concepts and categories that they associate with concepts of success and destination. This includes esteem, selfconcept, identity, family and quality of life as distinct from the economic and monetary destinations of job and salary that underpins much public policy discourse. Concepts that are given specific meanings in public policy discourse (e.g. disadvantage, success, etc.) frequently have a broader and redefining meaning in the understanding and learning life of students. Though disadvantaged mature students were originally the subject of the research, only insignificant differences were found between them and the general body of mature students.

This research attempts to fill a noticeable gap in the 'access story' that firmly supports the entry of mature students to Higher Education (HE) and has devised a range of creative, innovative and targeted measures to enable mature students to stay the course. But research has rarely looked at the lived experience of these students, how they view HE or what happens after graduation. This is in spite of the fact that there is a well elaborated, and widely diffused, discourse within access policy which claims that measurable economic benefits result from such measures both for the State and the students themselves. Through extensive research amongst graduates this report outlines the economic, social and personal benefits of participation in Higher Education based on their stories, lived experience and judgements. The report also identifies some of the continuing obstacles to access and to further progression in their career or postgraduate studies. Through gathering qualitative and quantitative data the 
study aims to:

1. Map the post-first degree destinations of those students who have entered $\mathrm{HE}$ via an access programme or equivalent in the past seven years

2. Explore the processes and experiences of these ex-students' transition from HE into (or back into) the workplace or other arenas

3. Investigate the reflections of graduates on their motivations for entering $\mathrm{HE}$, their expectations and experiences.

It is logical to assume that aims 1 and 2 are closely linked. However, to be able to adequately describe and explain any outcomes, it is critical that they are located within the lifeworlds of the ex-students. Aim 3 is a retrospective component of the study. It enables students to reflect on their experience and evaluate whether their original expectations were realised.

The research specifically focused on:

1 The relationship between experiences of being in HE institutions and postdegree destinations

2 The relationship between type of first degree and 'choice' of destination

3 The kind and form of supports offered and provided by HE institutions to help students in their career decision making

4 The identification of and relationship between non-HE factors (e.g. finance, family context, position in life-cycle, gender, ethnicity, geographical mobility etc.) and destinations

5 Short- and long-term expectations of career paths

6 Perceived barriers to secure graduate employment and the job application process

7 Expectations and experiences of the type and nature of employment postfirst degree.

The research gathered numerical and non-numerical data. Numerical data was 
gathered through a detailed survey questionnaire using a sampling frame from which a stratified random sample was selected for interview. The questionnaire yielded significant information that was further explored in individual face-to-face interviews and focus groups.

Though ambitious targets are set by state agencies for disadvantaged mature student progression to Higher Education (HEA, 2008a) and gains have been made, the research has found that the reality falls slightly short of the targets in most institutions. Women outnumber men in accessing HE. Finance is a major facto, with many graduating in debt as a result. The state support through the Back to Education Allowance (BTEA) and other grants is essential though not sufficient. The vast majority of students worked while studying.

Nonetheless the vast majority, with only few exceptions, have positive experiences of their years of study. They deeply value the college experience, the learning, the qualification and, more often than not, the HE institutions in which they studied. In part, this is linked to overcoming previous educational exclusion earlier in their lives. For many graduates one of the most important aspects of their experience of tertiary education is that it strengthened their sense of confidence and agency. This included for many the sense that they were better placed to engage in the world around them and in their communities. The effort and sacrifices made by students were considerable and personal determination and focus were the primary characteristics of the stories told by graduates. Nonetheless, for most of the interviewees, community based education and access programmes were a vital springboard into tertiary education. In college, students relied on various supports such as grants, BTEA and access offices. Generally, graduates felt that without all, or nearly all, of these supports HE would not have been a realistic option for them.

Although financial and institutional support were important, peer support was vital. By far the most valued resource for non-traditional students was the support 
they received from their families. This included the students' family of origin and in particular their parents who in their early years encouraged learning, curiosity and engagement with questioning and discussion. This support continued through the years of study through financial and emotional support given by students' own families and their siblings. One of the key motivations for students was to be able to bring their learning, and their example, back into the family for the benefit of their children and partners.

The financial rewards for graduates are not huge although 52 per cent did increase their income. Though levels of unemployment are low among graduates (8 per cent) these figures are higher than expected when compared to the information available from the colleges. Many students were focused on using their qualification to escape from low-status, unstimulating and low-paid work. A degree was a bridge to finding work that was more meaningful. It meant having, longer holidays, more job security and greater levels of intellectual and emotional engagement. In particular, a marked number of graduates are choosing to work and start a career in education. In general this commitment to education for themselves and their families, the value placed on learning and the role they see education having amongst peers and neighbours led us to conclude that a grassroots version of the 'learning society' is flourishing among mature disadvantaged students.

The main finding is that the experience was worth it and that the escape from poverty, though a long journey, is significantly consolidated by the achievement of a university degree. However, most of the graduates we met did not come from the most disadvantaged sections of Irish society and if they had come originally from a disadvantaged background, they had, over time and through family and work, managed to overcome high levels of deprivation before studying in HE. 


\section{Recommendations}

For implementation by the Higher Education Authority and the Department of

\section{Education and Science:}

1. Support for mature disadvantaged students in education should be sustained and enhanced, even in difficult economic times. Investment in education is a vital part of the economic and social infrastructure. The graduates in this research were emphatic about both the economic and non-economic benefits of attending Higher Education. Access measures developed over the past decade have encouraged many people from underrepresented groups into Higher Education for the first time. To sustain this progress the widening access agenda should be strongly supported at all levels of education. Clearly this means maintaining free fees and the other modest financial supports, such as county councils grants, that are currently in place for mature disadvantaged students. One of the clearest findings of the research is that without such supports, attending Higher Education would have been either very difficult or impossible for many disadvantaged mature students.

2. For most graduates, access courses, adult basic education, formal and informal community education initiatives were a vital part of accessing Higher Education. The relatively modest state financial support for Adult Education should be maintained and the work of career guidance and other supports in adult education should be further integrated in widening access strategies and practices.

3. The HEA through colleges and universities should gather and make available more detailed disaggregated data on the progress and experience of mature disadvantaged students in $\mathrm{HE}$, including their postdegree destinations. Such data would be invaluable for evaluating progress on the targets that are set and would be enormously helpful for other policymakers, access offices in HEls and 'non-traditional students' 
themselves in evaluating the efficacy of widening access policies.

4. There continue to be inflexibilities in the HE system that impact on mature students. The HEA in cooperation with the HEls should re-examine the question of developing more flexible entry and progression routes into and in Higher Education. The vast majority of mature student graduates had studied in traditional full-time degree courses. Clearly, developing a greater range of options for accreditation would benefit mature students who are balancing study with other duties and major commitments. This also requires that students enrolling on recognised third level courses on a part-time basis are eligible for county council grants and other supports.

5. Any re-introduction of student fees will have a disproportionate impact on non-traditional students. Instead, financial support should be enhanced. Targeted financial support for maintenance costs is essential.

6. Learners are informed by a broader set of values than the dominant market fundamentalism of current state thinking. The benefits of supporting the wider range of motivations are significant as adults find it difficult to separate out and disconnect their career learning needs from the broader needs they have as members of families, communities and society. Lifelong learning is for workers and for citizens.

We propose for the CPA:

7 Continue to promote anti-poverty measures based on the understanding that to work against poverty is to ensure that the broad conditions for decent life are available. In a society in which attending Higher Education is increasingly seen as the norm this obviously includes improving access to education at all levels for those who, for various reasons, have been previously excluded from education. The paths from poverty are long and incremental, with few guarantees that the journey will be successful. 
Graduates rightly perceive Higher Education as an important marker on this journey which facilitates a degree of social mobility. However, improving access to education alone will clearly not be sufficient to help individuals escape from poverty.

8 Working to eliminate poverty is a multifaceted process and interventions that enhance the ability of families to encourage, support and value learning from an early age are particularly crucial. This should include strong support for affordable crèche and childminding services.

\section{We recommend that the Department of Social and Family Affairs:}

9 Maintain and develop the Back to Education Allowance initiative. This support was vital for many of the students we interviewed in their decision to attend Higher Education. With this in mind it is commendable that money for the BTEA was ring-fenced in the recent budget. However, given the large number of graduates interviewed and surveyed who felt that a postgraduate qualification was becoming 'necessary' for work in a credentialised society and the relatively small numbers of students in receipt of the BTEA, we propose that the decision in 2003 to limit the BTEA to primary degrees and teaching diplomas should be reconsidered.

10 Government departments and other responsible agencies should strive to disseminate more widely information about the available financial and social supports for mature students. Knowledge of such supports was uneven amongst graduates.

11 The Department of Education and Science, in tandem with other government bodies, should develop measures that encourage and incentivise employers to support employees in education. Support from this sector was noticeably absent amongst the students who attended TCD and NUIM. Employers should be encouraged to support third level 
learning.

For the administrators, teachers, access officers and management of the HEIs we advocate the following:

12 As noted earlier the HEA in cooperation with the HEls should re-examine the question of developing more flexible entry and progression routes into Higher Education. Rationalise the access and interview system for mature students and give increased emphasis to non-academic skills and background experience (as workers, etc.) in assessing suitability for study.

13 The work of access offices in HEls is fundamental to ensuring the participation of non-traditional students. Repeatedly students referred to help, advice and support as being important to them. Individual mature students may or may not require help but many do and it is fundamental that such support is available and that it is offered without stigma or condescension. This means that the work of Access Offices is seen as central to HEIs. In particular, the initial interview and first few months of study are critical to non-traditional students and Access Offices have a central role in both providing services and alerting staff to the needs of students at that time.

$14 \mathrm{HEls}$ concerned with improving access for migrants and HEls with a high level of 'non-national' students should consider offering targeted short courses and advice on writing and using academic English.

15 The HEls should offer age-appropriate career advice before and after degree for mature students, based on their specific needs and aspirations.

16 There is a need for more affordable, comprehensive crèche and childcare facilities for parents attending college. 
17 The persistence of poverty and disadvantage in specific geographic areas in Ireland means that local education schemes within these areas that are linked or feed into Higher Education Institutions are of real significance. Universities and colleges should continue to develop 'satellite' courses in such areas that are linked to local needs and issues but use the resources and knowledge of the university to offer high-quality accredited courses.

18 Schedule courses in HE at times that are consistent with the multiple responsibilities of adult life (child minding, time to travel, etc.).

19 Services that enhance the learning of students with disabilities have been expanded in recent years and are hugely successful. However, the EU criteria and assessment process involved in achieving recognition as a disabled person is used to allocate ordinary facilities such as car park space. HEls in allocating such facilities (e.g. car park spaces) are rigid and the procedures too onerous for students who may not meet all the criteria for full disability status but who require facilities that may be for a 'comparatively slight' or temporary disability (post-operation, or ill health due to coronary condition, etc).

20 Child minding supports and travel grants are essential and when provided are crucial to widening the participation by non-traditional groups.

21 Encourage lecturing staff in colleges and universities to be better informed about the learning needs of students with disabilities.

22 Colleges and universities should keep accurate and accessible data on non-traditional and mature students' access and progression. 


\section{Introduction}

The concept of 'human capital' has gained prominence within European and Irish contemporary education and training policy discourses. A predominant strand has been a focus on 'access' opportunities and routes to Higher Education programmes for non-standard entrants. In effect this is an input-led approach, and we know very little about the 'output' of this policy drive in terms of the 'lived experience' (Green, 2003) of students. The aim of the study is to explore the post first-degree destinations (employment, postgraduate education or otherwise) of mature students. Whilst much emphasis of a political, rhetorical and systemic nature has been placed on generating wider forms of access for this heterogeneous group of adults, little consideration has been given to what happens to them after graduation. The rationale for the state supporting students in Higher Education always refers to the increased economic benefit for the student and for society.

The report utilises a broader understood concept of destination that in normal discourse usually means employment and earning power. It is a finding of the report that destination, from the perspective of the students who graduated, includes a much broader range of concepts and categories with which they associate the concepts of success and destination. This includes esteem, selfconcept, identity, family and quality of life as distinct from the merely economic and monetary destinations of job and salary that underpin much public policy discourse. Concepts that are given specific meanings in public policy discourse (e.g. disadvantage, success, etc.) frequently have a broader and redefined meaning in the understanding and learning life of students.

In addition, the concept of disadvantage, though given specific meanings in public policy and in the newly introduced tracking mechanism used on registration, again has broader meanings in the understanding of students and was of limited use in disaggregating the impact on mature students compared to disadvantaged mature students. We met very few students who came from the 
most disadvantaged sectors of society but also met many graduates who had been, in the past, not sure of their ability to escape poverty and disadvantage. Though not fulfilling all the requirements of disadvantage many adults, by being awarded a Back to Education Allowance or who met another indicator of disadvantage (previous salary or educational achievement), qualified as 'disadvantage' for the purposes of this study. The concept of disadvantage, though given a specific meaning on the on-line registration forms for students, is in practice open to a wider range of meanings. Some of these, for example the one utilised by the TCD Access Programme (TAP) for entry onto its pre-degree foundation course, are broader and nearer the students' understanding of disadvantage:

Left school early

Attended a designated disadvantage school

Lives in a geographic area with a low progression rate into higher education

The first in family to progress to third level

A lone parent

Unemployed

Living with a disability

Has a skill loss due to life history

Member of a socio-economic group that is under represented in third level.

Such an understanding of disadvantage traverses socio-cultural as well as economic factors. These indicators are also of course highly contestable, based more on probabilities than absolutes, and are context specific.

In developing the theme of heterogeneity, this study worked with samples of exstudents from three quite distinct Higher Education Institutions (HEIs): the National University of Ireland Maynooth (NUIM), Trinity College Dublin (TCD) and the Dublin Institute of Technology (DIT). The research team comprised both academic members of staff and researchers who were already working in these 
HEIs. The research team as 'insider researchers' (Loxley and Seery 2008) developed both 'numeric' and 'non-numeric' modes of data collection and the administration of these research tools was customised by each research team for each HEI.

This report is structured into four main sections; the first section (Chapters 1-3) sets out the contextual environment in terms of literature, policy and descriptions of the three HEls. The second section (Chapters 4-7) presents the findings from each HEl separately. Section three (Chapter 8) moves towards a comparative analysis of the findings, signposting some practical considerations. The final section (Chapter 9-10) concludes and sets out what can be gained from this research and identifies policy recommendations.

The research focused on time-stratified samples of ex-students who have graduated from their first degree in each of the HEls and sought to ascertain the economic, social and personal benefits, as expressed by the participants, in the three sample groups. The research explored the participants, experiences and expectations of their participation in Higher Education and identified barriers to further progression in their career or graduate studies.

The three HE institutions involved are actively committed to working with mature students, but the effectiveness of the policies and initiatives these HEI institutions use have not been measured. The main reason for keeping the findings from the three institutions disaggregated concerns the very different institutions involved (their institutional habitus so to speak), each offering a unique range of courses and experiences and addressing different learning agendas. 


\section{Literature review: Introduction}

The following literature review outlines the context for the research by examining (1) the way disadvantaged mature students are understood within current social and educational policies; (2) the limitations of properly assessing access policies including an overview of relevant international and Irish literature that deals with mature students. This is followed by (3) an overview of what is known about postprimary degree destinations and concludes with (4) an outline of how a critique of human capital models, often dominant within contemporary educational policies, can be usefully supplemented with a theory of cultural capital and a critical version of lifelong learning. This is informed by a perspective that supports both widening access for non-traditional students and a 'thick' conception of equality (Lynch and Baker, 2005) which argues that attention should be paid to both an

equality of opportunity and an equality of outcomes. However, the primary goal of the literature review is to delineate how mature students are constructed in policy and understood in academic literature in order to frame the empirical findings of the research rather than offer a review of the literature on mature students, social mobility and third level education.

\subsection{The context for the research: Mature students in educational and social policy and social trends}

The Irish tertiary education system has been transformed over three decades (White, 2001), a process that has been further accelerated by recent rapid economic growth and social change. A once elite system of third level education has evolved into an increasingly diversified and flexible network of institutions of mass education. The overall rate of admission has risen from 20 per cent of school leavers in 1980 to 46 per cent in 1998; to 55 per cent in 2004 and to over 60 per cent in 2007 (Byrne, et al., 2008:33). The most significant expansion to date occurred in the period between 1991, when there were 69,988 full-time students in third level education, and 1996, when that number increased to 102,662. Figure 1 depicts the total number of persons in full-time HE from 1966 to 2005 , separating out the numbers in universities and the institutes of 
technology.

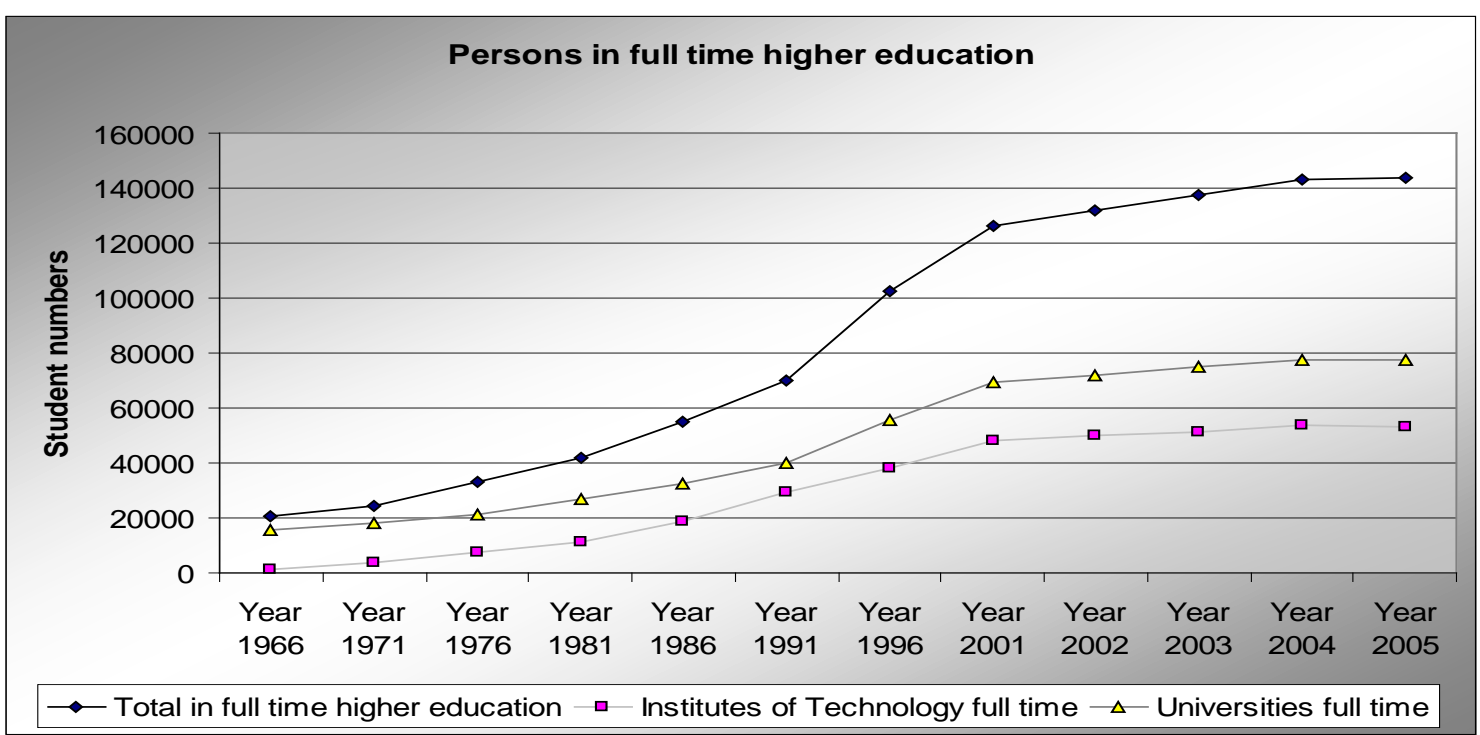

Figure 1: Total number of persons in full-time Third Level Education from 1966 to 2005, according to Universities and Institutes of Technology (adapted from CSO, DES and HEA figures).

These changes are in line with international trends (Trow, 1979). This is clearly linked to broader social, technological and economic changes that have transformed the role of third level education in relation to the market and society. As a consequence, tertiary education occupies a prominent role in government policy and is now tasked with addressing wider social and economic agendas.

The government (HEA, 2008a) is committed to further increasing participation in third level education up to 2015 (Figure 2). Since the early 1990s Irish policymakers have prioritised improving access and widening participation for people who have traditionally been under-represented. Widening participation has been given greater impetus by recent legislation such as the Equal Status Act, 2000 and Disability Act, 2005.

Improving access to education is seen as the key to solving a range of social issues and overcoming the disadvantage experienced by working class and other 'non-traditional' students (DES, 1995, 2000, 2001; NOEA, 2005, 2007, 2008; 
Skilbeck and O'Connell, 2000a). This expansion has great importance for ensuring the future vitality of tertiary institutions (DES, 2001) and for maintaining economic competitiveness and flexibility (Dempsey, 2004; HEA, 2008b) a point of view that is also advocated by the OECD (2004) and the EU (CEC, 2000).

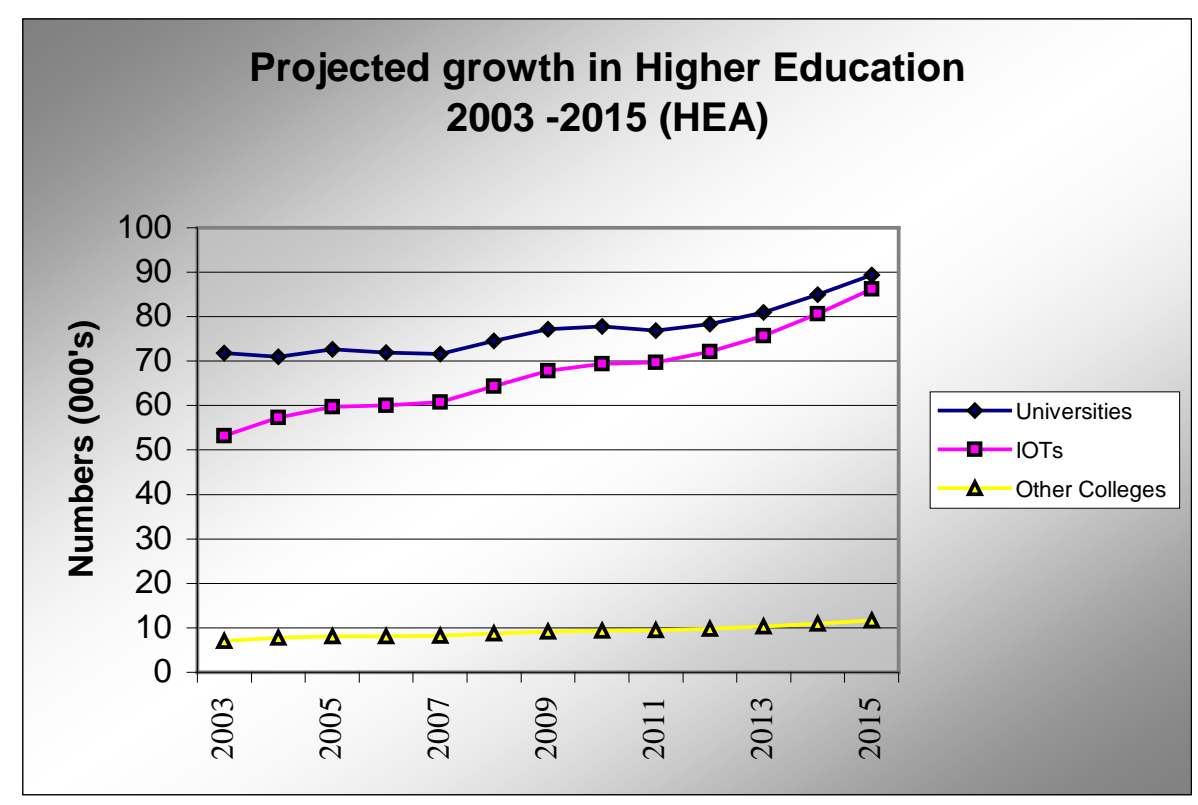

Figure 2: Projected growth in Higher Education 2003-2015 (adapted from the IoFTI, 2008).

This rationale underpins some of the central proposals of the National Development Plan 2007-2013 (Irish Government, 2007) which sets out the Government's strategic goals and intended investment (totalling €25.8 billion) relating to education and training from primary through to HE. Under the widening of participation target (Irish Government, 2007:203), 'access for disadvantaged and under-represented groups' is specifically mentioned. This is further developed in the section that details the Government's commitment to the Strategic Innovation Fund (2007:205). A key objective is to support access, retention and progression both at individual institutional level and through interinstitutional, sectoral and inter-sectoral collaboration'. This strategy is supported by the Expert Group for Future Skills Needs (EGFSN, 2007) report Towards a National Skills Strategy, which sets out in fine detail the need to 'upskill' the workforce. It also set a target to 'upskill' 500,000 members of the current 
workforce by at least one level of the National Framework of Qualifications (NFQ) by 2020 . Within this labour force cohort 170,000 individuals need to 'upskill' by one level (NFQ level 6-10). The report further develops a specific 'vision' for promoting degree-level Higher Education in the labour force (NFQ levels 8-10) ,stating that at present 20 per cent $(392,000)$ of the labour force currently hold a degree, forecasting the need for this to reach 32 per cent of the labour force $(776,000)$ by 2020 .

As part of this increasing access and widening participation agenda a number of target groups have been consistently identified as being under-represented within HE. Research shows that economic inequality continues to have an enormous influence on participation rates (Clancy, 1982, 1988, 1995; Clancy and Wall, 2000; O'Connell, et al., 2006) and students of all ages from disadvantaged and lower socio-economic backgrounds face considerable obstacles to attending third level education. With the increased numbers and broadening of the base there continues to be both gendered and class differentials in the numbers progressing to HE. Girls outperform boys. Sixty four per cent of girls and 57 per cent or boys progress to HE. When occupation of parents is included, those from unemployed or manual background have a progression rate of 45 per cent (Byrne, et al., 2008:35). This is compared to those from managerial (65 per cent) and farming (70 per cent) backgrounds. The education level of parents is also a factor and 85 per cent of those whose mother has a degree progress to Higher Education. But of those whose mother left school before the Junior Certificate only 41 per cent progress to HE. The figures are even higher for those who finish secondary school and whose mother has a degree (95 per cent). When these statistics are linked to rates of unemployment, the possibility of escaping poverty is closely linked to the ability of society to address the generational issues that impact on educational attainment.

The difficulties faced by prospective students with disabilities, students from ethnic minorities, such as Travellers, and vulnerable migrants such as refugees 
have been highlighted. Mature students, who may or may not have experienced these other forms of disadvantage, are also considered an important target group in their own right (HEA, 2001, 2008a). For reasons that will be explained below the exact relationship between these various categories of disadvantage amongst mature students remains unclear. What is abundantly clear is that bringing mature students into $\mathrm{HE}$ is of considerable importance to policymakers. For instance the White Paper on Adult Education notes the 'low levels of educational attainment of Irish adults when compared to other industrialised countries' and is concerned that access to HE continues to be dominated by a 'narrow sequential pathway following school' (DES, 2000:139-147). In a more recent report from the HEA it is estimated that 'over 750,000 adults in Ireland between 25 and 64 years of age have little or no formal educational qualifications' (HEA, 2004:8). Ireland also continues to have very low levels of participation in lifelong learning compared to other EU countries (HEA, 2008a).

Targets have been set for access and the HEA in 2008 set a key national target of 72 per cent entry to Higher Education by 2020. Based on the principle that no group should have participation rates in Higher Education that are less than three-quarters of the national average, the Plan sets a target that all socioeconomic groups will have entry rates of at least 54 per cent by 2020. The plan aims to ensure that mature students (over 23 years of age) will comprise at least 20 per cent of total full-time entrants and 27 per cent of total overall (full-time and part-time) entrants to Higher Education by 2013. The number of people with physical and sensory disabilities who benefit from Higher Education will, according to the Plan, be doubled by 2013 (NOEA, 2008:12).

So increasing access for mature disadvantaged students is a key part of a broader process of widening participation in HE. It is motivated by the perception of an educational 'shortfall' amongst Irish adults that may hinder economic growth. This is combined with a concern for addressing social inequality (DES, 2001). Education of parents or of children may be an effective way of intervening 
in the pernicious generational reproduction of disadvantage and poverty. There is an ongoing initiative in the Shannon region which underlines the importance of understanding access as an integrated process that requires multiple and flexible entry points to Higher Education; structured support for non-traditional students while they are studying for a degree; and targeted support for some nontraditional students after graduation (Shannon, 2010).

\subsection{Issues and problems in assessing the impact of access policies}

Considerable effort has been made by policymakers, access workers and educationalists to develop comprehensive strategies that enable and promote 'equitable access routes' for non-traditional students in order to broaden participation in $\mathrm{HE}$. Over the past decade a wide range of programmes, procedures and targets to promote access has been devised (DES, 2001; HEA, 2008a). In 2003 a National Office of Equity of Access was established to oversee access policies. Steps have also been taken to reflect upon, evaluate and improve access policies (HEA, 2004; Osborne and Leith, 2000; Skilbeck and O'Connell, 2000) and there is a body of evidence that shows that this has had some success. In fact a recent report on access suggests that most of the targets set by the HEA have been met, with the number of mature students in HE rising from 4.5 per cent in 1998 to 12.8 per cent. In the same period participation of all the lower socio-economic groups (with the exception of non-manual workers) has increased and there has been an increase in the participation rates of students with disabilities from 1.1 per cent in 1998 to 3.2 per cent within the full cohort of undergraduate students (HEA, 2008b).

However, Lynch (2005), although strongly supportive of recent access measures, contends that in broad terms we have only seen 'relatively minor gains', arguing that overcoming structural social inequalities will require much greater levels of investment, research and institutional change. According to Lynch meaningful access policies will ultimately require a society-wide commitment to equality. It is certainly true that despite the successes cited in the HEA report (2008b) class 
background continues to have a major influence on who enters third level education. This has been documented in a number of studies of participation rates of socio-economic groups (Clancy, 1982, 1988, 1995; Clancy and Wall, 2000; O'Connell, et al., 2006). A recent study (Byrne, et al., 2008) confirms that there remains an enormous disparity between the participation rates of the wealthiest and the least well off in Irish society.

While there has been a substantial increase in the full-time Higher Education student population over the last 20 years, the entry routes into Higher Education seem to have remained by and large the same. This is despite the fact that more flexible and differentiated access routes have been repeatedly recommended as essential for bringing disadvantaged students, and in particular disadvantaged mature students, into Higher Education. According to the Eurostat Survey (Darmody, et al., 2005:24) the traditional access route accounts for 80 per cent of full-time entrants and 52 per cent of part-time course entrants. It appears that large numbers of potential mature students are not availing of the variety of entry routes and access initiatives that HEIs are offering. The OECD (2008:35) Synthesis Report on Tertiary Education, which explores data from 20 participating countries for the period 1998-2005, suggests that Ireland had one of the lowest median ages for new entrants to tertiary education at age 19. The benchmark set out in the European Union Lisbon Strategy 2010 is a participation rate in education and training of 12.5 per cent for the population aged 25-64. The European Universities Associations (2006:24) Review of the Effectiveness of the Quality Assurance Procedures in Irish Universities states that only one of Ireland's universities has met the national target of 15 per cent participation rate for mature students. The findings of these reports lead to questions about the effectiveness of current entry routes and access policies for attracting mature students to HE. A considerable amount of work remains to be done if the targets are to be met (HEA, 2008b).

Access to HE in Ireland is strongly influenced by social class and the number of 
mature students remains very low by international standards. Unfortunately, quantitative data that might offer a more nuanced understanding of disadvantaged mature students, and how the experience of various forms of disadvantage might be related, is not available. At present very little data collated by the HEA or the DES is disaggregated so that trends amongst various types of non-traditional students can be analysed. This is an issue that has been (Osborne and Leith, 2000) an obstacle to creating effective access policies. More recently the HEA has put in place more detailed data-gathering systems which will hopefully yield useful information in the future.

Another problem in trying to assess the position of mature students, and more specifically disadvantaged mature students, is that there is very little relevant academic research on the topic apart from the policy and planning work already cited, and much of the existing research is more than ten years old (Fleming, et al., 1999; Morris, 1997). While Inglis and Murphy (1999) and Lynch (1997) are invaluable in outlining a sociological profile of mature students, the datasets are also outdated. With some exceptions, there is a dearth of qualitative research about the experiences of mature students (Fleming and Murphy, 1998; Morris, 1997) that gives a clear and complete picture of the access story both as a process and in terms of its value for students.

Despite these gaps in the research there can be little doubt that the access rationale has been diffused widely and that important changes have occurred in Higher Education institutions. Without further work it will remain open to question whether this has entailed the profound rethinking of pedagogy, curricula and courses that respond to the needs, values and experiences of the students that some scholars have advocated (Bourgeois, et al., 1999; Fleming and Finnegan, 2009b; Lynch, 1999; Thompson, 2000) and to date there is only a small amount of relevant empirical research that touches on these issues (Kelly, 2005; Risquez, et al., 2007). Without such research the question of how access is viewed and valued by students and the complex relationship between class, 
identity, social inclusion and power in HE that has produced such a rich seam of research work internationally (Archer, et al., 2003; Bourdieu and Passeron, 1977; Thomas and Quinn, 2007) will remain unclear.

\subsection{Access to what? Graduate outcomes and post-degree destinations}

If the nature of mature student experience in third level education is underresearched it is also true that the access story has been overwhelmingly concerned with understanding the cultural, economic and social obstacles to entry and to a lesser extent how non-traditional students can be supported while at college. To conflate access with entry or even retention and to develop a more egalitarian model of education demands attention and concern for equality of outcomes. The literature that deals with the post-degree destinations of access students either in Ireland or internationally is noticeably scant. Although Inglis and Murphy (1999) and Morris (1997) briefly outlined some findings, this question has not been explored in great detail. Research is completed annually on the post-degree destinations of all students by the HEA but the data are not disaggregated in a way that allows us to understand the specific outcomes for non-traditional students. Instead, we have to rely on more general datasets such as the HEA (2008b) What do Graduates Do? This provides detailed data on the destination of graduates from HE programmes ranging from undergraduate and graduate certificates, diplomas and degree courses, including research Masters and PhDs. Once more we want to highlight the broadening of the concept of destination that includes not only the public policy understanding as jobs and salary but the more student-centred understandings as benefiting the family and lifestyle. This also leads to understanding lifelong learning in a very different way to the dominant instrumental version.

In relation to the first destination of Honours Degree Graduates the HEA (2008b:14) reports that 6 per cent were unavailable for work or study; 2 per cent were seeking employment; 33 per cent went on to do further study; and 53 per cent were in employment. Seventy-two per cent of ordinary degree graduates went on to further studies. Dublin seems to be the main region for graduate 
employment and 43 per cent of Honours Degree Graduates were employed in this region. Most students found jobs in business, finance and insurance services (29.9 per cent). Only 21 per cent of graduates find employment in their county of origin. For non-traditional and mature students, this may be significant as such students may be less mobile than traditional students.

'Older graduates' tend to earn higher initial salaries then younger graduates (HEA, 2008b:27) as older graduates may have previous work experience and more knowledge of the labour market. Figure 3 depicts the salary related to age trend line of these graduates. International research suggests that there can be a significant difference in the labour market success of younger students compared to older students.

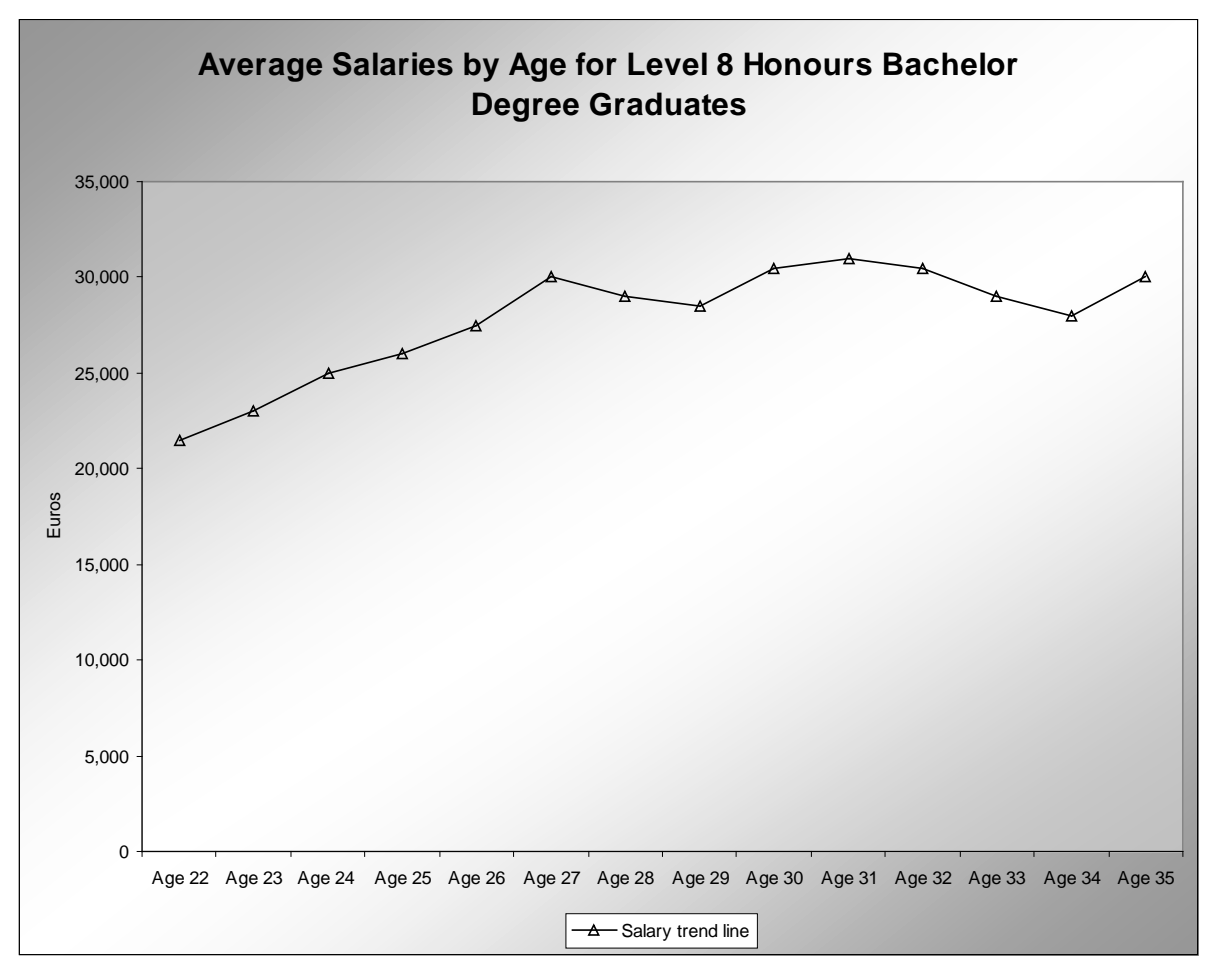

Figure 3: Average salaries by age of Level 8 Honours Bachelors Degree Graduates (adapted from HEA, 2008b).

The most common salary band for Level 8 Honours Bachelor Degree 2006 graduates is the $€ 21,000-€ 24,999$ category, the same as for 2005 graduates (HEA, 2008b:28). Fifty-nine per cent of those who graduated with an Ordinary 
Bachelor Degree in 2006 earned more than $€ 25,000$, while 24 per cent earned more than $€ 33,000$. This represents a substantial increase over the class of 2005 where 45 per cent of graduates earned more than $€ 25,000$ in April 2006, while 16 per cent earned more than $€ 33,000$. There was no increase in the most common salary band for Honours Bachelor Degree 2006 graduates. As in 2005 this was the $€ 21,000-€ 24,999$ band. Fifty-eight per cent earned more than $€ 25,000$ upon graduation, a slight increase on the 55 per cent observed in 2005 in this category (HEA, 2008b:28).

It has also been found that 'third level graduates were less likely to be unemployed then non graduates'. This is illustrated in Figure 4, which details the trend in unemployment rates classified at the highest levels of education attained. The 'Third level degree or above' category has maintained the lowest levels of unemployment. There is a positive correlation between educational attainment and a reduced likelihood of unemployment.

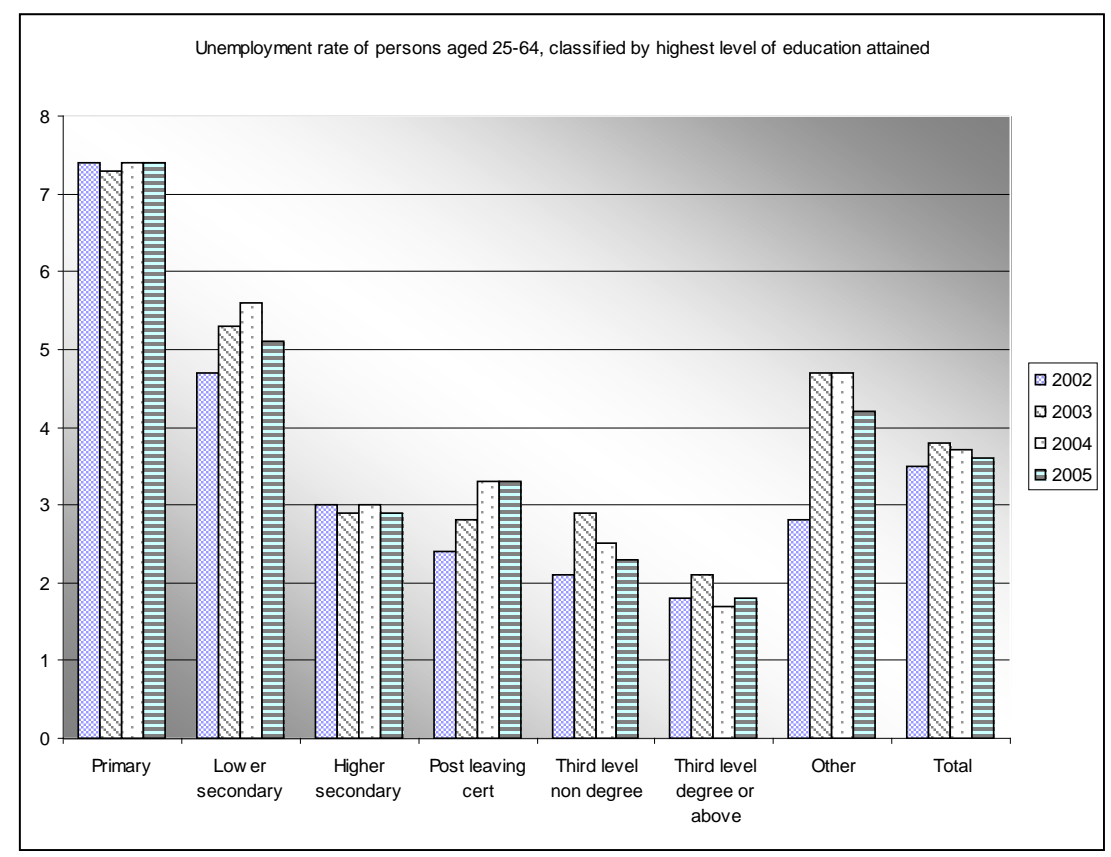

Figure 4: Unemployment rate of persons aged 25-64, classified by highest level of education attained. Source CSO (2006)

This snapshot of immediate post-degree destinations can be examined beside 
the small amount of work that has examined education to labour force transitions over a longer period (Gash and O'Connell, 2000). But again the absence of disaggregated data makes it difficult to understand the post-degree destinations of disadvantaged mature students.

\subsection{Human capital, cultural capital and lifelong learning: Theoretical considerations}

This idea that increasing participation and widening access to education and training is an 'investment' in the future working life of an adult may be put in jeopardy due to the current macro economic and financial crisis. Questions need to be asked regarding the capacity and capability of the Higher Education sector; whether it has got the infrastructure and resources to accommodate an expansionist strategy. Putting these reservations to one side it is also clear from what has been outlined that access and the role of disadvantaged mature students within HEls is largely understood within a set of powerful, if somewhat vague, discourses about the benefits of credentials (NQAl), formal learning and upskilling in an era of lifelong learning.

There can be little doubt that the restructuring of Higher Education is inextricably linked to a number of broader social and economic developments in society. A wide range of contending theories have sought to explain the characteristics and form of contemporary society and many of the most prominent and influential theories have argued that knowledge, information and communication are now more central than ever to modern society and the generation of wealth (Beck et al., 1994; Bell, 1974; Baumann, 2000; Hardt and Negri, 2000; Harvey, 1989). However, current policy does not reflect these wide-ranging debates. Instead, to a large extent the knowledge society is presented as a self-evident reality in which 'lifewide' and 'lifelong learning' is the key to maintaining competitiveness and ensuring social cohesion (CEC, 2000; DES, 2OOO; OECD, 2004). HE is one of the primary social spaces in which this occurs.

This 'human capital' approach to education has been important for many years in 
public policy, originating in the Investment in Education (Irish Government, 1965) and continued since. It is firmly linked to the EU Lisbon Strategy specifically aligned to the Lifelong Learning paradigm (CEC, 2000) in which the emphasis is on encouraging citizens to continuously engage in education and training in order to upskill and contribute to the economy. The main concepts underpinning lifelong learning are based on human capital theory, claiming that an individual's investment in education and training will have a positive return in terms of employment opportunities and remuneration. This state investment should lead to a return in terms of increased productivity, innovation, employment growth and revenue returns.

Over the past two decades the OECD has been an influential promoter of human capital theory, producing numerous research reports claiming a positive correlation between investment in education and training and economic and social returns to the state. The European Union Lisbon strategy could also be construed as a human capital manifesto, proclaiming the need for member states to increase targeted investment in education and training systems, in order to make the EU a competitive, knowledge driven economy by 2010.

The Irish Government's National Development Plan 2007-2013 (2007) strongly reflects this policy priority. The upskilling of the labour force is regarded as a primary driver to maintaining economic advantage and delivering new, high quality employment opportunities.

Education and training policy and initiatives need to be put in place by state agencies, providers and employers in order to encourage individuals to make a rational choice to invest in their own intrinsic human capital by pursuing relevant education and training opportunities. Within this functional model education and training operate in a hierarchical credentialist system, where qualifications and awards are the currency of the system. As such, education and training become commodities that can be traded in the labour market. Human agency is reduced and confined within an economic imperative. In this world view education is 
perceived as instrumental, a mechanism utilised to transfer useful knowledge, skills and competences. The full complexity of social life and the interaction between agency and structure is not dealt with within the functionalist economic perspective. Coleman (1988) sought to address this factor by adopting a functional-structuralist perspective, incorporating the social factors that contributed to the development of human capital. Social structure and social action impact on the formation and cohesion of social networks, communities, families, norms and reciprocity rules and (Coleman, 1988:100)

Just as physical capital is created by changes in materials to form tools and facilitate production, human capital is created by changes in persons that bring about skills and capabilities that make them able to act in new ways. Social capital comes about through changes in the relations among persons that facilitate action.

Social capital which is developed through social interaction with others, relationships with family, peers, networks and communities, has a direct bearing on the formation of human capital. Social capital can provide an important supportive network(s) for individual agency and act as a motivation factor to engage in education and training.

If one accepts that inequality is deeply embedded in social structures and that this system tends to regulate itself in a manner that ensures that it reproduces power unequally, the access agenda and the knowledge society need to be theorised somewhat differently. There is a body of scholarship that has examined the manner in which a potentially useful concept of lifelong learning has been instrumentalised by employing a functionalist and economistic 'human capital' model of education. Any study of the experience of disadvantaged mature students in Higher Education thus necessarily involves an account of the lived reality of the learning society and offers an opportunity to examine how lifelong learning is understood and practised in the light of the claims of academics and the rhetoric of policymakers. The current research has attempted to do this. 


\section{Research methodology}

\subsection{An overview of the research process}

The research used a mixed methods approach to gathering both numerical and non-numerical data. Using questionnaires in tandem with in-depth, semistructured interviews allowed the researchers to identify and analyse broad trends while paying close attention to the lived experience of the graduates.

Over a period of 18 months (December 2007 to June 2009), the research team took a collaborative approach to all the aspects of the study. This also allowed the researchers to engage in constant data comparison (ref Glaser, 1992; Charmaz, 2006) and theory building.

The first phase of the research concentrated on gathering numeric data on a national and institutional level. Extensive use was made of secondary data such as key facts and figures detailed in policy and institutional documents and artifacts relating to mature students. The tools developed during this phase reflected both the key issues identified in the literature as well as those that were grounded in the experience and expertise of each partner. Each team adhered to the highest ethical standards based on the guidelines and procedures established in each HEI while negotiating access to interviewees and in the subsequent gathering and analysis of data.

All data-processing was undertaken separately in each institution. No confidential information was shared or personal information disclosed between the research partners and each HEI fully anonymised data before they were examined collectively. Significant gaps in the available numeric data were discovered during this initial period of research. The dearth of relevant information in existing datasets created a number of difficulties, overcome by amending the research 
design. The changes made to the research design are detailed below (Section 2.2).

The second phase of the research involved gathering data through questionnaires. Using SPSS the aggregated data from the questionnaire was shared between the partners for analysis (copy of Questionnaire in Appendix 3). This numeric data was then disaggregated in order to identify disadvantaged mature students.

This process was vital for the third phase of the research in which we explored with greater depth and fine-grained detail the initial research questions and identified and contacted the interview cohort. We also selected key themes that we wished to address during the semi-structured interviews with the graduates. The interview data was kept separate but each institution brought a detailed summary of their research to team meetings to facilitate comparative analysis. This allowed us to return to the numeric data with a set of grounded themes and

findings derived from the qualitative data and build upon these numeric and nonnumeric datasets to outline the overall findings of the research. The primary aim of the inquiry was to discover how graduates viewed and valued their experience of Higher Education and how this impacted on subsequent destinations. As a consequence, although a mixed methods approach was employed, the qualitative data has been fore grounded in our findings.

\subsection{Collecting and using the numeric data}

As noted earlier, to date there has been very little disaggregated data published nationally on mature students and none at all that would allow us to map how many mature students attending Higher Education are socially or economically disadvantaged. Similarly, there is very little information dealing specifically with mature student destinations and none which deals with mature disadvantaged students. 
This lack of relevant disaggregated data was an issue in all three HEIs. In all three colleges difficulties were encountered in accessing information and no usable datasets on disadvantage, social class and mature students were readily available. As a consequence the research was redesigned in order to generate basic quantitative data with which we could accurately contextualise the experience of disadvantaged mature students.

The main instrument used to generate primary numerical data consisted of a multi-structured questionnaire, comprising six main sections (see Appendix 3):

1. Personal profile

2. Degree qualifications

3. Financing their studies

4. Experience as a student

5. Work and employment

6. Further study

A pilot questionnaire was administered in June 2008. Comments received were incorporated into the finished tool. The final questionnaire utilised multiple choice, Likert scale and additional text options. The questionnaire was administrated locally in each $\mathrm{HEl}$, and members of the research team adopted the most appropriate process to gain access to their sample populations that fulfilled the sample frame criteria. In NUIM the access office facilitated contact by post in June 2008 with all 820 mature students who had graduated from NUIM between 2000 and 2007. Each mature graduate was sent a questionnaire. On the basis of the returned questionnaires (218) we created a general mature graduate dataset from which a dataset on mature disadvantaged students (97) was developed (see Chapter 5 for further details on this cohort). The graduates for interviews were selected from this cohort as a representative sample.

In the case of both TCD and DIT some issues arose in gaining access to records 
to construct appropriate sampling frames. Although this slowed the datacollection phase of the study, these issues were successfully resolved and TCD sent the questionnaire to all on the list of students supplied by the university by post in December 2008. In DIT a defined sample was identified under the auspices of the Alumni Office and invitations to participate in the questionnaire were circulated via email; the questionnaire was administered by both email and post to those who requested it in November 2008. Though increasingly sophisticated systems have been introduced over recent years in these institutions, access to defined cohorts or subgroups is not readily available for research purposes. NUIM team had access to all the mature graduates. Table 2.1 below provides a snapshot of the questionnaire administration sample populations, methods used and the returns.

\section{Table 2.1 Questionnaire Administration}

Questionnaire administration, method, populations sample size
and returns

\begin{tabular}{|c|c|c|}
\hline NUIM & TCD & DIT \\
\hline $\begin{array}{l}\text { By post to all } 820 \\
\text { mature student } \\
\text { graduate population }\end{array}$ & $\begin{array}{l}\text { By post to sample } \\
\text { population of } 500 \\
\text { supplied by Record } \\
\text { Office }\end{array}$ & $\begin{array}{l}\text { By email to all } 450 \\
\text { alumni. } \\
75 \text { requested a } \\
\text { questionnaire. }\end{array}$ \\
\hline Returned 218. & Returned 140. & Returns 57. \\
\hline $\begin{array}{l}\text { Response rate } 26 \% \text {. } \\
\text { Sample agreeing to } \\
\text { interview } 97 \text { of } 218 \text {. }\end{array}$ & $\begin{array}{l}\text { Response rate } 28 \% \text {. } \\
\text { Sample for interview } 30 \\
\text { taken from the } 140 .\end{array}$ & $\begin{array}{l}\text { Response rate } 14 \% \text {. } \\
\text { Sample for interview } \\
\text { taken from } 57 .\end{array}$ \\
\hline
\end{tabular}

It is clear that all colleges had various ways of accessing data on students and this was more difficult when dealing with students who graduated a number of years previously. The scale and diversity of DIT was an additional challenge and these factors need to be kept in mind when analysing data and comparing 
findings. Analysis (in both descriptive and inferential forms) of the questionnaire data was undertaken using SPSS. The team decided to use the general data gathered on mature students alongside the subsets and the qualitative research to map the differences and similarities between all mature students' experience and the experience of mature graduates who have encountered disadvantage. This added dimension allowed us to offer a more complete and 'global' perspective on disadvantaged mature student experience.

\subsection{Gathering and analysing the qualitative data}

The non-numeric data consisted of in-depth interviews with mature disadvantaged graduates. The sampling for the individual interviews was obtained through a self-selection process; participants who completed the questionnaires noted their willingness to participate in a follow-up interview, and provided their contact details.

Each HEI selected its cohort differently because numeric data was gathered differently. In NUIM the cohort of interviewees was selected from a subset of the 218 mature students who responded to the questionnaire and was based on socio-economic grouping, occupation, educational history, ethnicity, disability and whether they were on social welfare. The selected cohort was representative in terms of gender and age and the sample reflected diverse views on college experience as expressed in the questionnaire.

The sampling frame for TCD was constructed with the assistance of the Student Records Office. By using the criteria of 'age' (i.e. 23 and above) as the cut-off point the office generated a series of Excel spreadsheets of those who had commenced study in the years 1997 to 2003 . Where addresses existed for graduates, they were placed in the final sampling frame and were sent a questionnaire. The selection of the sub-sampling frame for interview was based on an analysis of the distribution of participant characteristics from the questionnaire returns. There was a view that this sub-sample should be drawn on 
the basis of age, degree programme taken, post-degree destination, gender and mode of financial support. Thirty participants were selected, contacted and agreed to be interviewed, and 15 were interviewed.

The proxy measures used in the questionnaire for 'disadvantage' were based mainly on the receipt of social welfare and/or grant payments. Whilst these, like all measures, are contestable, they did allow for a degree of consistency across participants. In summary, to be eligible for a grant requires applicants to be subjected to a 'means test'; effectively determining suitability based on familial (or a single person's) income in the year prior to college admission. Furthermore, this is based on a sliding scale, which has attached to it varying amounts of support. For example, those on or below the minimum threshold level will receive a '100 per cent grant and registration fees', whereas those at the top will only get '25 per cent grant and full registration fees' ${ }^{1}$. The second measure is that of the Back to Education Allowance. Whilst this is not means tested in the same way as the maintenance grant, eligibility is contingent upon the applicant already being in receipt of one or more forms of state benefit. ${ }^{2}$

In DIT different central services have different approaches to recording student data and this was problematic. Eventually the newly formed Alumni Office distributed an invitation to all 450 alumni on their circulation list. Graduates wishing to participate were requested to send their contact details to a member of the research team. Questionnaires were sent by email to the 75 qualified graduates who responded. From this sample group came 57 completed responses. These were in turn invited to participate in the follow-up interviews;

\footnotetext{
${ }^{1}$ For example, for those students who have a spouse and no dependent children entering higher education in 2009-10, the income range for full grant and tuition fees is €0-41,110.

${ }^{2}$ Currently this includes: Jobseeker's Allowance, Jobseeker's Benefit, Farm Assist, One-Parent Family Payment, Deserted Wife's Allowance, Deserted Wife's Benefit, Widow's or Widower's Non-Contributory Pension, Widow's or Widower's Contributory Pension, Prisoner's Wife's Allowance, Illness Benefit, Disability Allowance, Blind Pension, Invalidity Pension, Incapacity Supplement or Carer's Allowance.
} 
25 agreed to be interviewed and 18 were interviewed by telephone.

The research team utilised an agreed, standardised, semi-structured interview schedule (see Appendix 2). This was informed by the original research questions and a preliminary analysis of the quantitative data. In this regard the questionnaires provided both an invaluable source of information for charting the destinations and the general experience of mature students and an aid to understanding some of the themes relevant to disadvantaged students.

Between 15 and 20 participants in each of the HEls were interviewed. The interviews were carried out mostly in face-to-face settings and a small number by telephone. The face-to-face interviews were in-depth and often lengthy (between 40 minutes and two hours). All interviews were recorded. In order to maintain the anonymity of participants from the different HEls only transcripts stripped of any identifying personal information were made available to the full research team. The interviews took place over a number of months which allowed the researchers to compare and check data in a 'grounded' way (Charmaz, 2006). After the interviews were completed focus group sessions were used in each $\mathrm{HEI}$ to gather feedback on our preliminary findings. A number of interviewees from NUIM were also sent an early draft of the report for comment or criticism.

As noted earlier the research team was aware that even the finest meshed data tools will inevitably fail to capture the full richness of social experience. This is especially so in the case of this project which sought to give 'voice' (Thomas, 1993) to the 'lived experience' of the graduates. In this sense the purpose of the qualitative element of research was not to test static pre-established categories but to explore how higher education impacted on the life trajectories of mature students who have suffered from disadvantage from their own perspective. Thus in coding, theorising and analysing the interviews the way the participants defined and understood their 'destination' in relation to education and its impact on disadvantage was given particular importance. 
In addition, further contextual information was gained through face-to-face interviews with critical stakeholders, such as Access Officers, Graduate Career Guidance Workers, and a number of senior managers and policymakers in the Higher Education sector (see interview schedule in Appendix 2).

Table 2.2 Interview sample sizes

\begin{tabular}{lll}
\hline Interview sample size and methods utilised & \\
\hline NUIM & TCD & DIT \\
Face-to-face & Telephone and face-to- & Telephone interviews \\
interviews & face interviews & \\
Interviewed 20 & Interviewed 15 & Interviewed 18 \\
\hline
\end{tabular}

Through detailed and careful construction of the samples for interviews all three institutions' interview cohorts were representative of the total population. The team undertook a comparative analysis based on both quantitative and qualitative data gathered. However, it is clear that though potentially of significant interest the dilemmas of comparing such differing cohorts in institutions of differing orientation to mature students were difficult to overcome. The final report synthesises both numeric and non-numeric data from students and staff from three distinct HEls alongside extensive paper research. The variety of data sources from the three HEls offers a multidimensional, and unprecedented, insight into the impact that Higher Education has had on mature graduates in contemporary Ireland. 


\section{Brief Information on the Three Higher Education Institutions}

\subsection{National University of Ireland Maynooth (NUIM)}

NUI Maynooth is one of Ireland's seven Universities. It began as St Patrick's College, a Roman Catholic seminary, established in 1795. In 1966 the college accepted lay students and has steadily grown as a non-denominational university. The seminary continues its affiliation with the Pontifical University in Rome. Over the past three decades Maynooth has evolved into a modern liberal arts and science university.

In 2006 NUIM had approximately 6,574 students in 26 academic departments. All but 840 students are engaged in full-time courses. A large proportion of the student body (3,192 of the total) are full-time, 3-year undergraduate BA students. The science and technology primary degree courses (BSc) are completed over a four-year cycle. Of the 1,240 postgraduate students at the university in 2006, 348 were undertaking $\mathrm{PhD}$ research and 892 students were registered for 2-year Masters or Diploma qualifications. PhD registrations in 2006 were split almost equally between science and engineering and in the social sciences and humanities. There is approximately 800 staff in the university.

In common with all of Ireland's third level institutions the majority of students come through the traditional CAO route. NUIM has a high intake of mature students, just fewer than 15 per cent, and the highest proportion of any university in the Republic of Ireland. NUIM has consistently exceeded government targets for mature student enrolment. There is also a well established access programme that aims to encourage and support non-traditional students and which, amongst other activities, has expanded the number of places in the 
university for access students from 26 a decade ago to 210 in 2007/2008. NUIM has a higher percentage of students (the estimate was 25 per cent) who came from poorer socio-economic groups than other Irish universities and the college enjoys a reputation as accessible and catering for the needs of non-traditional students. In 2007-2008 there were 667 mature students registered. The college plans to expand the number of non-traditional students. The current number of undergraduate students in NUIM (2008-2009) is 4,788 - projected to rise to 5,260 in 2010.

\subsection{Trinity College Dublin (TCD)}

Trinity College Dublin was founded in 1592 as the sole and only constituent college of the University of Dublin. Currently (2007 data) it has a student population of 15,942 of which 10,689 are undergraduates (10,193 full-time and 496 part-time). There are 4,803 postgraduates (2,824 full-time and 1,979 parttime). TCD employs 2,676 (2,146 full-time, 530 part-time). Of this 828 are academic staff, 536 are academic research staff and 1,312 are administrative, service and technical staff. TCD is highly placed amongst the top 50 European universities (13th) by the Times Higher Education - QS World University Rankings.

In 2007 the total number of CAO applicants to Trinity College was 16,207 compared to 16,731 in 2006 and 17,455 in 2005. However, in relation to what TCD refer to as 'non-traditional applicants' these fall into three categories: (1) students with a disability, (2) mature students, and (3) socio-economically disadvantaged students. More specifically, TCD has set itself quota of 'taking in' 15 per cent of its undergraduates who are classified as non-traditional. In particular, access for mature students can either be directly through the CAO process, the mature students' dispensation route, or the Trinity Access Programme (TAP) for 'mature disadvantaged' students.

In 2007, 410 (326 in 2006) non-traditional students registered on undergraduate 
degree programmes (17 per cent of the CAO intake); 58 per cent of the nontraditional students registered in 2007 were mature students. In 2007 the number of applications for admission under the Mature Student Dispensation Scheme was 750 . In terms of actual registration 126 mature students signed up as undergraduates, 123 in 2006, 148 in 2005, 118 in 2004, and 101 in 2003. The number of students is relatively small, but this needs to be set in the context of TCD's undergraduate degree programmes that normally last four years and are usually full-time. Despite the laudable aim of setting quotas and actively encouraging potential students to apply, this lack of structural flexibility can be problematic.

\subsection{Dublin Institute of Technology (DIT)}

The DIT is a comprehensive Higher Education institution, fulfilling a national and international role by providing full-time and part-time programmes across the spectrum of Higher Education. It was established as an autonomous institution under the DIT Act, 1992, but its origins go back to 1887 and the establishment of technical education in Ireland. Under the DIT Act 1992 six colleges of Higher Education formerly under the City of Dublin Vocational Educational Committee were merged to establish the DIT: College of Technology, Kevin Street (founded 1887); College of Music, Chatham Row (founded 1890); College of Commerce, Rathmines (founded 1901); College of Marketing and Design, Mountjoy Square (founded 1905); College of Technology, Bolton Street (founded 1911); College of Catering, Cathal Brugha Street (founded 1941). DIT is the largest third-level institution in Ireland.

The Institute caters for over 22,000 students annually, comprising 3,000 apprentices, 10,000 full-time undergraduates, 7,200 part time students, and 1,289 full-time postgraduates.

DIT established LEAP, an access project for disadvantaged mature students, in 1999. This has become the Access Programme and has catered for over 500 students to date. The DIT Access Strategy 2007/08-2009/10 sets an access target for educationally disadvantaged students entering the first year intake of 5 
per cent for 2010. The Access Office has a proactive working relationship with 70 primary and secondary schools Dublin city centre. In 2008 DIT appointed a Mature Student Officer to develop policy and initiative to support the needs of mature students in DIT.

The Kelly Report (Kelly, 2005) examined mature students' full-time programmes in 2002/03 and estimated that there were 544 mature students in DIT's undergraduate programmes. Many of this cohort (214) were in the Faculty of Applied Arts and estimates for other Faculties were: Engineering 99; Science 79; Built Environment 77; Tourism and Food 59; and Business 22. The Director of Academic Affairs Report to the DIT Governing Body (McMahon, 2008) states that the estimated number of mature students in undergraduate DIT programmes is 672. 


\section{The research findings}

\subsection{The numerical data: Preface}

This section will provide a non-disaggregated overview of the numerical data collected for the study. Although institutional factors do play a part in how our participants reflect on their experiences and view the trajectory of their postdegree lives and work these data provide a valuable 'snapshot' of mature students. The questionnaire comprised 157 variables and generated in total some 415 responses. This section will discuss the findings using descriptive and, where necessary, inferential statistics. Some of the findings emerging from the numerical data come from the interview data, which provides us with some degree of experiential convergence (from the participants' perspective), but also adds a richness and depth that is only hinted at in the questionnaire data.

\subsection{The data}

In terms of basic demographics, 66 per cent the respondents were female and 34 per cent male. Their ages ranged from 27 to 77 (see Table 4.1 below). Most respondents were in the 30-50 age range. In terms of marital status 57 per cent of respondents were 'married', 26 per cent 'single', 13 per cent 'living with a partner' and 1 per cent 'separated'.

\section{Table 4.1 Age of respondents ( $n$ \& per cent)}

\begin{tabular}{ccc}
\hline Age band & $\mathbf{N}$ & Per cent \\
$<39$ & 163 & 41.9 \\
$40-49$ & 112 & 28.8 \\
$50-59$ & 79 & 20.3 \\
$60>$ & 35 & 9.0 \\
Total & 389 & 100.0 \\
\hline
\end{tabular}

Table 4.2 shows the degrees that participants were awarded. The vast majority (70 per cent) held a BA, followed by 20 per cent with a BSc. Ten per cent had quite specific qualifications such as architecture and engineering. It should also be noted that 15 people reported that they held what is normally seen as a 
postgraduate qualification (MSc, MBA, MPhil).

Table 4.2 Type of award (degree)

\begin{tabular}{lcc}
\hline \multicolumn{1}{c}{ Award } & $\mathbf{n}$ & per cent \\
BA & 273 & 70.1 \\
BSc & 77 & 19.8 \\
BEd & 12 & 3.1 \\
LLB & 5 & 1.3 \\
MA & 3 & .8 \\
BArch & 1 & .3 \\
MSc & 10 & 2.6 \\
MPhil & 1 & .3 \\
BEng & 1 & .3 \\
BTech & 1 & .3 \\
MBA & 1 & .3 \\
BSs & 2 & .5 \\
Total & 387 & 100.0 \\
\hline
\end{tabular}

Interestingly, 92 per cent of participants studied full-time and 8 per cent part-time; from the perspective of institutional flexibility this is a revealing finding to which we will return later in the report. In relation to motivation to undertake a degree, 47 per cent cited to 'improve employment prospects', 43 per cent 'personal interest' and 7 per cent 'other'. Within the 'other' category the kinds of responses given ranged from: 'change in career direction', 'not getting the chance earlier', 'always wanted to go to college', 'gain a qualification' to 'had never been to college'. These themes will be explored in more detail below through the interview data and they reveal an intricate web of motives on which the questionnaire can only touch. We also asked participants if they would choose the same course again, and 80 per cent said 'yes'.

To explore how finance impacted on their experiences firstly we asked about people's work situation prior to starting their degree: 82 per cent said they had a job and 17 per cent did not. Of those who were working, 61 per cent worked fulltime and 21 per cent part-time. Excluding those who studied part-time, this 
suggests that 211 (53 per cent) respondents gave up full-time work to take up full-time study; a commitment not to be taken lightly. The socioeconomic groups to which people 'belonged' prior to studying are shown in Table 4.3 below.

\section{Table 4.3 Socioeconomic groups prior to studying}

\begin{tabular}{lcc}
\hline & $\mathbf{n}$ & per cent \\
Employer \& Managers & 36 & 11 \\
Higher Professionals & 25 & 8 \\
Lower Professionals & 75 & 23 \\
Non-Manual & 135 & 42 \\
Manual Skilled & 14 & 4 \\
Semi-skilled & 27 & 8 \\
Self-employed & 6 & 2 \\
Farmer & 2 & 1 \\
Others & 2 & 1 \\
Total & 322 & \\
\hline
\end{tabular}

Fifty-three per cent $(n=210)$ of respondents reported that they worked while studying for between 2 to 60 hours per week; the median was 16 hours. Table 4.4 below shows the distribution of working hours across the sample.

\section{Table 4.4 Hours worked while studying}

\begin{tabular}{ccc}
\hline Hours & $\mathbf{n}$ & per cent \\
$0-10$ & 45 & 25.0 \\
$11-20$ & 77 & 42.8 \\
$21-30$ & 20 & 11.1 \\
$31-40$ & 25 & 13.9 \\
$41>$ & 13 & 7.2 \\
Total & 180 & 100.0 \\
\hline
\end{tabular}

A small number of people $(n=17)$ indicated that they received financial support from their employers. This tended to take two forms: sponsorship and/or having their fees paid. A small number $(n=13)$ also had a 'scholarship' whilst they were studying, and 33 people reported that they had financial support from a community group or organisation. The rest of the responses were distributed as 
follows: 36 per cent $(n=133)$ received no state related financial support, 41 per cent $(n=148)$ said that they received support from Social Welfare, 23 per cent $(n=84$ per cent) received only a grant and 12 per cent $(n=45)$ received only social welfare support. However, it should be noted that 28 per cent $(n=103)$ got both social welfare and a grant. Also within the social welfare category, 129 people said they had the Back to Education Allowance (BTEA) and 26 said 'other'. Although we did not ask people to indicate what their gross income was at the beginning of their studies, the receipt of BTEA is a good proxy indicator as to the financial status of the family and/or individuals. Fifty-one per cent $(n=187)$ of respondents reported that they received a grant.

In relation to martial status and social welfare the following pattern is generated (see Table 4.5). Through the use of a Chi square procedure, it was found that the two variables are associated with each other. There appears to be some connection (though it is weak as indicated by Cramer's v), between marital status and student income.

Table 4.5 Marital status by income (n)

\begin{tabular}{lccccc}
\hline & SocW & Grant & None & SocW+Grant & Total \\
Married & 35 & 40 & 92 & 34 & 201 \\
Single & 6 & 26 & 29 & 51 & 112 \\
Partner & 4 & 16 & 11 & 15 & 46 \\
Separated & 0 & 1 & 1 & 3 & 5 \\
Total & 45 & 83 & 133 & 103 & 364 \\
\hline
\end{tabular}

SocW = social welfare; none $=$ neither social welfare nor grant recipient

Table 4.6 (below) shows the distribution of responses to the question that asked about paid employment while studying. We found that 57 per cent $(n=196)$ of people who responded to this question said that they worked while they were a student; equally, 43 per cent did not. This provides some indication about the need to work (or not) as a student relative to the kind of support (or not) with which they were provided. It appears that students who received no state support 
were 1.5 times more likely to work than not work, and those who received a grant were 2.2 times more likely to work than not. For those on social welfare with or without a grant, the ratio of working to not working was more even, suggesting that there is less chance of working. However, the 'choice' (to put it euphemistically), as to whether students work or not is of course more complicated than whether or not they receive a certain form of, or combination of state supports. It is also bound up with their own personal and familial contexts that for whatever reason, are capable (or not), of providing financial support. Nonetheless, a sizable majority of students whether in receipt of state support or not, did need to work.

Table 4.6 Paid employment by social welfare and grant status (per cent)

\begin{tabular}{lccc}
\hline & Yes & No & Total \\
Social Welfare & 5 & 8 & 13 \\
Grant & 16 & 7 & 23 \\
None & 22 & 14 & 36 \\
Social Welfare + Grant & 13.4 & 52 & 99 \\
Total (n) & $(196)$ & $(154)$ & \\
\hline
\end{tabular}

Table 4.7 shows the average number of hours people worked as a student. A majority (68 per cent) of those who worked did between 2 and 20 hours per week, with 43 per cent in the 11-20 hours band.

Table 4.7 Reported average hours worked whilst studying

\begin{tabular}{ccc}
\hline Hours Worked & $\mathbf{N}$ & Per cent \\
$<10$ & 45 & 25 \\
$11-20$ & 77 & 43 \\
$21-30$ & 20 & 11 \\
$31-40$ & 25 & 14 \\
$>41$ & 13 & 7 \\
Total & 180 & \\
\hline
\end{tabular}

Table 4.8 shows the distribution of hours worked in the form of the mean and range and tabulated by social welfare and grant status. 


\section{Table 4.8 Mean hours worked by social welfare and grant status}

\begin{tabular}{lcc}
\hline Status & $\begin{array}{c}\text { Mean } \\
\text { hours }\end{array}$ & Range \\
Social Welfare & 14.1 & $6-25$ \\
Grant & 16.5 & $1-48$ \\
None & 22.9 & $3-50$ \\
Social + Grant & 16.2 & $2-40$ \\
\hline
\end{tabular}

Even though the range for the groups is similar (though less marked for the 'social welfare only group'), the 'none' group had the highest mean number of hours worked by between 8 to 6 hours relative to the other groups. Although the numbers of respondents are quite small, 16 of the part-time students worked between 31-40 hours $(n=11)$ and some more than 41 hours $(n=5)$; none of these received any state-related financial support. However, a small number of full-time students $(n=12)$ also reported working in these two upper bands: 2 received a grant only, 3 received social welfare as well as a grant and 7 received neither.

Table 4.9 shows the 'importance' of social welfare support; these data have been cross-tabulated by whether or not the respondent worked as a student. This distribution of responses suggests that whether students worked or not, did not affect the way in which they rated the importance of social welfare support. In addition, we asked to what extent social welfare support covered their costs of studying: of the 104 people who responded to this question, 24 per cent said it covered 'all of their costs' and 76 per cent said it covered 'some of their costs'. When cross-tabulated against whether they worked or not and their 'important' $v$ 'quite important' rating, there was no statistically significant difference across the responses.

This section on work and the participants' financing their studies highlights the magnitude of the need for financial support in whatever form. However, from this raw data alone it is not easy to determine the vicissitudes of being able to study 
as a mature student and all the complexities of adult life.

Table 4.9 Importance of social welfare support (per cent)

\begin{tabular}{lcc}
\hline & \multicolumn{2}{c}{ Worked as a } \\
& \multicolumn{2}{c}{ Student } \\
& Yes & No \\
Not important & 16 & 13 \\
Quite important & 5 & 6 \\
Very important & 26 & 31 \\
\hline
\end{tabular}

Although some of the numerical data is somewhat ambiguous in places there is a sense which is reinforced by the interview data, that social welfare support is a necessary, but not sufficient support for financing a degree.

Of the 368 people who replied to the question about whether they had incurred debt, 41 per cent $(n=154)$ built up debts and 58 per cent $(n=214)$ did not. We did ask them to indicate the scale of their indebtedness using the categories shown above. In linking these data to type of financial support, 66 people (44 per cent) who got either a grant, social welfare or both incurred debt in the €૦$€ 10,000$ range; 27 people who had no financial support fell into this debt category. Those in the higher debt bands tended to be on a grant or received no support. Table 4.11 shows their response by whether they worked or not. Table 4.12 shows their response by type of financial support.

Table 4.10 Size of debt incurred whilst studying

\begin{tabular}{ccc}
\hline Debt $(€ k)$ & $n$ & per cent \\
$0-10 \mathrm{k}$ & 100 & 67 \\
$11-20 \mathrm{k}$ & 33 & 22 \\
$21-30 \mathrm{k}$ & 8 & 5 \\
$>31 \mathrm{k}$ & 8 & 5 \\
Total & 149 & \\
\hline
\end{tabular}

The data in Table 4.11 do not generate a statistically significant outcome. 
Table 4.11 Debts incurred by worked whilst studying (per cent)

\begin{tabular}{lcc}
\hline & \multicolumn{2}{c}{ Debts } \\
& Yes & No \\
Yes & 26 & 30 \\
No & 16 & 28 \\
\hline
\end{tabular}

It can be seen that 30 per cent of those who worked did not incur any debts, as opposed to the 26 per cent who incurred a debt and also worked. The 'no work' category generated a smaller proportion of post-degree 'debtors', with a slightly smaller number (28 per cent) of respondents falling into the 'no debt' category. There also does not seem to be any relationship (statistically speaking) between whether a person worked or not and the size of debt. But empirically this is quite telling as 42 per cent of people who reported being in the debt range $€ 0-€ 10,000$ also worked while studying and 13 per cent who fell into the next highest debt category $(€ 11,000-€ 21,000)$ also worked.

Table 4.12 provides a different perspective on debt as seen through the 'prism' of financial support and covers the entire sample. Apart from the 'grant only' people (but only just), a higher proportion of respondents in the other financial support groupings fall into the 'no debt' category. Whether persons get into debt or not, based on what kind of financial support they receive (or not) as students, is difficult to determine. A high proportion of people did incur debt whilst studying. If these proportions are replicated across the population of mature students, this represents quite a major commitment by this group of students.

Table 4.12 Debts incurred by financial support (per cent)

\begin{tabular}{lcc}
\hline & \multicolumn{2}{c}{ Debts } \\
& Yes & No \\
Social Welfare Only & 4 & 8 \\
Grant Only & 13 & 11 \\
None & 13 & 22 \\
Social Welfare \& Grant & 11 & 18 \\
\hline
\end{tabular}


Part 5 of the study explored the participants' experience of college and of studying. The inclusion of 27 statements was designed to gain insight into how, as mature students, they navigated and experienced institutions that are predominantly 'populated' by and designed to meet the needs of 'non-mature' students.

The statements can be clustered into five broad areas: (i) teaching and learning (6 items), (ii) relationships: non-college (7 items), (iii) relationships: college (7 items), (iv) personal impact (5 items), ( $v$ ) institutional (2 items). Table 4.13 provides an overview of selected items from Part 5 which relate to the above themes.

In general, the data suggest that the large majority of respondents had a positive experience of being a student and that this also extended into their lives outside college. For instance, 90 per cent of participants stated that 'the college was a welcoming place' and 72 per cent 'agreed' or 'strongly agreed' with this statement: 'The approaches to teaching that I experienced were well matched to how adults learn.' Ninety-two per cent also disagreed with the statement 'I generally found my experience of college to be a negative one'. There was a high level of agreement with the statement 'Studying on a degree course has changed the way I approach my job.' Only 5 per cent of respondents 'strongly disagreed' or 'disagreed' with the statement 'My family members were supportive of me whilst I was at college', which appears to be indicative of a positive attitude towards their time as a student. A similar response is also shown to the statement 'My non-college friends were supportive of me whilst I was at college' and 75 per cent 'agreed' or 'strongly agreed' with these statements.

However, 56 per cent of participants who had a supportive home background indicated that being a student did interfere with their home life. This was not perceived as being harmful. Being a student and its attendant shifts in lifestyle did not necessarily bring about a negative impact on the quality of the 
relationships they have with family and friends.

This seems to suggest that even though financial issues did emerge for the respondents during their time as students, it did not impact on the quality of their relationships as 'measured' by the level of support they received.

In shifting the analysis into the area of 'work and employment', Part 6 of the questionnaire presented participants with 22 statements which explored their opinions about:

1 the relationship between degree level education and occupational status 2 their choice of course and their occupational situation (present and future) and 3 the consequences of completing the degree in terms of personal investment (i.e. time and finance).

This part of the questionnaire looked at the participants' sense of how their acquired 'academic capital' gets converted into 'occupational capital'. In addition to this, the questionnaire also asked about respondents' current and immediate post-degree occupational situation, including income, job changes, promotion and training at work. Table 4.14 below sets out some of the items from the initial 22 statements.

The cluster of statements in Table 4.13 provides a rich insight into how the respondents view the value of a degree in relation to work. In starting with the first item, 'I had a clear idea of the job I wanted when I chose my course', there is a split in the distribution of the responses between those who agreed (42 per cent) and those who disagreed with the statement (42 per cent). This split corresponds to the question regarding 'motivation' which was asked earlier on in the questionnaire. The next item asks about changes in career plans; 26 per cent $(n=99)$ of respondents who were in the 'disagree' categories for the previous item fell into 'agree' categories for this item. 
Table 4.13 Selected items about students' experience studying (per cent)

\begin{tabular}{|c|c|c|c|c|c|}
\hline Statement & $\begin{array}{l}\text { Strongly } \\
\text { Disagree }\end{array}$ & Disagree & $\begin{array}{l}\text { Neither Agree } \\
\text { or Disagree }\end{array}$ & Agree & Strongly Agree \\
\hline $\begin{array}{l}\text { In general the college was a } \\
\text { welcoming place }\end{array}$ & 0 & 3 & 8 & 46 & 44 \\
\hline $\begin{array}{l}\text { I felt unprepared for studying } \\
\text { at degree level }\end{array}$ & 25 & 37 & 13 & 19 & 6 \\
\hline $\begin{array}{l}\text { The approach(es) to teaching } \\
\text { that I experienced was well } \\
\text { matched to how adults learn }\end{array}$ & 1 & 10 & 17 & 52 & 20 \\
\hline $\begin{array}{l}\text { I found other students on my } \\
\text { course supportive }\end{array}$ & 2 & 3 & 9 & 52 & 33 \\
\hline $\begin{array}{l}\text { I met a lot of students from a } \\
\text { similar background (e.g. age, } \\
\text { social class etc) as myself at } \\
\text { college }\end{array}$ & 7 & 21 & 17 & 36 & 19 \\
\hline $\begin{array}{l}\text { Studying for a degree has } \\
\text { changed me personally }\end{array}$ & 4 & 9 & 21 & 41 & 26 \\
\hline $\begin{array}{l}\text { I generally found my } \\
\text { experience of college to be a } \\
\text { negative one }\end{array}$ & 69 & 23 & 5 & 1 & 2 \\
\hline $\begin{array}{l}\text { My age impacted on my } \\
\text { experience of college }\end{array}$ & 19 & 18 & 10 & 41 & 12 \\
\hline $\begin{array}{l}\text { My life experience was an } \\
\text { advantage to me }\end{array}$ & 1 & 2 & 7 & 49 & 42 \\
\hline $\begin{array}{l}\text { Studying on a degree course } \\
\text { has changed the way I } \\
\text { approach my job }\end{array}$ & 4 & 13 & 12 & 53 & 18 \\
\hline $\begin{array}{l}\text { I developed lasting } \\
\text { friendships at college }\end{array}$ & 3 & 13 & 13 & 40 & 30 \\
\hline $\begin{array}{l}\text { My socio-economic class had } \\
\text { a negative impact on my } \\
\text { experience of college }\end{array}$ & 39 & 36 & 16 & 8 & 2 \\
\hline $\begin{array}{l}\text { My non-college friends were } \\
\text { supportive of me whilst I was } \\
\text { at college }\end{array}$ & 2 & 6 & 18 & 37 & 38 \\
\hline $\begin{array}{l}\text { Balancing the demands of } \\
\text { childcare with studying was } \\
\text { very difficult }\end{array}$ & 5 & 7 & 44 & 26 & 18 \\
\hline $\begin{array}{l}\text { My family members were } \\
\text { supportive of me whilst I was } \\
\text { at college }\end{array}$ & 2 & 3 & 8 & 25 & 63 \\
\hline $\begin{array}{l}\text { My life experience was } \\
\text { viewed negatively by } \\
\text { lecturers }\end{array}$ & 38 & 38 & 17 & 5 & 2 \\
\hline $\begin{array}{l}\text { During my studies my quality } \\
\text { time with my family was } \\
\text { reduced }\end{array}$ & 6 & 16 & 16 & 43 & 20 \\
\hline
\end{tabular}


Although there is no direct causal link between the two items, it suggests that participants either develop career plans or change them as they progress through their degrees. However, for some this is not through the mechanisms of their academic departments or the colleges' career guidance services. Fortyseven per cent 'agreed' or 'strongly agreed' with the statement 'The career advisory service at my college was a useful resource' and 21 per cent with the statement 'My academic department(s) helped me to explore my career options.' In looking closer, 14 per cent who indicated that their career plans had changed, used the career services; 13 per cent used their academic departments; and 14 per cent said they used both. In addition, 71 per cent of people agreed with the statement 'It was necessary for me to have a degree for the job I wanted' and 17 per cent 'neither agreed nor disgareed'.

There was a strong view that a degree is perceived as a 'passport' to different occupational trajectories; 80 per cent of respondents 'strongly agreed' or 'agreed' with the statement 'My degree has opened up employment opportunities for me which I did not previously have.' Linked to this, 74 per cent responded positively to the statement 'Having a degree makes me feel confident about my career prospects.'

In relation to the statement concerning the influence possessing a degree has had on their experiences and perceptions of the world of work, Table 4.14 sets out a range of statements. It should also be noted again that there is no significant statistical difference (as calculated using Mann-Whitney $U$ ) between the 'disadvantaged' and the 'non-disadvantaged' group (i.e. those who received neither a grant not funding via the BTEA). What this crudely suggests is that value attached to having a degree, at least in relation to work, is not differentiated due to these criteria; then again, there is no reason to presume that it should be. It is important to note that there is little useful or significant difference between mature students whether disadvantaged or not. 
Table 4.14 Selected items about students' work and employment postdegree (per cent) (\%)

\begin{tabular}{|c|c|c|c|c|c|}
\hline Statement & $\begin{array}{l}\text { Strongly } \\
\text { Disagree }\end{array}$ & Disagree & $\begin{array}{l}\text { Neither Agree } \\
\text { nor Disagree }\end{array}$ & Agree & Strongly Agree \\
\hline $\begin{array}{l}\text { I had a clear idea of the job } \\
\text { I wanted when I chose my } \\
\text { course }\end{array}$ & 14 & 33 & 13 & 23 & 17 \\
\hline $\begin{array}{l}\text { My career plans changed } \\
\text { over the duration of the } \\
\text { course }\end{array}$ & 8 & 22 & 22 & 42 & 7 \\
\hline $\begin{array}{l}\text { I was overqualified for the } \\
\text { job I had after my degree }\end{array}$ & 13 & 33 & 29 & 20 & 6 \\
\hline $\begin{array}{l}\text { Having a degree made a } \\
\text { big difference to my short- } \\
\text { term career opportunities }\end{array}$ & 2 & 18 & 30 & 34 & 17 \\
\hline $\begin{array}{l}\text { Most of my work } \\
\text { colleagues have degrees }\end{array}$ & 6 & 14 & 19 & 32 & 29 \\
\hline $\begin{array}{l}\text { It was necessary for me to } \\
\text { have a degree for the type } \\
\text { of job I wanted }\end{array}$ & 3 & 10 & 17 & 33 & 38 \\
\hline $\begin{array}{l}\text { I think a degree will make a } \\
\text { big difference to my long- } \\
\text { term career opportunities }\end{array}$ & 2 & 5 & 13 & 37 & 43 \\
\hline $\begin{array}{l}\text { The content of my degree } \\
\text { course was very useful to } \\
\text { me in my job }\end{array}$ & 5 & 10 & 21 & 29 & 34 \\
\hline $\begin{array}{l}\text { My choice of college } \\
\text { course was not about the } \\
\text { kind of job I intended to do } \\
\text { after graduation }\end{array}$ & 19 & 22 & 15 & 29 & 15 \\
\hline $\begin{array}{l}\text { I think a degree is } \\
\text { necessary for a good job }\end{array}$ & 6 & 14 & 19 & 37 & 23 \\
\hline $\begin{array}{l}\text { My degree has opened up } \\
\text { employment opportunities } \\
\text { for me which I did not } \\
\text { previously have }\end{array}$ & 4 & 5 & 11 & 40 & 40 \\
\hline $\begin{array}{l}\text { Having a degree makes } \\
\text { me feel confident about my } \\
\text { career prospects }\end{array}$ & 1 & 7 & 19 & 40 & 33 \\
\hline $\begin{array}{l}\text { The time I invested gaining } \\
\text { a degree was worthwhile }\end{array}$ & 1 & 1 & 4 & 35 & 59 \\
\hline $\begin{array}{l}\text { The financial investment I } \\
\text { made in gaining a degree } \\
\text { was worthwhile }\end{array}$ & 2 & 3 & 11 & 41 & 43 \\
\hline $\begin{array}{l}\text { Following my degree I now } \\
\text { have a greater range of } \\
\text { choice of jobs }\end{array}$ & 3 & 7 & 17 & 42 & 30 \\
\hline
\end{tabular}


There was also a view that having a degree had both a short- and long-term benefit. Although a degree was necessary, it would not be instantly convertible into economic capital (crudely speaking). There was also a perception that 'a degree is necessary for a good job.' Degree level acreditation was seen as one of the critical points of entry into what might be perceived as more rewarding jobs.

How did the content of the degree programme map on to the participants' current job? Over 70 per cent stated that the skills were useful. The relationship between degree content and job role is partly contingent on the degree taken. This is relatively obvious in the case of professional and vocationally orienteted programmes (social work, teaching, nursing, law, etc.); but less so with the more 'traditional' programmes whose content has a less clear link with specific jobs.

We asked the participants whether or not they 'looked for work immediately after graduation?' Fifty per cent said 'yes' and 50 per cent said 'no'. We added an additional question as to what people might opt to do instead of work (either fulltime or part-time). Table 4.15 shows the responses.

\section{Table 4.15 Non-paid work destinations (per cent)}

\begin{tabular}{lcc}
\hline & N & Per Cent \\
Looking for another & 101 & 57 \\
course & 4 & 2 \\
Traveling & 9 & 5 \\
Volunteer work & 29 & 16 \\
Doing unpaid work home & 35 & 20 \\
Other & 178 & \\
Total & \\
\hline
\end{tabular}

The proportion of respondents who indicated that they opted to undertake 'further study' after they graduated constituted 50 per cent of the 'other' sub-sample, but 26 per cent of the total sample. At the time of completing the questionnaire, 77 
per cent of respondents were working and of this group 209 (70 per cent) were 'full-time' and 87 (30 per cent) 'part-time'. Chart 2.1 shows the distribution of income of participants.

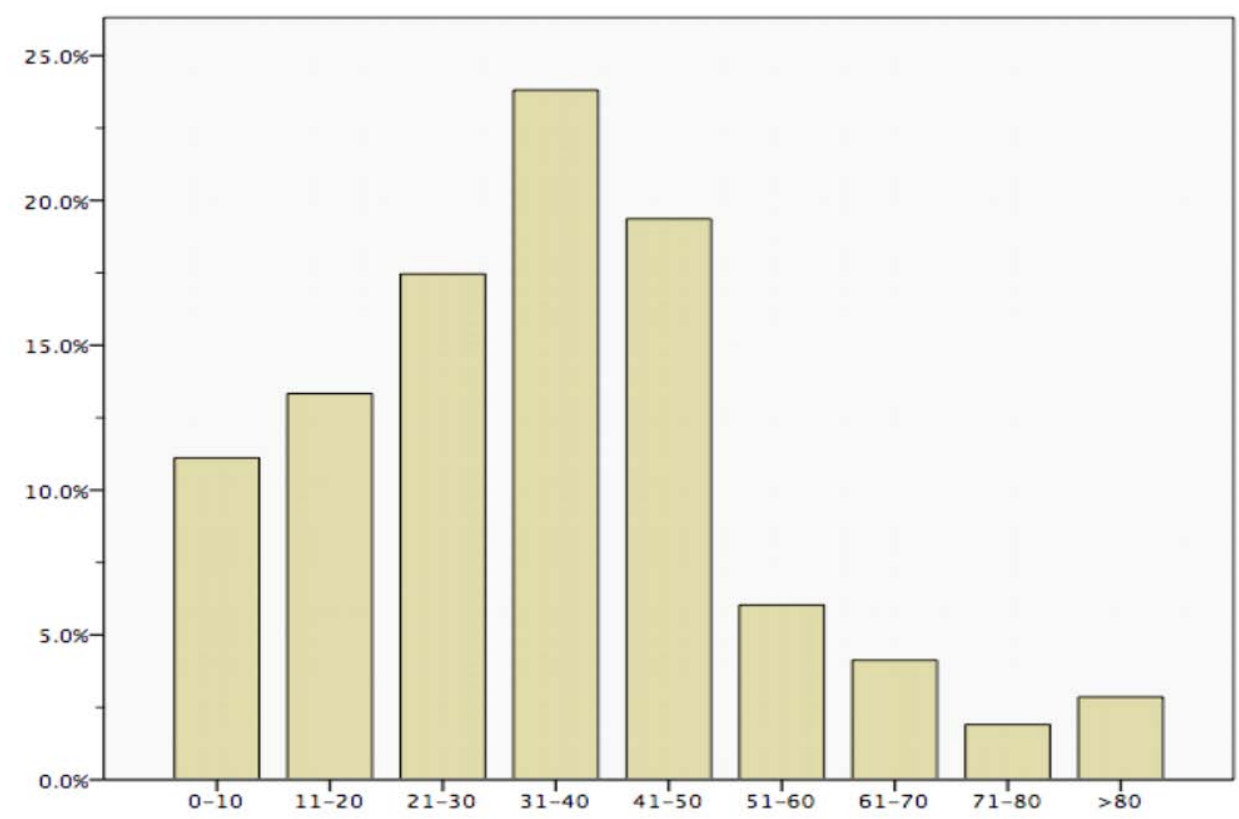

Chart 2.1 Distribution of current [2008] gross annual income in €k (per cent)

The majority of the respondents (60 per cent) fall into the $€ 21,000-€ 50,000$ income range, with 17 per cent and 19 per cent of respondents on either side of the modal (€31,000-€40,000) band. A small proportion (10 per cent) was in the upper range (over €61,000), but a much larger proportion (25 per cent) in the lower bands (under €20,000). However, as soon as we explore income in relation to some of the other variables, a more complex scenario emerges. Tables 4.16 and 4.17 offer a view of the income data 'filtered' through the lenses of 'age' and 'employment status' (which in this context is either full-time or part-time) and 'gender'. Note that the category of 'income' has been re-coded into four 'bands' to make the table easier to read. 
Table 4.16 Income by age and employment status (n)

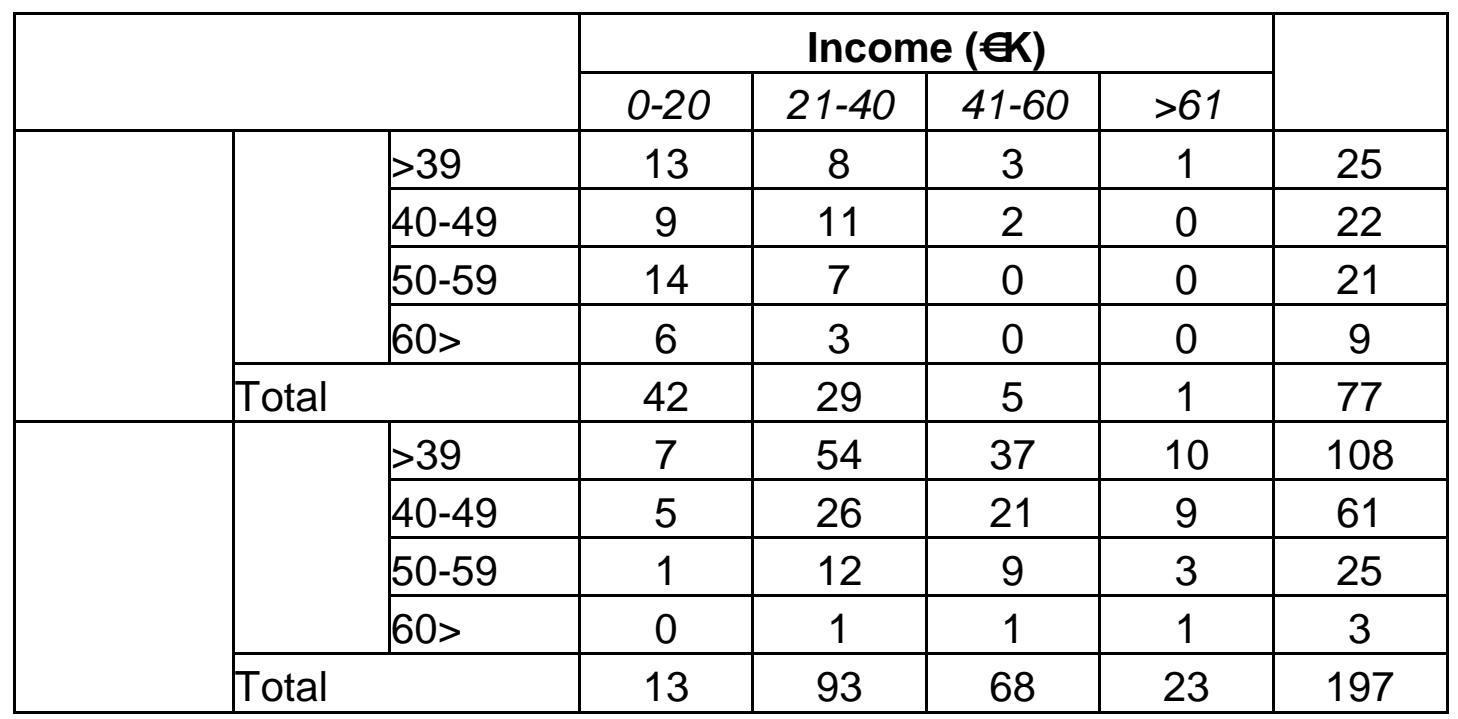

Table 4.17 Income by gender (per cent)

\begin{tabular}{cccc}
\hline Income $(€ \mathrm{k})$ & Female & Male & Total \\
$0-10$ & 9 & 2 & 11 \\
$11-20$ & 9 & 4 & 13 \\
$21-30$ & 13 & 14 & 18 \\
$31-40$ & 16 & 8 & 24 \\
$41-50$ & 10 & 9 & 19 \\
$51-60$ & 4 & 2 & 6 \\
$>61$ & 3 & 6 & 9 \\
\hline$($ Total $n)$ & $(201)$ & $(111)$ & $(312)$ \\
\hline
\end{tabular}

Two further questions asked about whether or not people expected their earnings to increase after graduation. The results are in Table 4.18 below.

Table 4.18 Expected $v$ actual earnings post-degree (per cent)

\begin{tabular}{lcc}
\hline & \multicolumn{2}{c}{ Did Increase } \\
Expected increase & Yes & No \\
Yes & 58 & 16 \\
No & 5 & 21 \\
\hline
\end{tabular}

Of the 318 people who responded to these two questions (see Table 4.18) 58 per 
cent had said they expected an increase in earnings and also received an increase in their earnings post-degree. But,16 per cent of people expected an increase and did not get one and 5 per cent did not expect an increase but got one anyway. An indication of the range of income after graduation is shown in Table 4.19.

Table 4.19 Income post-degree by actual increase

\begin{tabular}{cccc}
\hline Income $(€ K)$ & \multicolumn{3}{c}{ Increase } \\
& Yes & No & Total \\
$0-10$ & 3 & 8 & 11 \\
$11-20$ & 6 & 7 & 13 \\
$21-30$ & 9 & 8 & 17 \\
$31-40$ & 18 & 6 & 24 \\
$41-50$ & 17 & 3 & 20 \\
$51-60$ & 5 & 2 & 7 \\
$>61$ & 8 & 1 & 9 \\
\hline Total $(\mathrm{n})$ & $(197)$ & $(104)$ & $(301)$ \\
\hline
\end{tabular}

Another way of looking at the issue of occupational mobility is to recode the raw data that participants provided about their jobs before and after their degree programmes. It was recoded to correspond with the Office for National Statistics (ONS) social class and socioeconomic categories, which provide us with a picture of the participants' social status as measured by these two indicators. Table 4.20 shows a cross-tabulation between the participants' social class before and after they started their studies.

In exploring the disadvantaged participants' social class both before and after graduation, it can be seen in Table 4.20 below that when looked at in terms of mobility, they appear to be fairly clustered around the 'non-manual' and 'managerial \& technical' classifications, in terms of both starting point (prior to degree) and finishing point (as reported at the time of the study). There appears to be vertical movement from the small numbers of people from the 'semi-skilled' and 'skilled manual' into the 'managerial \& technical' category', whereas 32 of the 
non-manual have shifted into this category. What is interesting is that the 44 people who started in the 'managerial \& technical' class have remained there. It should be noted that only one person came from the 'unskilled' part of the social class spectrum, 26 were from the 'semi-skilled' category, whereas the majority (112), started in the 'non-manual' and 'managerial \& technical'. This suggests that the majority of the participants for this study do not necessarily, at least in terms of social class, come from what would be considered marginal groups. This is a theme we will return to later in the report.

Table 4.20 Social class 'now' by social class 'then' (n)

\begin{tabular}{|l|c|c|c|c|c|c|c|c|}
\hline & \multicolumn{7}{|c|}{ Social Class 'Now' } & \multirow{2}{*}{ Total } \\
\hline $\begin{array}{c}\text { Social } \\
\text { Class } \\
\text { 'Then' }\end{array}$ & Professional & $\begin{array}{r}\text { Managerial } \\
\text { \&Technical }\end{array}$ & $\begin{array}{c}\text { Non- } \\
\text { Manual }\end{array}$ & $\begin{array}{c}\text { Skilled } \\
\text { Manual }\end{array}$ & $\begin{array}{c}\text { Semi- } \\
\text { skilled }\end{array}$ & Unskilled & Other & \\
\hline \begin{tabular}{l|c|c|c|c|c|c|c|c|c|} 
Professional \\
Managerial \\
\&Technical
\end{tabular} & 0 & 5 & 0 & 0 & 0 & 0 & 4 & 9 \\
\hline Non-Manual & 3 & 44 & 4 & 1 & 0 & 0 & 8 & 62 \\
\hline $\begin{array}{l}\text { Skilled } \\
\text { Manual }\end{array}$ & 5 & 32 & 8 & 2 & 0 & 1 & 4 & 50 \\
\hline Semi-skilled & 4 & 10 & 3 & 2 & 1 & 0 & 6 & 26 \\
\hline Unskilled & 1 & 0 & 0 & 0 & 0 & 0 & 0 & 1 \\
\hline Other & 0 & 2 & 0 & 0 & 0 & 0 & 0 & 2 \\
\hline Total & 18 & 102 & 16 & 5 & 2 & 1 & 24 & 168 \\
\hline
\end{tabular}

It is clear that two things are happening:

1. Students from a semi-skilled and skilled manual background are more likely to be upwardly mobile (social class wise) if they come from a non-disadvantaged background. The implication of this is that advantage, and disadvantage, are maintained by students to a significant degree in their passage through higher education.

2. Though progression to a higher social class is evidenced in these findings the categories are not sufficiently differentiated to show the incremental moves achieved by students on graduation.

Part 7 of the questionnaire explored participation in and attitudes towards 
postgraduate study. In total, 260 (65 per cent) people reported that they either completed a postgraduate qualification, were involved in a postgraduate programme or were about to start one. Since finishing their first degree, 142 (36 per cent) had completed a postgraduate qualification - see Table 4.21.

\section{Table 4.21 Type of postgraduate programme completed}

\begin{tabular}{lcc}
\hline Programme & $\mathrm{n}$ & per cent \\
MA & 73 & 40 \\
PhD & 73 & 40 \\
Med & 7 & 4 \\
MPhil & 4 & 2 \\
MSc & 14 & 8 \\
PGDip & 10 & 5 \\
Other & 3 & 2 \\
Total & 184 & \\
\hline
\end{tabular}

Additionally, 30 per cent of people said that they were 'currently or about to embark on postgraduate study'. Over 80 per cent said that their postgraduate course was or is related to their primary degree and less that 20 per cent said it was not. This suggests that postgraduate study is, for this group at least, about continuity and augmentation and is even more pertinent when two out of three reported that it was motivated by the need to 'enhance employment prospects'.

There is a strong sense that undertaking degree level study was, in terms of time and resources (financial), a worthwhile act, out of which the acquisition of this academic capital (to put it in those terms), was also seen as opening up for them the possibility of a qualitatively and quantitatively different relationship with the labour market. Qualitatively, it produces a shift in occupational horizons, whether vertically (up the socio-economic ladder from classroom assistant to teacher) or horizontally (stay within same socio-economic position but different job, e.g. from teacher to social worker). Quantitatively, it may open the possibility of many more occupations from which to choose. Again we can infer from the 71 per cent of participants who agreed and strongly agreed with the statement that 'It was 
necessary for me to have a degree for the type of job I wanted', that there was a strong instrumental motivation (re occupational mobility) for undertaking a degree. But this is also tempered by a desire to engage in the act of learing for its own sake. This emerges strongly in the interview data. Additionally, along with this academic capital is a more affective sense of 'confidence' about their longand short-term career prospects.

At the time of data collection 79 per cent of this 'disadvantaged' group reported that they were in paid employment and 21 per cent were not; additionally of those working, 27 per cent said that were in part-time employment and 73 per cent in full-time employment. A high proportion (53 per cent) stated that they looked for work 'immediately following graduation' and 46 per cent said they did not. Of this latter group 61 per cent went on to do another course, 4 per cent went travelling, 2 per cent undertook volunteer work and 17 per cent worked in the home.

In relation to income 63 per cent said they had an increase in their income whereas 37 per cent did not. However, 78 per cent remarked that they had 'expected an increase' in income post-degree. Again there was no statistically significant difference (via a Mann-Whitney $\mathrm{U}$ test) between the 'disadvantaged' and 'non-disadvantaged' group. As with the all of the sample, this group is far from being classified as 'high earners', with only 8 per cent of people reported to earn over $€ 50 \mathrm{~K}$. Indeed 74 per cent of this group earns less than $€ 40 \mathrm{~K}$. But one difference was found between the 'disadvantaged' and 'non-disadvantaged' groups in terms of income. When controlled for by whether they worked part-time or full-time the former did not produce a significant difference whereas the latter did.

Table 4.22 Income post degree: Disadvantaged

\begin{tabular}{|c|c|c|}
\hline & $\mathrm{N}$ & $\%$ \\
\hline $0-10$ & 24 & 12 \\
\hline $11-20$ & 29 & 15 \\
\hline
\end{tabular}




\begin{tabular}{|c|c|c|}
\hline $21-30$ & 41 & 21 \\
\hline $31-40$ & 52 & 26 \\
\hline $41-50$ & 35 & 17 \\
\hline $51-60$ & 11 & 6 \\
\hline $61-70$ & 4 & 2 \\
\hline $71-80$ & 1 & 1 \\
\hline$>80$ & 1 & 1 \\
\hline Total & 198 & \\
\hline
\end{tabular}

In relation to postgraduate study, 35 per cent $(n=71)$ reported that they were 'currently or about to embark' on this mode of study and 40 per cent $(n=80)$ said that they had completed a postgraduate course. This gives a total of 76 per cent $(n=151)$ who were or did engage in further study. With regard to their motivation to engage in further study, 95 people cited 'employment prospects' and 37 'interest in area'. Additionally, 113 people reported that the area of postgraduate study was connected with their primary degree. 


\section{The disaggregated data}

\subsection{Preface}

This part of the report will focus on the findings from each HEI. It is presented as separate cases in order to maintain the richness and uniqueness of the findings from each $\mathrm{HEl}$. It draws on both the numeric and non-numeric data and for the sake of continuity each case is subdivided into the following headings:

1) An overview of the students at each college

2) An overview of the interviewees

3) The price of the ticket: financing a degree

4) The graduates' assessment of institutional supports for 'non-traditional students'

5) The importance of family support - as a historical experience, a present reality and a future benefit

6) Post-degree destinations in the labour market

7) So was it worth it? Esteem, social inclusion and becoming a lifelong learner.

We emphasise again that the understanding of 'destination' as understood in this report is based on the findings of the research. These findings re-frame the conventional or normal understanding of 'destination' found in public policy discourse that emphasises jobs, careers and financial rewards for the individual through salary and the state from taxes. But in talking to students this understanding is substantially re-framed to include what public policy calls social outcomes. Students give these a high priority and resist any separation of 'destinations' into economic and social categories. Mature students define 'destination' in complex, connected and broader categories to include benefits for themselves and their families. They speak eloquently of a non-reductionist understanding of lifelong learning. For once it is the case that it is not the economy stupid! Our interviewees also reframe the concept of disadvantage and 
put a more 'bottom-up' understanding in place. For the sake of brevity, the findings from DIT and TCD that follow this section will emphasise findings that are different to the NUIM findings.

\subsection{Findings from NUIM}

\subsubsection{Introduction}

The first section gives a broad sociological overview of the NUIM mature students, the second looks at the number of students who may have experienced disadvantage and the third section gives a brief sketch of the interview cohort. The remaining five sections present the empirical findings based on the research questions and the themes that suggested themselves most strongly through a grounded examination of the data from the questionnaire and the interviews.

\subsubsection{An overview of all mature graduates from NUIM}

Almost 70 per cent (68 per cent) of the 218 survey respondents were female. Ten per cent were in their 20 s and 10 per cent were over 60 . The remainder was spread evenly over the decades of $30 \mathrm{~s}, 40 \mathrm{~s}$ and $50 \mathrm{~s}$. Two out of every three were married (58 per cent) or living with a partner ( 8 per cent). One in three had no children and one in three had three children or more. In Maynooth 90 per cent of those surveyed chose to do a humanities or social science course leading to a BA degree. The subjects studied reflected the traditional popular choices for adults, with largest numbers choosing Greek and Roman Civilisation, Psychology, History, Anthropology, English and Sociology.

Maynooth normally expects mature applicants to undertake an access course. In fact, 90 per cent do one or other of the NUIM Return to Learning courses, an NUI Certificate in Science or Engineering, a FETAC award through VTOS or a repeat sitting of the Leaving Certificate. Each student applies through the CAO application system and many undergo an additional interview as a number of departments in NUIM operate their own access tests for mature students. Each of these departments is different in what they require prospective students to 
undertake as part of the test.

NUIM attracts students from across the country but mature students come predominantly from the surrounding counties of Meath, Kildare and Dublin (in particular from the suburbs of west Dublin). A large number (25) came from Tallaght, a mainly working class area of Dublin with a long established tradition of programmes that encourage adult progression to HE. Although these numbers per head of population are tiny the trend is encouraging. It was noteworthy that very few of the respondents, in terms of income and occupation, were from the most privileged sections of Irish society. Only 13 respondents were in senior managerial, higher professional or very highly paid work before starting their degree. Thirty-one of the respondents were in 'lower professional' work. This included a significant number of educationalists (15) (teachers, private teachers, instructors and adult educators) and five nurses. There was also a small cluster of other skilled 'knowledge workers' such as technicians and IT workers. Fourteen people had a trade or did skilled and semi-skilled manual work and there were only two farmers. There were four small business owners.

A very large number (56) did not indicate what their occupation was before college. Based on the interviews and the fact that 42 of these 56 respondents were women (only one out of the 218 respondents described their work at home as an occupation), it can be surmised from this that a significant proportion of mature students were doing unpaid work in the home before university.

The occupations of the respondents strongly reflected some of the other changes that have taken place in the structure of the Irish labour market over the past thirty years. The majority (68) of mature students who were in paid work before college were part of the 'non-manual' socio-economic group. The majority of the respondents to the NUIM survey worked in the service and retail sectors or did administrative work (respectively 30, 18 and 26 people). This socio-economic group is very heterogeneous (and includes, and this is not an exhaustive list, 
social workers, Gardaí, clerical and office workers, personal services and salespeople). Consequentially, in terms of status, pay, conditions and career prospects the non-manual group is a very stratified socio-economic grouping.

\subsubsection{The prevalence of disadvantage amongst mature students at NUIM}

It has been repeatedly demonstrated that socio-economic background has a very strong influence on participation levels in HE. Research on mature students has also indicated that mature students are much more likely to come from higher socio-economic groups (Lynch, 1997). In the light of these findings the relatively high number of lower professional mature students is unsurprising as is the relatively small numbers of skilled and semi-skilled workers. On the other hand, it is significant that the socio-economic group with the lowest level of participation in $\mathrm{HE}$, the non-manual group, which in 2004 had a national entry rate of 27 per cent (HEA, 2008, p. 59), are attending NUIM in large numbers.

However, despite the correlation between socio-economic disadvantage and participation in Higher Education the heterogeneity of this group means that on its own having a non-manual occupation is a poor predictor that someone is disadvantaged. The exact type of work, the level of autonomy it allows, promotion prospects, income levels etc. all play a part in determining the likelihood that someone from this group may have encountered social as well as educational disadvantage. In this case, it is clear from the details supplied by respondents and the interviewees that many of these non-manual workers were involved in routine, and often insecure or low income work which, by and large, they left either just before entering college or once they had acquired their degree. It will be argued below that this is important in understanding the sort of transitional space NUIM and higher education has offered to mature students.

This is also reflected in the high number of mature students (meaning the entire cohort of matures) who qualified for and availed of state-sponsored financial supports. Fifty-six per cent of respondents availed of County Council grants and 
almost 40 per cent qualified for the BTEA, a programme aimed at overcoming educational disadvantage especially amongst low paid workers and unemployed people. Six per cent of the students surveyed who did not receive BTEA relied on other social welfare payments such as Lone Parents' Allowance and Disability Benefits. Five of the recipients of social welfare came from occupations in the two highest socio-economic groups. Nine recipients were from a lower professional background. Forty-two recipients had been engaged in non-manual work before studying, twenty-four had no occupation before college and seven of the fourteen people who had a trade or did skilled or semi-skilled manual work qualified for social welfare support. So, unsurprisingly, receipt of social welfare is more likely in lower socio-economic groupings, home workers and significantly a large proportion of the non-manual group. Twenty-one students also received small grants from Partnerships, regeneration groups, the Millennium Fund and in one or two cases from trade union or religious charities.

The occupational profile of the students, the fact that a high number of students relied, at least in part, on state benefits along with the other details gathered in the survey about income, educational history, life experience and place of residence makes it clear that a very large number of NUIM's mature students come from a working class background and furthermore, based on the qualitative data, many of them have encountered serious economic, social and educational disadvantage during their lives.

The questionnaire also asked students with disabilities and migrants about their experience. The student body was not ethnically diverse, the overwhelming majority of respondents were Irish-born citizens (207) and five of the non-national students were from the UK, Canada or the USA. How representative this cohort actually is remains somewhat questionable as a postal questionnaire may be less likely to reach some of the NUIM's non-national students. Five per cent (11) of those surveyed had a disability. 
These different datasets that partially overlapped, based on a multifactorial conception of education and disadvantage, were synthesised in a single dataset. The basic cohort was defined as those who were in receipt of some sort of social welfare support and was supplemented with a cohort of students with disabilities and socio-economically vulnerable migrants. This dataset accounts for forty-four per cent (97) of all mature students who graduated from Maynooth. All figures cited below are drawn from the disadvantaged dataset unless it is explicitly stated that we are referring to all mature students. All the interviewees with two exceptions were drawn from this cohort.

Interestingly, this smaller dataset of disadvantaged is almost identical in terms of the gender of students (67 per cent were female) and their type of degree (90 per cent opted for a BA) and subject choices. However, the age profile is somewhat different as 35 per cent of these students were in their thirties, 25 per cent were in their forties, 25 per cent in their fifties with the remainder in the late twenties, sixties and seventies. Forty-seven per cent of this cohort are married (47 per cent) and 8 per cent are living with their partner and are less likely to have children than the general mature student body (40 per cent had no children at the time of the survey).

\subsubsection{An overview of the interviewees}

The interviewees were a representative sample of the larger cohort of those who responded to the questionnaire in terms of gender (sixteen were women and four were men), degree type and subject choice (eighteen of the participants studied arts, most commonly English, History, Sociology and Greek and Roman Civilisation, and the other two interviewees studied for a science degree choosing Biology, Math and Chemistry); and in terms of age (the youngest interviewee attended college in her mid-twenties and the oldest started studying in her sixties). The majority of the group studied in their thirties and forties. Care was also taken to speak with students who had graduated in different years in order to find out if the way students viewed their experience of Higher Education 
was dependent on the year they had graduated (due to labour market conditions, time spent away from the institution, etc). Twelve of the interviewees were married with children, three were single parents, one interviewee was separated from spouse with a family and the others were either single or living with partners. The majority (13) of graduates were based in Dublin, particularly west Dublin. Although three students lived a considerable distance from the campus most of the other students lived in Kildare and Meath. The interview sample included two people with a learning difficulty and one migrant from a non-English speaking country in Africa (now an Irish citizen).

All the graduates interviewed had either not worked before their degree (4 of the cohort) or had worked in routine non-manual (12 interviewees) or skilled or semiskilled manual jobs (4). Although most of the interviewees were in poorly paid jobs, four of them (a salesperson, an office administrator, a worker in the hotel industry and a taxi-driver) had middle-income jobs. Seventeen interviewees finished school before the Leaving Certificate. All except three of the graduates attended access courses and/or took part in community-based Further Education programmes for a period ranging between one to four years before entering university. Only two interviewees had a parent with a university education. None had third level qualifications at the start of their studies and only one of the graduates had started a third level course elsewhere before coming to Maynooth.

Eighteen of the twenty graduates received BTEA and a County Council Grant. However, early on in the interview stage of the research it became clear that in a minority of cases, due to a lack of readily available clear information on the qualifying criteria or how to apply for the allowance, some low-paid workers did not receive the BTEA. The original general dataset was then re-examined for potential participants who had used other sources of funding to get through college such as savings and redundancy.

\subsubsection{The price of the ticket: Financing a degree}


The graduates spoke in measured and uncomplaining terms about the financial situation during their student days. Generally speaking a picture emerged in which students relied on savings, redundancy payments, pensions and, most frequently, their immediate family to support them. Studying, as a mature student, required very tight budgeting. Remarkably, none of the students surveyed or interviewed had received any financial support from their employers. The BTEA was seen as extremely important (according to 80 per cent) and was often crucial to these students' choice to enter Higher Education. It was not always sufficient by itself and often had to be supplemented in various ways:

You would have a really hard time surviving on the grant and on what you're given and stuff. But yes, I feel so lucky with the grant and the scholarship and the County Council. But to be expected to live off those alone, your life would be very poor but the fact that you have them at all, you have a chance. But life would have been extremely miserable without these grants and scholarships.

Several interviewees saw the BTEA as significant in another way. It sent an important signal that State rhetoric about access was genuine and that they were 'wanted' as students. Just under 38 per cent of students built up debts ranging from $€ 10,000$ to $€ 40,000$, with the vast majority of these indebted students (almost 84 per cent) owing up to $€ 10,000$, on graduation.

Overall, the students were enthusiastic about the support they received. This is significant because previous studies have suggested that less wealthy students see Higher Education as more financially and socially risky than privileged students (Archer, Hutchings and Ross, 2003). The existence of financial support made a tremendous difference and was a vital part of an ecosystem of supports that allowed them to take the risk of going to university. Several interviewees raised the question of the absence of support for postgraduate work which meant that some discontinued their studies prematurely. 


\subsubsection{The graduates' assessment of institutional supports at NUIM}

The interviewees were unanimous that formal access routes are very important in widening participation and helping position the applicant for a degree level study programme. Most of those interviewed had attended between 1 to 4 years of preparatory courses before entering university and agreed that this had been vital for building confidence, learning skills and building informal support networks with other students who often remained an important resource through their degree courses.

A large number of survey respondents and all the interviewees chose NUIM because it was seen as 'mature student friendly'. Maynooth appears to have retained some of the positive associations of Higher Education without being seen as an exclusive or elite institution. It also became clear from the interviews that several of the adult education access programmes in Dublin promote NUIM as the university most likely to support mature students and that informal friendship networks are an important influence on the choice of institution. Maynooth has undoubtedly benefited from the advice of some access programmes and a decade of institutional measures aimed at encouraging nontraditional students.

The initial face-to-face contact with the university appears to be vital for mature students who favor informal assessment procedures that take account of nonacademic experience and skills:

I walked into the old campus and thought 'What am I doing here?' It nearly didn't occur to me that l'd be accepted. One of them [interviewer] said 'I'll be seeing you again very shortly'. He was saying these words and kind of intimating without formalities that I was going to be accepted. It was a moment I will never forget in my life. 
Many graduates in all the colleges mentioned the programmes and work of the Mature Student Offices. However, interviewees who did not need specific supports were still overwhelmingly positive about the Access Office. When asked what specifically made the campus welcoming, the graduates mentioned the relatively large number of mature students within the student body, the small scale of NUIM, and a general adult-friendly ethos amongst the staff as the most important factors in creating a sense of 'institutional' support. The way staff treat mature students was continually mentioned as being of the utmost importance. In the numerous mainly positive and only occasionally negative anecdotes the graduates explained what interactions and pedagogy they preferred. Ideally, according to the graduates, staff have to strike a delicate balance between acknowledging life experience and specific learning needs without singling out or making special pleading for 'mature students'. Unsurprisingly, the interviewees also need high levels of encouragement in the beginning of their university career and regular, fair and constructive feedback throughout the degree. There were several complaints about a lack of clarity from departments about prior knowledge requirements, especially for subjects that are on the Leaving Certificate, and the amount of time required for reading. Complaints about some services and facilities, such as the library in NUIM, were also made but on the whole this did not appear to mar their overall experience.

While some interviewees were conscious of their socio-economic background and initially of arriving somewhere that was not meant for them they did not think that their social class or gender impacted on their experience of university. In fact many mentioned how social diversity (social class, ethnicity and gender) in the student body was a positive learning experience. However, the complex interaction of cultural expectations in relation to class and gender did, for a large minority of the interviewees, impact on their personal life outside the university and these students found that family, friends or work colleagues were sometimes dismissive or unsupportive. 
In an interview with a foreign graduate the specific obstacles faced by a mature student who was also a migrant were explored in some depth. Again NUIM was described as inclusive and attending the university was seen as an important part of a broader process of meaningfully embedding herself in Irish society. In this she felt generally supported but encountered certain difficulties in terms of writing and learning in a language that was not her mother tongue.

The 11 students with disabilities who responded to the survey had more mixed feelings about the level of support they received from NUIM. On the whole they felt positive about college support but a number thought that lecturers and some students showed a lack of understanding of their needs. It was also noteworthy that only half of these students were supported by social welfare and that all but one of them was a woman. In two interviews with students with disabilities both described how getting through Higher Education had been a fundamental part of overcoming some of the stigma and prejudices surrounding disability. As one teacher who now works with dyslexic children said:

The kids in 1st year know l'm dyslexic. Now the whole school don't know but there are certain pockets ... I find that because I was dyslexic it's not a hang-up any more. That's a huge thing. It's not a hang-up. If anybody has a problem with whether I'm dyslexic, that's their problem. I have an honours degree. I have a [postgrad]. And they can do what they like ... I always felt 'I'm stupid'. You know what I mean. One girl said it to me, 'We thought you were thick but look at you now.' And they did think I was stupid.

\subsubsection{The family dimension in overcoming educational disadvantage in the past, present and future}

All students told another type of access story eloquently and passionately which centred on their own family and childhood. Stories were told about parents and the values of the family. Access to books, television programmes, debates and 
discussions in the home are among the most widely experienced positive access stories. A large number of graduates traced their desire, ambition and ability to engage in HE back to those events. We call them access stories because they functioned as such, allowing people to 'gather' their strengths, abilities and interests and this contributed hugely to their later conviction that they could access HE and succeed:

I had a decent father ... he inadvertently gave us all a gift, in that there was always books around the house. There were always books and we went to the library as well ... My father had a great love for libraries and joined the library.

Another student confirmed that:

My dad and mum would have got us sitting down, looking at science and nature programmes on TV when we were very small. I loved them, my brothers and sisters would all be the same, you know. So that formulated in my mind a bit without even realising it. I'd love to study something like this. You know, science.

So many expressed these sentiments in powerful stories:

Oh yeah, Dad used to say to me 'Mary, you'll always be a learner.' I loved learning new things. I think back, and Dad and Mam set up that informal learning atmosphere in the house. That was there right from the beginning. I don't think you can pay for that. They were very curious people by nature. Dad would be a very intelligent man. Dad and Mam did their first year of secondary school. Then they would have had to have left because they didn't get scholarships. Dad knew an awful lot.

When asked about how long they were preparing to return, one summed it up 
like this:

Years. I literally felt l'd been preparing for years. I reckon in my subconscious I was preparing for about 11 or 12 years. In fact, I'd nearly been preparing since the day I left secondary school.

Support for students who have been successful at university comes primarily from the family and it confirms the importance and effectiveness of approaches to poverty that emphasise family support. Family support continued through their student days, often through direct support but also through support for the ambition of the students to better themselves. Direct support included finance and childcare. For those without such support the absence of family networks meant that the pressures of child minding and emotional support were increased. This was particularly onerous for the migrant student.

In the interviews the vast majority also identified events in the family as potentially the most powerful barrier to completing their studies. The death or serious illness of a parent, child or partner was clearly identified as raising the real possibility of not completing the course.

On the other hand a significant minority of the interviewees said that the experience of poverty, lack of stability and the low expectations of their family had hampered them when they were younger and they now felt it was necessary to break away from this situation in order to get through Higher Education. Arriving at the point in which they felt confident to make a break with the gravitational pull of difficult circumstances required both enormous effort and determination. During the research this type of negative access story was more prevalent amongst women.

The graduates valued the opportunity to demonstrate to their partners and especially their children that university was a place that they also could go to, if 
they chose to do so, in the future. Some students even described how they studied alongside their own children. Most of the interviewees were emphatic that their personal 'learning story' was in a strong sense a family learning story that touched on their past, present and future.

\subsubsection{The graduates' post-degree destinations in the labour market}

Mapping the sort of social mobility facilitated by access to Higher Education for disadvantaged mature students is a complex issue. First of all, it is difficult to estimate accurately the extent to which some of the benefits and opportunities presented to the graduates may have been the fruits of a long economic boom rather than a direct result of Higher Education credentials. Secondly, the transitions being managed by the graduates were complex and varied. Many of those surveyed were entering the labour market after a period of unpaid work at home, just over 5 per cent were preparing for retirement and some never intended to change their occupation. In explaining their motivation for going to college both respondents and interviewees rejected the idea that it was a dichotomous choice between 'learning for the sake of learning' or creating career opportunities. It was about both of these things. The research also demonstrated that the post-degree labour market destinations sought by these graduates was bound up with how they envisaged these destinations in terms of status, security, and personal development rather than monetary reward.

In fact, the NUIM graduates have had relatively modest return on their degree in monetary terms. For instance, although the majority (76.5 per cent) expected to increase their earnings after graduation, less than 60 per cent have got an increase in salary (these figures are almost identical in the larger survey cohort as well). About 70 per cent of graduates were earning under €30,000; 24 per cent between $€ 31,000$ and $€ 40,000$; and only just over 5 per cent were earning more than $€ 40,000$. This compares poorly with the average industrial wage for men (€32,000) and certainly falls short of the salaries paid to teachers ( $€ 50,000)$ and other public servants (CSO, 2006). This also compares poorly with the 
percentage of high earners in the larger cohort in which 16 per cent were earning over $€ 40,000$. Students with disabilities had even lower wages, with 52 per cent earning less than $€ 20,000$. Few graduates have been promoted (approx 9 per cent which again compares poorly to the 15 per cent of larger sample of all mature graduates who were promoted) and none were earning large salaries. One graduate estimated that he had a 50 per cent drop in salary since his degree. We discovered that salary was not viewed as the main priority for many graduates. One woman who worked in a routine administration job explains;

Well, I was earning about €40,000 when I left (work) ... I could have gone up to even more, so I went down to a very modest salary, it would have been around $€ 10,000$ a year. But I was a lot more content in myself which was amazing. And I still am.

Going to university was explicitly linked to the desire for qualitative changes in their working life. Those interviewed often wanted to escape a life of sometimes hard, and often boring work in which they felt pinched by routine. One graduate, a taxi driver who has since become a teacher, explained:

I was making money in the 1980s when no one was but I worked round the clock 80 to 100 hours a week and felt invisible, unstimulated and unfulfilled in this work.

The desire to communicate with others and to have meaning, purpose and respect featured in this and most other accounts. Most of the graduates left college with these types of aims in mind even if they had not arrived at the university with a clear idea of what career changes they wanted to make. In this regard it is striking just how many graduates in all the research cohorts moved from routine work into 'lower professional' occupations or higher status work with greater prospects. 
Most striking of all was how many graduates went on to become teachers or continued with their studies at a higher level after their degree. This commitment to education is one of the most noteworthy findings of the research as a whole. This is true of the larger and smaller cohort. In the smaller cohort of ninety-seven there were thirty-six people working in education (including 23 teachers and 7 adult education tutors) and nineteen people studying. There was a marked transition away from administrative, retail and service work to educational work (19 people) and studying (8 people). Those who were not working before college included 5 educational workers and the eight postgraduate students. It should be noted though that at least a third of teachers were unqualified for teaching and a large number were on part-time contracts. The other occupational clusters were workers in community and youth work (3), research (2) and administrative and secretarial work (4).

Nine of the twenty interviewees had chosen to teach in schools or adult education after graduation and this allowed us to explore why so many graduates, especially disadvantaged students, chose teaching. One typically explained:

I hold the position of teacher in esteem. It is a job of esteem and I still feel that. When you are working class, you look for esteem ... we held teacher, priest and garda sergeant in esteem. I had the perception that these are positions of recognition. I was probably looking for that.

Besides the status, potentially good working conditions, and the communicative richness of teaching, the graduates became educators because they wanted to give something back and bring people along. The idea that they were becoming a node in learning webs was a real source of pride for these teachers. Even those who were no longer involved in formal teaching or learning all mentioned the way their experience continued to be a positive resource for partners, children, neighbours, friends, workmates and even parents. This concern to 
support peers in Higher Education led one interviewee to donate his relatively substantial library that he built up during his degree to his old department so the books could be used by others.

Eleven per cent of students remained in the same occupation that they had before college and 7 per cent did not indicate any occupation after university. It is not clear how many were doing so of their own volition and two interviewees discussed how they had sought a different job after their degree work without success and found settling back into work very difficult as a result. A relatively high percentage ( 7 per cent) of the cohort were unemployed when surveyed and towards the conclusion of the research project in May 2009 when some of those interviewed were contacted for their feedback on the preliminary findings, we found that 3 of the 10 contacted were now unemployed. The subset of fourteen skilled and unskilled manual workers within the cohort were more likely to be unemployed (14 per cent). On the other hand this small subset had slightly higher levels of income than the rest of the cohort which may reflect the higher number of men in this group. However, the small sample means that these findings may not be representative.

\subsubsection{So was it worth it? The graduate's evaluation of their post-degree transitions: Esteem and social inclusion}

The NUIM graduates frequently spoke about how profoundly they valued their experience of Higher Education. Despite making considerable sacrifices in terms of money, time and effort while juggling the various demands of relationships, work and study, the participants asserted that going to college was 'the best thing they had ever done' and 'the most rewarding experience of my life'. Overall, 85 per cent of mature graduates and all but one of the interviewees indicated they would opt for the same course again if they had the choice. The minority who would not do so cited poor choice of subject and limited career prospects after being awarded their degree as their main concerns. In this regard there appears to be a specific problem encountered by science graduates, with the majority of 
BSc graduates unhappy with their post-degree career opportunities. Typical of the comments made was this from a graduate in science:

The job I ended up doing when I left college was in a lab. [Pay] was only $€ 19 \mathrm{~K}$. I expected to earn €20K more than that ... I was really disappointed. I thought I would be higher up the scale. I have all this experience, all this technical skill, management skill. All this stuff had nothing to do with the job. They're all workable skills. But there's no job. Like the jobs were quality assurance/quality control, press a button, do this. You don't need any other skill ... I was in shock ... [I] worked really hard ... I put in the effort to do things properly and now it would pay off and I would keep moving up and up and up. And I would be given more responsibility. It just didn't happen like that.

However, there can be little doubt that the overwhelming majority of graduates value their degree very highly. In fact, perhaps paradoxically, the graduate quoted above went on to explain that her degree was very important to her. Predictably, the graduates valued the experience for all sorts of reasons: to feel stimulated, engaged and challenged, or having a space to reflect on life, to meet new types of people or to hone organisational skills. In general they agreed that going to university was important because it offered credentials, improved career opportunities and gave them the chance to prove their intellectual worth. They also spoke convincingly and unpretentiously of their love and passion for learning and the subjects they studied.

The extent to which attending university was linked to a change in the students' sense of themselves and an increase in their esteem and confidence was striking. In fact, the unanimity and depth of passion on this issue surprised us. As one graduate put it:

The experience of getting a degree has huge benefits. You feel physically 
better. You walk more confidently and your life is better because you feel like you have really achieved something ... As a mature student you grow just as much [as younger students] just in a different way ... I think you become more of yourself.

This emphasis on change and esteem is absolutely typical of the graduates whom we interviewed and has already been noted how and why this might be so for students who are migrants or students with disabilities. A good deal of its importance can be explained by examining the graduates' previous educational experiences. A recurrent theme amongst the participants was of dealing with 'unfinished business' by making use of educational opportunities that had been denied them earlier in their lives. As one graduate said:

All avenues were closed to you when you are from the wrong end of town.

One interviewee explained that she left school early because:

I was terrified of it all the way through school, really terrified. Primary school was rather vicious, rather vicious lay teachers. Very vicious, yeah. It was only in secondary school ... oh my God they don't hit you here ... You know I wasn't a bad student. One of friends actually changed school. She froze when she was asked anything, terrified. She got beaten for being late or misspelling an Irish word, I can still remember the word.

Bad teaching, violence, financial pressures, low cultural and institutional expectations, poorly understood learning difficulties and family circumstances meant that for all but one of the interviewees they had no option but to leave school earlier than they wanted. Some were clear about the link between educational and social disadvantage in Ireland:

To me, you can talk about democracy and equal rights, but people are not 
getting the same opportunities. This is the thing that [has] most changed my life. I felt very frustrated. Ireland to me was a terrible, terrible place. It was demeaning to be from certain areas of society. You were held down ... It was a great place for certain people. Lots of people never realised that the opportunities were there. But it has changed now. This country is now a different place ... So how can you value that? You look on the country of your birth in a different way.

This exclusion gave some of the interviewees, particularly the older graduates, a sense of being unworthy, leaving them with what Sennett and Cobb (1977) have termed 'the hidden injuries of class'.

For all, going to university was a long cherished dream, the realisation of which confirmed both their capacity to succeed and their intelligence. When asked when they first wanted to go to university interviewees said again and again: Always. Entering Higher Education allowed them to finish their 'interrupted learning stories', gave them proof of their intellectual and human worth and marked for them the end of a certain form of social exclusion:

It is about acceptance and your worth being recognised. It was a chance to learn, to learn about myself and to be on an equal footing with other people.

Attending university also gave many of the graduates the confidence to be able to partake in broad public discussions and think critically in a way that seemed beyond them before:

I bring myself back to ... listening to something on the radio, a political discussion or on history, and always having the feeling that this wasn't for me, that other people would understand it. I wouldn't ... It sounded like a different language. 
Several ascribed their new-found confidence to seeing themselves as able to understand the world of power, politics and history and of being visible, included and respected.

Higher Education appears to have made a profound difference to the students we spoke to in terms of their self-image, confidence, general working conditions and ability to participate in society. In addition, going to university not only allowed them to build on their lifelong ambition but provided an important platform to continue learning. Though they were always learning they wanted to continue and be lifelong learners:

For years I felt my brain was under-utilised. I was bored out of my tree! Now I'm feeling that I'm learning so quickly. Never thought l'd be into areas like this at all. But I hope I'll never stop learning until the day I die. I am going to be learning all my life.

The research strongly validates the idea that mature students who are encouraged back in to further education and given the financial and institutional support are very willing to continue formal learning. Ninety per cent of these graduates indicated they would consider returning to Higher Education and 34 per cent had embarked upon or completed postgraduate work.

In a modest way the graduates were claiming a new form of learning society and elaborating a set of practices and ideas about lifelong learning that are in many respects quite different from mainstream policy. Recent education policy in Europe has been strongly influenced by conceptions of 'lifelong learning' (CEC, 2000) and it is one of the central ideas informing the Irish White Paper on Adult Education (DES, 2000). It is, in certain respects, a potentially radical idea that acknowledges the value of learning outside formal institutions and has emerged and re-emerged in educational thinking in a variety of forms since the 1970s 
(Borg and Mayo, 2005). However, many policy recommendations currently linked with lifelong learning have been underpinned by a form of market functionalism (Borg and Mayo, 2005; Tett, 2002), and lifelong learning is conceptualised largely in terms of maintaining a flexible and competitive economy in the modern 'knowledge society'.

The paradigm of a ceaseless and uncontrollable globalisation that requires an ever more flexible workforce is massively influential (OECD, 2004) and has certainly shaped the views of Irish politicians and policy makers (Dempsey, 2004). However, while all the ex-students saw themselves as lifelong learners their emphasis on democratic, personally meaningful knowledge, increased occupational security, greater free time, social purpose and communicative richness is a far cry from economic functionalism and the utilitarianism that underpins much of the discussion about lifelong learning. Rather, it fuses strategic action with pragmatic social concern, a traditional liberal conception of the value of a broad education and an intense awareness of the value of personal agency.

\subsubsection{Summary of findings}

Improving access to Higher Education and increasing the participation of mature students has been a policy priority in Ireland for over a decade. The research in NUIM indicates that as a consequence there may have been a shift in the sociological profile of mature students. While lower professionals still accounted for a large proportion of the intake the high numbers of routine non-manual and people who had no previous occupation shows that access policies have had some success. It is clear that targeted measures to develop access routes from Further Education to Higher Education and the availability of financial support has had an important role in this process.

The changing profile of mature students is obviously linked to broader sociological processes and in particular the feminisation of the workforce, the 
growth of the service economy and the increasing importance of academic credentials. The boom and the changing structure of the labour market has allowed mature students to explore new life paths. This however does not apply to all socio-economic groups or genders equally and the relatively small number of unskilled, semi-skilled and skilled workers in the sample was remarkable.

When we examined other student groups who might have encountered disadvantage the results were also mixed. While the numbers of mature students with disabilities (5 per cent of all students surveyed) was well above the national average of 3.2 per cent the graduates had mixed feelings about the support that they could avail of in university. The number of non-national mature students was low (again 5 per cent of all respondents) and there were very small numbers of migrants.

All students viewed Higher Education as an important transitional space which offered them some of the resources that they needed in order to flourish both individually and as citizens. Attending university was part of a longer trajectory away from disadvantage. While a number of the interviewees had experienced considerable hardship and difficulty in the past, the conditions for overcoming disadvantage were largely in place before they came to college. In this sense HE is not a transitional space that combats economic disadvantage. It requires that students are already on a trajectory away from disadvantage. There was little evidence that the most disadvantaged or impoverished sections of Irish society were attending NUIM as mature students. However, for the interviewees the process of overcoming early experiences of educational disadvantage was seen as a strong validation of their social worth in the here and now. For the graduates to whom we spoke this was a fundamental part of their post-degree destination and integral to the way they valued their degree. The emphasis on esteem, based on achieving a greater degree of 'parity of participation' in society, empirically demonstrates the importance of the ongoing debates that have sought to understand the 'moral grammar of social life' (Fraser and Honneth, 
2003; Honneth, 1995) and the negative force of what Bourdieu would term symbolic violence of being demeaned or undervalued. Other scholarship has highlighted the importance of Honneth's ideas for understanding the sociology of self-esteem (Fleming and Finnegan, 2009a).

For the graduates, labour market transitions were explicitly linked to this sense of social validation. The monetary rewards of acquiring a degree were relatively small but an astonishing number of previously disadvantaged students managed to change socio-economic group and improve their working life. In particular mature students who study for a degree at NUIM are either pursuing further studies or working in education. Targeted financial support has established a firm basis for genuine lifelong learning in formal institutions, the community and the family. Interestingly, these transitions and destinations were almost identical to the trajectories and destinations in the broader mature student cohort.

Our research shows that mature students, whether disadvantaged or not, rely on a web of financial, social, emotional and institutional support to get through Higher Education. This is a delicate, finely meshed ecosystem that students tell us clearly could easily be disturbed. If we characterise institutional measures that support mature students and broaden participation of disadvantaged learners as vertical supports, we can characterise supports from family and community as horizontal supports. It is a clear finding of this study that both vertical and horizontal supports are essential and supports that address poverty and exclusion should be delivered in a way that recognises the importance of both vertical and horizontal factors.

In speaking about the importance of the family as a location for fundamental support it is important to note that we do not have a view of the family as a homogenous unit of society. The family is complex. As new and diverse forms of family emerge (from the obvious single parent model to multi-cultural, gay, divorced and remarried), this prevents a 'one size fits all' approach to support 
and interventions. However, irrespective of how the modern family is evolving it is clear that when students experience success at university it is almost always identified as being supported by the experiences, values, culture, cultural capital and ethos of the family. Interventions that support students, whether young or mature, are enriched by supports for the family that enhance the ability of the family to value education and learning. 


\section{Findings from DIT}

\subsection{Overview of mature students (DIT)}

The DIT students in the survey group were 79 per cent male, 21 per cent female; age range 33 years to 61 years; the mean age was 40 years; 85 per cent of respondents were Irish, 6 per cent were British and the remainder came from Bosnia, Germany and South Africa. Sixty-eight per cent of the sample were married, 19 per cent were single and 13 per cent stated they were lived with a partner. In relation to children, 31 per cent of the sample group had no children.

Most graduates were in the professional areas of construction, engineering, management, business and information and communications technology (ICT). The most popular degrees were BSc (25 per cent) and MSc (24 per cent). For 50 per cent of the students access to the programme was through consideration of their previous work experience and an interview. Sixty-two per cent of respondents undertook a part-time degree and the remaining 38 per cent studied full-time. Fifteen per cent were motivated to study for personal reasons (interest, development, always wanted to go to college) but the majority chose for career related reasons, e.g. wanting a career change, increase their employment options, increase their promotional opportunities and improve their work skills. Seventy-five per cent of respondents stated that they would choose the same course again.

The interview sample group had a balanced gender distribution (8 female, 9 male); most of the participants' age range was 30-35 (7 participants); the age range spanned from the youngest in the 25-30 range (one participant) and the oldest in the 50-55 range (2 participants). Four participants stated that they were out of full-time employment at present.

The reason participants gave for choosing DIT were: 1 ) Reputation (family members, past students, friends and employers), 2) Central location, 3) Reasonable costs, 4) Career-focused programmes, 5) Programme structure 
(part-time and modular structure of programmes).

One female participant's comment captured these categories:

I had a couple of friends who went to DIT and they spoke highly of it; also I was aware of DIT's reputation. DIT seemed to be the best option at the time, not too expensive; just had a child and could work around the DIT course schedule.

It is clear that participants came from a variety of socio-economic backgrounds. However, only three participants reported that they came from a working class background. Four participants noted that they were the first person in their extended family to receive a Higher Education degree.

None of the participants gained access through the DIT Access Programme. All came through the CAO. Some expressed concerns about the CAO, reporting that it was quite difficult to fit in, for someone who had not been engaged with education for some time. One participant stated:

When I applied I did not have a primary degree; application was assessed on my previous work experience and on a professional Diploma I had. It took about three months to go through this process. I was starting at Masters Level.

Overall, participants reported they had a positive experience of accessing DIT, and most noted they had 'done their homework', accessed programme information, went to open days and talked to lecturers before applying.

\subsection{The price of the ticket: Financing a degree}

In some cases participants reported getting fee support from their employers. Some had difficulty getting enough money to run the family home, to purchase 
books, specialised material and equipment. Some spoke about the high cost of child minding. A high number (34 per cent) were in debt after they graduated. Participants adopted different strategies to finance their studies; some were in full-time employment already and could manage to redirect some of their earnings to finance indirect costs. Others specifically sought part-time employment to cover these costs. Two of the participants managed to get grant aid. One participant stated:

Costs: my partner assisted me I supported him when he was studying. We took turns.

Support from a partner was frequently mentioned. Two participants who lived outside Dublin expressed concerns about travel costs and suggested the school should be more concerned about organising activities outside the regular 'nine to five' day. Similar concern was expressed about child minding.

\subsection{The graduates' assessment of institutional supports at DIT}

Participants expressed a mixed experience of the supports on offer in DIT for mature students. Comments ranged from:

I wasn't aware of any support services. I was not informed of any services. There was the career guidance ... touched base once ... wasn't really suitable for my needs

to another participant's comment:

Yes, there were a lot of us returning to college ... had not studied in a while. There were courses on how to use the library, do an assignment. These were quite good. Everything you needed was there and all the support you needed.

Participants (51 per cent) generally made positive comments relating to the 
support and encouragement provided by lecturing staff. However, they expressed concerns about the provision of adequate information in relation to other support services. Many did not seem to be informed about the services available and some did not have the time to search or access these supports.

Participants mentioned the library service in a very positive way; the staff were reported as being very friendly and helpful. As mature students they had different support needs to the general student body. The participants wanted support services to assist them in academic writing, study skills, time management, financial management and in some cases ICT skills (particularly for older mature students). Three participants noted that they had dyslexia; one of these participants had a positive and supportive experience while the other two participants expressed more negative comments about the institute's understanding of their 'disability'.

Participants reported that they received most support from and developed closeknit support networks with other mature students. These support networks have extended to post-degree, and members stay in touch with each other. In cases where there were only one or two mature students in a class there was no reporting of network activities and some participants felt isolated as they were the only mature student:

I was the only mature student out of 100 . This was isolating... nothing in common with the other students. Had a family and could not engage in student activities.

This sense of difference was reported by other participants and was about a variety of factors, e.g. life and work experience, thinking differentially, and different priorities in life. 


\subsection{The importance of family support}

All participants made reference, as in the NUIM findings, to their family. Some noted that their families did not understand what they were doing;

Family were supportive but did not know that much about what I was doing; not part of our culture. This was my last chance; married and a father, now or never to go back to college.

There were also issues raised based on gender, position in the lifecycle and responsibilities in the home. Gender was implicit as in one woman's comments;

Family context was a big juggling act. Time was significant: going to college, then collecting kids, then getting them to bed, then studying. The age I was wasn't a good age to go back; maybe before the kids or when they are older. Women have children in their 20s-30s. This stops your career path.

Participants with children detailed how the added responsibilities had a direct impact on their studies. One man stated:

Family context was incredibly difficult. Studying and working from home, looking after the kids, assignments and then housework. First year we managed. The second year the strain was showing on everybody. The pressure was intense.

Studying at home seemed to be possible when the children were either very young or grown (late teens), but it proved very difficult when children were in school. One woman said:

I had no kids so gender was not relevant. If I had kids I don't know how I would have done it.

Child rearing is a big factor in terms of individual stress, coping with multiple demands and maintaining family relationships. 


\subsection{Post-degree destinations in the labour market}

Most participants in this sample group were already in employment, some went into part-time employment during their study period and one was seeking to return to the labour market. Generally participants had a clear focus on the job they wanted. In some cases this was a promotional opportunity in their present employment and in other cases a new career. The survey data also supports this. Most participants succeeded in achieving some of their goals in terms of promotion or career change. They reported that their investment in Higher Education had a positive return. For example, one person stated:

Yes definitely. I think the benefits were economic because I got head hunted, but there was a more social benefit to me in terms of standing and confidence; having never gone to college achieving a masters qualification is a buzz to me.

Gaining the degree award enhanced participants' confidence in terms of social status and willingness to take a risk by taking a new career path. They were happier in their new positions and had the skills and know-how to manage new work responsibilities. Some felt that they may not have the full opportunities to apply their new learning in the workplace due to the decrease in employment opportunities and possible recession:

When I read this question I laughed. At the moment I am working in a Bank (name withheld). I just want to keep my job. I thought I would move into HR but I moved away from this because they were thinking of outsourcing this area. The term they use is 'right sizing'. I moved to operations and projects.

\subsection{So was it worth it? Student motivation and the perceived value of a degree}

Most of the sample group reported that their primary motivation for returning to education was career orientated. One participant stated: 
I wasn't in a good place in the job I was at the time, no luck with applications for new jobs. The job I was in wasn't very demanding, ... wanted something more stimulating.

For whatever reason at different points in their lifecycle and career, participants seemed to have reflected on their present position, explored their future options and felt a need to change their life choices. One woman, an engineer, stated:

I had worked in the dispatch industry, courier, trainer, office manager,... got as far as I could go, ... wanted to change career.

Another woman reported she had raised her family and she wanted to get back into the labour force, wanted to start building her career. She was aware of the obstacles in her way but was prepared to tackle them. Participants also talked about the desire to prove to themselves and to others that they were capable of achieving a degree. They considered this was a form of both personal and social status associated with holding a degree. Another reported a critical event that occurred in his family, which sparked off his desire for change:

One of my kids was sick with cancer and I said, That's it, time to change a load of things.

Participants seemed to enter a reflective mode of thought due to different social and personal factors. However, whilst they were in this reflective mode they seem to be prepared to make life-changing decisions and take decisive action. 


\section{Findings from TCD}

\subsection{Overview of mature students TCD}

Seventy per cent of the TCD sample was female and 30 per cent male, with a mean age of 42. Forty-six per cent were between 29 and 39, 29 per cent between 40 and 49, 17 per cent between 50 and 59 and the remaining 6 per cent over the age of 60 . Fifty-four per cent were married, 26 per cent single, 18 per cent were living with a partner and 2 per cent were separated. Thirty-six per cent of people said that they did not have children. TCD students can 'mix and match' different disciplines and areas either within or across Schools or Departments. For example, the 'twin subject moderator' allows students to mix subjects across disciplines. Eighteen per cent undertook an 'arts' degree, 4 per cent languages, 4 per cent business studies, 30 per cent social sciences and 17 per cent natural sciences and 16 per cent nursing. Seven per cent reported that they mixed 'arts' with 'social sciences', 3 per cent 'social sciences' and 'science'. The routes into TCD for mature students are either via the Trinity Access Programme (TAP) (that still requires graduates of this programme to compete openly with other applicants for access), the CAO and the TCD mature student dispensation scheme.

TCD participants came mainly from social classes 2 (37 per cent), 3 (24 per cent), and 5 (22 per cent). Eight per cent came from social class 1, and only 1 per cent social class 6 . The majority of entrants to TCD were drawn from the middle classes and non-manual working classes. There are very few participants drawn from the lower social classes. The data on the current social class of the graduates imply that there has been movement up the social class 'ladder', with 32 per cent of participants moved from social class 3 into social class 2; and 17 per cent moved from social classes 6 to 2 . However, it is also worth stating that 10 per cent of people were classified as 'other', covering being full-time students, retired or working in the home.

In terms of demographics, 10 of the participants interviewed were female and the 
remaining 5 male. Their ages ranged from 35 to 62 , with most falling between late 30 s to late 40 s. Eleven reported they received financial support from BTEA and grants, one on a scholarship, one on a grant only and one person had no 'outside' financial support. In addition, ten people had completed postgraduate degree programmes (a mix of masters, doctoral and diplomas). In terms of occupations, seven were teachers, two worked as researchers, one was a social worker and two worked in management and administration.

\subsection{The price of the ticket: Financing a degree}

If 'getting in' (i.e. matriculating) was seen as a major achievement for all of the interviewees, maintaining themselves financially was equally important. About 60 per cent indicated that they had to work an average of 15 hours per week while studying. Fifty-three people received social welfare support and of these 34 also had a grant; 76 people received no state support and 9 had scholarships. Fortysix per cent had accumulated debts as a student. Thirty-one people had debts in the €0-10K band, 21 in the $€ 11-20 \mathrm{~K}$ band and 9 people in the various categories between $€ 21$ and $80 \mathrm{~K}$. This stark numerical picture however takes on a different hue when placed in the context of the interview data. The support from the state in the form of the BTEA and/or other grants was very important. For one person the combination of redundancy money and her position in the family-cycle were key factors in not only going to college but maintaining a presence there. Another remarked that:

It wasn't for me [a problem financially] ... my husband ... is not earning huge amounts of money, but when I left [work] I got a redundancy payment. Even though I didn't touch it when I was doing my degree it was always there as a cushion. I applied for the back to education allowance and I got it. So I got a cheque coming in the post every week for me and that paid my expenses and I didn't have to pay fees either. But it was expensive as I had to buy a lot of equipment.

Another person remarked that the combination of grants and allowances they 
had as a student, along with their part-time work, actually led to an increase in income for them, and having previously been accustomed to living on a small income did not find this aspect of student life problematic. This sense of 'getting on' and 'getting by' was common. If anything, being prepared financially, either in the form of saving money or accepting a lower standard of living was seen as a necessary component of going to college:

There was a panic at the beginning [of the programme] ... can you work on this budget? But as you retract your spending over the first few months I became aware that I had far less money but doing something I was pleased with.

Families willingly gave support and occasionally this had been a tradition in the family.

Free fees were critical, as were allowances, but finding out about them was not easy as you had to do a lot of digging around to find them. There was also for some a strong sense of 'deferred gratification' where they were willing to accept financial hardship in the short term, as the 'pay off' in the long term would be worth the risk of going to college. And the 'pay off' was not simply financial.

\subsection{The graduates' assessment of institutional supports at TCD}

The interviewees were highly positive about their experience of being in TCD and over 80 per cent found it a welcoming place. The vast majority (over 90 per cent) found going to TCD a positive experience. As a group, they tended to be exceedingly complimentary towards lecturers and 80 per cent were well supported by the teaching staff.

TCD is predominantly a university of traditional (non-mature and nondisadvantaged) students. The responses to questions about age were typically nuanced and did not presume a 'them' and 'us' position about age: 
That course I did do, there were a lot of other mature students on it and we became friends very quickly because it was obvious we were the mature students ... It was noticeable but it was more of a natural thing that you gravitated towards someone your own age or in your own position ... If you were going to do that course from school you were obviously quite bright, but when you're coming from a mature student point of view you're, especially in the first year, doubting your ability to get through, 'What am I doing here?' 'Look at all these bright sparks!' I found our little gang helped each other through ... thinking 'we'll get there, we'll get through. Especially in the first year, it wasn't so bad after the first year ... but as it was a four-year course I would have made friends with the younger people who went straight from school. It wasn't that you didn't talk to them ... but as the classes got smaller it was easier to talk to people.

There is some awareness of age difference:

In a lecture hall of a hundred people there might be three or four roughly my age bracket and we would tend to sit together even though we weren't pally. The rest just did not talk to us. I was mature enough to realise that they just didn't know what to talk to us about. It was towards the end of the second year that I developed acquaintances ... but I had a good social network outside of college so I treated it [college] a bit like work.

The first class I walked into they [students] all looked around and looked at me as though I was the teacher.

The size of the first year classes inhibited interaction, which in turn seemed to be reinforced by this sense of self-imposed demarcation. But this 'barrier' was overcome as the programmes progressed and the class sizes diminished. Gender never emerged as an issue for any of the interviews. The issue of being 
or not being prepared for college life was seen as a mixed point of anxiety for most of the interviewees. The access programme (TAP) was a good foundation from the perspective of

Knowing the college, the library ... study skills, academic essay writing ... having been out of education for a lot of years it was invaluable.

Another commented when asked if they were prepared for being a student:

No not at all. I hadn't clue. Writing skills were terrible. First essay was a tough one; there were more commas than words. I felt insecure when it came to getting into the work.

Also observed by some of the interviewees, and not in a negative way, was a different kind of ethos towards college work:

I would have been panicking to get everything done well ahead of time and they [the younger students] didn't have that sense of urgency. A lot of them were away from home for the first time, and there were boys and there were girls. It was nights out, which I think is very important.

The first year was also seen as being the hardest as they were attempting to navigate the rigours and different expectations of not only being a student, but of presenting work to lecturers. These early writings were viewed with trepidation as they became an objectification of their sense of adequacy (or not) as a student:

You're just all over the place and you're constantly doubting: 'Why am I here?'

However, the rest of their time was noticeably less fraught as they settled down to the rhythms of college life. Interestingly, issues about quality, quantity or type of feedback of their academic work (sometimes problematic for mature students) were not mentioned. 
There were no comments about the physical facilities or resources (such as the library or ICT) and 72 per cent found the type of resources and their accessibility were adequate for their needs.

\subsection{The importance of family support}

The support provided by family was viewed as a fundamental dimension of not only going to college but staying there. No one when asked (in the interviews) about how their families responded to their decision to go to college gave a negative response. Although undertaking the degree was the decision of an individual, 89 per cent experienced their family members as supportive while at college. The support ranged from finance and childcare to more affective support. One mature student argued that having a structure made life less erratic:

Ok, I had the money problems but I just went home from here [TCD] and if my husband was home first, the dinner was ready and the kids were old enough to be doing their own homework before I got home.

The age of one's children seemed to affect the decision as to when to go to college. There is a complex intersection between age, social class and culture in the way family and friends view and support the person at college, as well as the appropriate time to go to college.

For some from 'middle class' backgrounds, going to third level was part of the cultural doxa. They were aware that they were slightly out of kilter in terms by going to university later than their peers or friends, but they experienced positive support:

[My] family were great. They were very supportive. As it happens I have friends outside college who would have gone back as mature students either before or after me. I had friends who had gone to college after school but were doing masters when I was in first year ... it happened 
that we were all changing careers at the same time. It wasn't as though I was sitting in studying and everyone was out on the town... people would admire you for it.

In asking about support from friends there was a mixed response:

At the start it was difficult, not so much family but friends. You lost touch with friends a lot, you were in a different world, moved in different circles I suppose... but that's settled down now and I'm back with the same friends that I had.

Or another:

They [family and friends] were fed up listening to me grumble about work for years so by the time I jumped ship [become a student] it was 'Finally he's stopped talking about it.' They worried a bit about What will you do for money? What will you do for work?

\subsection{Post-degree destinations in the labour market}

Attempting a cost-benefit analysis of what happens to graduates after they leave college and where they find or place themselves occupationally is problematic. The mix of motives and personal transformations that interviewees spoke of during their time at college draws away from what Foucault terms a simple act of calculus in stating that if I do ' $x$ ' kind of programme I would end up with ' $y$ ' kind of job/salary. It would not be correct say that these kinds of judgments do not form part of an individual's decision-making. If anything, what people decided to do post-degree is as much based on financial considerations, i.e. the need to reenter the labour market and find a rewarding job.

\subsection{Was it worth it? Student motivation and the perceived value of a degree}

Almost half (46 per cent) of the TCD questionnaire respondents indicated that they opted to go to college to 'improve their employment prospects' and 45 per cent for 'personal interest'. The instrumental (i.e. employment) versus the 
transformative motivations provide a useful, but crude level of demarcation. However, from the interview data a much richer and more complicated set of personal narratives is discernible, which pulls together these two broad motivations. The idea of going to TCD was a 'slow burner'. The thought of going to third level education pre-dated by a long time their actual participation. The three quotes below, from two individuals in their late 30 s, captures quite well the flavour of the stories told by the other interviewees:

I used to pass the college [TCD] when I was going to Grafton Street and I would see all these student types coming in and out and as I said I left school at 14 and thought that I could never belong in a place like that. I guess I envied the young people with the opportunities they had and I thought l'd give it a go. I didn't even know I would get it. I applied for [other courses] and when I did get it I was a bit 'iffy' as I'd picked that college for personal reasons and was it the best course?

The decision to go to university emerged after this person had completed a social science course, so even though there was an aspiration at an early age, the route to college only became realisable at a specific juncture in her own educational story:

I did the leaving cert when I was 16 and at that time I definitely wanted to go to college, but I don't think my father subscribed to the idea of educating girls. I was a victim of that and I had to go out and get a job ... Many, many years later I put myself forward for redundancy and that was my ticket basically to get to college.

This person had worked for nearly 20 years since leaving school and saw the move to full-time education as a way of transcending a routine and unrewarding job. This view that going to college as a way of enhancing or changing 'career' direction was also part of the narratives:

I felt in my job I had been doing it for so long I became aware that I 
hadn't learned anything new in years ... and the more frustrated I got in work the more it pushed me into education. The education route out had been bubbling away for a couple of years.

One person who was working in a highly technical environment, decided not to enhance their status and deepen their knowledge in this area, but opted to take an arts degree and wanted to open doors. Another of the interviewees saw taking a degree as being both a sideways move and an upward move. In order to gain access to new or different parts of the labour market, degree level qualifications were viewed as essential. So bound up with their sense of personal transformation about their involvement was also the motivation of career and occupational goals and aspirations. Motivations for going to college are a combination of personal transformative and occupational goals and aspirations. Most participants do not live in a world of 'independent means' but have to return to living outside academia and earn a living. 


\section{Comparative analysis}

This section offers a comparative view of the data via the prism of three institutions. For the sake of continuity it is structured using the same themes as above. It should be noted that care should be taken in reading some of the numerical data due to the differences in sample size, particularly that of DIT, given that we have stuck to descriptive statistics only and reported mainly the absolutes rather than percentages to avoid misleading comparisons. Table 8.12 at the end of this section provides a summary of the findings for the three institutions in a matrix form.

\subsection{The price of the ticket: Financing a degree}

We would argue that social capital (as well as the more obvious financial variety), in terms of the family network played a central role in supporting the degree. State support was accessed to a greater extent by NUIM and TCD groups compared to DIT students who in contrast gained support from employers and sponsorship. A high percentage of all groups worked part-time during their studies. DIT had a high percentage of full-time workers as well as some selfemployed. The NUIM group explicitly reported that they graduated in debt. Fiftyfive per cent of the sample reported that they worked whilst being a student. Table 8.1 below shows the number of hours worked while HE students, as reported by 180 participants.

Table 8.1 Reported Hours Worked as Student (n)

\begin{tabular}{lcccccc}
\hline & \multicolumn{7}{c}{ Hours worked } \\
& $<10$ & $11-20$ & $21-30$ & $31-40$ & $>41$ & \\
Maynooth & 22 & 39 & 9 & 7 & 1 & 78 \\
DIT & 2 & 4 & 2 & 15 & 11 & 34 \\
TCD & 21 & 34 & 9 & 3 & 1 & 68 \\
Total & 45 & 77 & 20 & 25 & 13 & 180 \\
\hline
\end{tabular}

Participants received different combinations of financial support. Table 8.2 is a cross tabulation showing the relationship between those participants who 
received social welfare support, a grant and no support at all.

Table 8.2 Financial Support by Institutions (n)

\begin{tabular}{|c|c|c|c|}
\hline & \multicolumn{2}{|c|}{ Grant } \\
\hline & & Yes & No \\
\hline \multirow{3}{*}{$\begin{array}{l}\text { Welfare } \\
\text { Yes }\end{array}$} & Maynooth & 66 & 26 \\
\hline & DIT & 3 & 0 \\
\hline & TCD & 34 & 19 \\
\hline \multirow{3}{*}{$\begin{array}{l}\text { Welfare } \\
\text { No }\end{array}$} & Maynooth & 46 & 67 \\
\hline & DIT & 3 & 25 \\
\hline & TCD & 35 & 41 \\
\hline
\end{tabular}

Table 8.3 shows the level of debt accumulated whilst studying in each HEl.

Table 8.3 Reported Level of Student Debt by Institutions (per cent)

\begin{tabular}{|l|c|c|c|c|c|}
\hline & €0-10K & €11-20K & €21-30K & $\mathbf{>} \mathbf{4 0 K}$ & $\begin{array}{c}\text { Total } \\
(\mathrm{n})\end{array}$ \\
\hline Maynooth & 42 & 6 & 1 & 2 & $(76)$ \\
\hline DIT & 5 & 2 & 1 & 1 & $(12)$ \\
\hline TCD & 21 & 14 & 3 & 3 & $(61)$ \\
\hline $\begin{array}{l}\text { Total per } \\
\text { cent }\end{array}$ & 68 & 22 & 5 & 6 & $(149)$ \\
\hline
\end{tabular}

It is worth reiterating that 39 per cent of the sample accumulated debts whilst they were studying and proportionally more people did so in Maynooth. Even with state support and part-time work, students could not avoid going into debt. Interestingly, 83 per cent of those who acquired debt agreed or strongly agreed that the debt was worthwhile. It seems that debt was seen, retrospectively at least, as an acceptable risk associated with the goal of successful study. How students who have failed their programmes view this is of course a question for further investigation.

\subsection{The graduates' assessment of institutional supports}

A high percentage reported a positive experience of the support services available to them. Lecturing staff were singled out for particular positive 
commentary. Participants noted the importance of informal group support; this was strongest in NUIM. Both the TCD and DIT group highlighted a 'sense of difference' from the main student body; some within the DIT reported the extreme case of difference in terms of a feeling of isolation and exclusion.

\subsection{The importance of family support}

While family support was central in terms of social capital, participants within each group clearly identified factors directly related to 'cultural capital', parents' attitudes to education, value systems, access to educational material in the home and class identity. Family supports included childminding, emotional support, encouragement and the expression of a sense of pride in the participant's achievement. This was also manifested in the sense of increased social status and standing in the extended family.

\subsection{Student motivation and the perceived value of a degree}

Motivation factors were both intrinsic and extrinsic; the majority of participants expressed a long-standing inner desire to return to education, a sense of unfinished business. In a smaller number of cases in NUIM and TCD, but to a larger extent in DIT, group motivation was driven by external instrumental factors to do with the world of work. All groups held the degree in high standing and perceived social status was increased. In terms of human capital the degree was perceived as a key credential that could enable greater employment opportunities. The three tables below offer a numerical reflection of how the participants saw the value of their time at college and seem to support the notion that their participation was based on a mix of both education and economic instrumentalism. 
Table 8.4 Responses to the statement: Studying for a degree has changed me personally (n)

\begin{tabular}{lcccccc}
\hline & \multicolumn{2}{c}{ Strongly } & & & \multicolumn{3}{c}{ Strongly } \\
& Disagree & Disagree & NAD & Agree & Agree & Total \\
Maynooth & 4 & 8 & 28 & 72 & 102 & 214 \\
DIT & 5 & 1 & 7 & 14 & 12 & 39 \\
TCD & 4 & 7 & 18 & 54 & 57 & 140 \\
Total & 13 & 16 & 53 & 140 & 171 & 393 \\
\hline
\end{tabular}

Table 8.5 Responses to the statement: Having a degree makes me feel confident about my career prospects (n)

\begin{tabular}{lcccccc}
\hline & \multicolumn{2}{c}{ Strongly } & & & \multicolumn{3}{c}{ Strongly } \\
& Disagree Disagree & NAD & Agree & Agree & Total \\
Maynooth & 3 & 16 & 33 & 85 & 67 & 204 \\
DIT & 0 & 4 & 5 & 13 & 16 & 38 \\
TCD & 2 & 6 & 28 & 56 & 45 & 137 \\
Total & 5 & 26 & 66 & 154 & 128 & 379 \\
\hline
\end{tabular}

Table 8.6 Responses to the statement: It was necessary for me to have a degree for the job I wanted (n)

\begin{tabular}{lcccccc}
\hline & \multicolumn{2}{c}{ Strongly } & & \multicolumn{3}{c}{ Strongly } \\
& Disagree & Disagree & NAD & Agree & Agree & Total \\
Maynooth & 5 & 18 & 42 & 64 & 67 & 196 \\
DIT & 6 & 3 & 6 & 14 & 9 & 38 \\
TCD & 4 & 10 & 14 & 49 & 59 & 136 \\
Total & 15 & 31 & 62 & 127 & 135 & 370 \\
\hline
\end{tabular}

\subsection{Post-degree destinations in the labour market}

There was considerable variance between colleges. The NUIM graduates located their careers in the social economy (teaching, community work, development work) in contrast to the DIT group who focused on the so-called 
'real economy' such as the professions, technology, manufacturing, services.

Table 8.7 Participants' Reported Gross Annual Income [2008] (n)

\begin{tabular}{|c|c|c|c|c|c|c|c|c|}
\hline & $€ 0-10$ & $€ 11-20$ & $€ 21-30$ & $€ 31-40$ & $€ 41-50$ & $€ 51-60$ & $>€ 60$ & Total \\
\hline NUIM & 26 & 29 & 41 & 36 & 18 & 3 & 5 & 158 \\
\hline DIT & 1 & 2 & 1 & 2 & 14 & 2 & 12 & 34 \\
\hline TCD & 8 & 11 & 13 & 37 & 28 & 13 & 11 & 121 \\
\hline Total & 35 & 42 & 55 & 75 & 60 & 18 & 28 & 313 \\
\hline
\end{tabular}

A high percentage of both the TCD and NUIM groups delayed entry into the labour market by continuing their studies. The following three tables offer some comparative data about the participants' earnings (actual and expected) and the following two tables some data on those who opted to undertake postgraduate study.

Table 8.8 Reported increase in earning post-degree (n)

\begin{tabular}{lccc}
\cline { 2 - 3 } & \multicolumn{2}{c}{ Increase in Earnings } & \\
NUIM & Yes & No & Total \\
DIT & 97 & 65 & 162 \\
TCD & 27 & 12 & 39 \\
Total & 82 & 43 & 125 \\
\hline
\end{tabular}

Table 8.9 Response to the question: Did you expect your earning to increase [post-degree] (n)

\begin{tabular}{lccc}
\hline \multicolumn{4}{c}{ Expect increased } \\
& Earnings & \\
& Yes & No & Total \\
NUIM & 121 & 41 & 162 \\
DIT & 28 & 11 & 39 \\
TCD & 91 & 31 & 122 \\
Total & 240 & 83 & 323 \\
\hline
\end{tabular}


Table 8.10 Completion of Postgraduate (PG) Qualifications (n)

\begin{tabular}{lccc}
\hline \multicolumn{4}{c}{ Completed PG Study } \\
Mes & No & \\
Maynooth & 90 & 102 & 192 \\
DIT & 21 & 11 & 32 \\
TCD & 31 & 80 & 111 \\
Total & 142 & 193 & 335 \\
\hline
\end{tabular}

In addition, 73 people from Maynooth, 5 from DIT and 40 from TCD replied that at the time of completing the questionnaire, they were in the process of undertaking a postgraduate qualification. Table 8.15 below shows the participants' motives for undertaking postgraduate study.

Table 8.11 Reasons for Undertaking Postgraduate Qualifications (n)

\begin{tabular}{lcccc}
\hline & Employment & Interest & Other & Total \\
Maynooth & 100 & 39 & 3 & 142 \\
DIT & 15 & 6 & 1 & 22 \\
TCD & 39 & 21 & 5 & 65 \\
Total & 154 & 66 & 9 & 229 \\
\hline
\end{tabular}


Table 8.12 Comparative Matrix of Interview Data

\begin{tabular}{|c|c|c|c|c|c|c|}
\hline \multicolumn{7}{|c|}{ Comparative matrix developed from the interview data gathered from the three HEI } \\
\hline Topic & \multicolumn{2}{|c|}{$\begin{array}{c}\text { Summary of interview data } \\
\text { NUIM }\end{array}$} & \multicolumn{2}{|c|}{ Summary of interview data TCD } & \multicolumn{2}{|c|}{ Summary of interview data DIT } \\
\hline $\begin{array}{l}\text { Financing the } \\
\text { degree }\end{array}$ & & $\begin{array}{l}1 \text { in every } 3 \\
\text { participants reported } \\
\text { that they had to work } \\
\text { during their studies. } \\
\text { A large percentage of } \\
\text { participants reported } \\
\text { they received financial } \\
\text { support from BTEA, } \\
\text { other state services or } \\
\text { sponsorship. } \\
\text { Additional finances } \\
\text { were obtained from, } \\
\text { personal savings, } \\
\text { redundancy payments } \\
\text { or family members. } \\
\text { A substantial amount } \\
\text { of participants } \\
\text { reported that they } \\
\text { were in debt because } \\
\text { of their studies (10- } \\
40 K \text { ) }\end{array}$ & $\begin{array}{l}\bullet 5 \\
\bullet 6 \\
\bullet 7 \\
\bullet 8\end{array}$ & $\begin{array}{l}\text { A significant amount of } \\
\text { participants reported } \\
\text { that they had to work to } \\
\text { finance their studies. } \\
\text { Some participants } \\
\text { reported that they } \\
\text { received different types } \\
\text { of state funding or } \\
\text { sponsorship. } \\
\text { Participants noted that } \\
\text { family support was } \\
\text { crucial, although they } \\
\text { considered that by } \\
\text { accessing this support a } \\
\text { new dependency was } \\
\text { formed. } \\
\text { Participants noted the } \\
\text { importance of Free } \\
\text { Fees; this greatly } \\
\text { assisted their financial } \\
\text { management. }\end{array}$ & $\begin{array}{l}\bullet 9 \\
\bullet 10 \\
\bullet 11 \\
\bullet 12\end{array}$ & $\begin{array}{l}\text { Majority of participants } \\
\text { were either working full- } \\
\text { time or part-time during } \\
\text { their studies. } \\
\text { A large percentage of } \\
\text { participants were self- } \\
\text { funding their studies; } \\
\text { other received assistance } \\
\text { from their employers; only } \\
\text { two participants reported } \\
\text { that they received the } \\
\text { BTEA. } \\
\text { Participants noted the } \\
\text { financial support they } \\
\text { received from their } \\
\text { partners and extended } \\
\text { families. } \\
\text { The indirect costs } \\
\text { associated with studying } \\
\text { were reported as } \\
\text { substantial and difficult to } \\
\text { finance (child care, } \\
\text { materials). }\end{array}$ \\
\hline $\begin{array}{l}\text { Graduates' } \\
\text { assessment } \\
\text { of } \\
\text { institutional } \\
\text { supports for } \\
\text { non- } \\
\text { traditional } \\
\text { students }\end{array}$ & $\begin{array}{l}\cdot \bullet 13 \\
\bullet 14 \\
\bullet 15 \\
\bullet 16\end{array}$ & $\begin{array}{l}\text { The majority of } \\
\text { participants reported } \\
\text { very positive } \\
\text { experiences of the } \\
\text { support services } \\
\text { available in NUIM for } \\
\text { mature students. } \\
\text { NUIM was perceived } \\
\text { by the participants to } \\
\text { be a mature student } \\
\text { friendly campus. } \\
\text { Participants reported } \\
\text { that they enjoyed their } \\
\text { lecturers and held the } \\
\text { lecturing staff in high } \\
\text { regard. } \\
\text { Three participants } \\
\text { who reported that they } \\
\text { had a disability were } \\
\text { more critical of the } \\
\text { services available to } \\
\text { cater for their } \\
\text { particular disability. }\end{array}$ & $\begin{array}{l}\bullet 17 \\
\bullet 18 \\
\bullet 19 \\
\bullet 20 \\
\bullet 21\end{array}$ & $\begin{array}{l}\text { The participants were } \\
\text { very positive about their } \\
\text { experience of life in } \\
\text { TCD. } \\
\text { Participants did not } \\
\text { report any negative } \\
\text { comments in relation to } \\
\text { support services. } \\
\text { Participants } \\
\text { complimented the } \\
\text { lecturing staff for their } \\
\text { support. } \\
\text { Age was noted as a } \\
\text { factor in terms of the } \\
\text { prospect of being } \\
\text { different from the } \\
\text { traditional students' } \\
\text { body. } \\
\text { Participants noted that } \\
\text { the } 1^{\text {st }} \text { year was the } \\
\text { hardest; once this was } \\
\text { successfully completed } \\
\text { the rest of the time } \\
\text { studying was relatively } \\
\text { manageable and } \\
\text { enjoyable. }\end{array}$ & $\begin{array}{l}\cdot 25 \\
\bullet 26\end{array}$ & $\begin{array}{l}\text { The participants reported } \\
\text { a very mixed assessment } \\
\text { of the support services } \\
\text { available for mature } \\
\text { students. Some } \\
\text { participants were not } \\
\text { aware of any support } \\
\text { services while others } \\
\text { reported satisfaction with } \\
\text { the services they } \\
\text { accessed. } \\
\text { Lecturing staff were } \\
\text { reported to be extremely } \\
\text { supportive and helpful. } \\
\text { Two participants who } \\
\text { reported they had dyslexia } \\
\text { stated that the support } \\
\text { services they accessed } \\
\text { were excellent. } \\
\text { Some participants noted } \\
\text { that they felt isolated from } \\
\text { the main body of students. } \\
\text { Participants noted they } \\
\text { received most support } \\
\text { from other mature } \\
\text { students }\end{array}$ \\
\hline $\begin{array}{c}\text { The } \\
\text { importance of } \\
\text { family } \\
\text { support }\end{array}$ & $\begin{array}{l}\cdot 27 \\
\bullet 28\end{array}$ & $\begin{array}{l}\text { Participants report that } \\
\text { their parents' attitudes } \\
\text { and educational } \\
\text { values were major } \\
\text { motivators for them to } \\
\text { return and succeed in } \\
\text { their own education. } \\
\text { The extended family } \\
\text { offers a variety of } \\
\text { support in terms of } \\
\text { finance, } \\
\text { encouragement and }\end{array}$ & $\begin{array}{l}\cdot 30 \\
\bullet 31\end{array}$ & $\begin{array}{l}\text { All participants make } \\
\text { positive comments } \\
\text { relating to the support } \\
\text { they received from their } \\
\text { families. } \\
\text { In one case there was } \\
\text { some envy expressed } \\
\text { by siblings about the } \\
\text { participants going to } \\
\text { college. } \\
\text { Other participants } \\
\text { reported that they had to }\end{array}$ & $\bullet 35$ & $\begin{array}{l}\text { All participants made } \\
\text { some kind of reference to } \\
\text { the positive support they } \\
\text { received from their } \\
\text { extended families, in } \\
\text { terms of emotional, } \\
\text { financial and time to } \\
\text { study. } \\
\text { Several parents reported } \\
\text { that child rearing duties } \\
\text { did have an effect on their } \\
\text { studies. }\end{array}$ \\
\hline
\end{tabular}




\begin{tabular}{|c|c|c|c|c|c|c|}
\hline & $\bullet 29$ & $\begin{array}{l}\text { childminding. } \\
\text { Participants noted that } \\
\text { critical events in the } \\
\text { extended family } \\
\text { (death, sickness) were } \\
\text { major barriers that } \\
\text { hampered their ability } \\
\text { to complete } \\
\text { components of their } \\
\text { programmes. }\end{array}$ & $\bullet 33$ & $\begin{array}{l}\text { negotiate with their } \\
\text { partner on how going to } \\
\text { college could be } \\
\text { facilitated. } \\
\text { Participants with } \\
\text { children reported that } \\
\text { they had to develop } \\
\text { numerous strategies to } \\
\text { cope with child rearing } \\
\text { and study }\end{array}$ & $\cdot 36$ & $\begin{array}{l}\text { Some participants } \\
\text { reported that their partner } \\
\text { was the main source of } \\
\text { support; in some cases } \\
\text { partners took turns } \\
\text { studying while the other } \\
\text { partner worked. }\end{array}$ \\
\hline $\begin{array}{l}\text { Student } \\
\text { motivation } \\
\text { and } \\
\text { perceived } \\
\text { value of } \\
\text { degree }\end{array}$ & $\begin{array}{l}\bullet 37 \\
\bullet 38 \\
\bullet 39 \\
\bullet 40 \\
\\
\bullet\end{array}$ & $\begin{array}{l}\text { Participants reported } \\
\text { that they always had a } \\
\text { desire to enter Higher } \\
\text { Education; by } \\
\text { participating in } \\
\text { preparation courses } \\
\text { they worked up the } \\
\text { knowledge and } \\
\text { capacity to gain } \\
\text { access to Higher } \\
\text { Education. } \\
\text { Participants reported } \\
\text { they were motivated } \\
\text { by personal reasons, } \\
\text { mainly to develop their } \\
\text { own intellectual } \\
\text { understanding. } \\
\text { Some participants } \\
\text { stated that it was time } \\
\text { for them to make a } \\
\text { change and move out } \\
\text { of their current life } \\
\text { position. } \\
\text { Participants reported } \\
\text { that achieving a } \\
\text { degree increased their } \\
\text { sense of self and self } \\
\text { esteem. }\end{array}$ & $\begin{array}{l}\bullet 41 \\
\bullet 42 \\
\bullet 43 \\
\bullet 44\end{array}$ & $\begin{array}{l}\text { Participants reported } \\
\text { mixed motivation } \\
\text { factors; some identified } \\
\text { career path } \\
\text { opportunities, or career } \\
\text { change, while others } \\
\text { were more motivated by } \\
\text { personal development } \\
\text { factors. } \\
\text { Participants held a high } \\
\text { regard for the status and } \\
\text { reputation of TCD. } \\
\text { Participants considered } \\
\text { gaining a degree from } \\
\text { TCD as a valuable } \\
\text { record of achievement } \\
\text { that held a high social } \\
\text { and economic value (in } \\
\text { terms of job } \\
\text { opportunities). } \\
\text { The process of gaining a } \\
\text { degree was considered } \\
\text { transformational. }\end{array}$ & $\begin{array}{l}\bullet 45 \\
.46 \\
\bullet 47 \\
\bullet 48 \\
\bullet 49\end{array}$ & $\begin{array}{l}\text { The majority of } \\
\text { participants reported that } \\
\text { they were motivated to } \\
\text { return to education in } \\
\text { order to either get } \\
\text { promotion in their job or } \\
\text { change career paths } \\
\text { altogether. } \\
\text { Some participants noted } \\
\text { that they were unhappy in } \\
\text { their present employment. } \\
\text { Other participants always } \\
\text { had a desire to go to } \\
\text { Higher Education but did } \\
\text { not have the } \\
\text { opportunities. } \\
\text { Participants consider that } \\
\text { a degree would improve } \\
\text { their career options. } \\
\text { Participants also talked } \\
\text { about the increased sense } \\
\text { of status in terms of both } \\
\text { social and personal that } \\
\text { they consider holding a } \\
\text { degree gave them. }\end{array}$ \\
\hline $\begin{array}{c}\text { Post-degree } \\
\text { destinations } \\
\text { in the labour } \\
\text { market }\end{array}$ & $\begin{array}{l}\cdot 50 \\
\bullet 51 \\
\bullet 52 \\
\bullet 53\end{array}$ & $\begin{array}{l}\text { Participants reported } \\
\text { they wanted } \\
\text { qualitative change in } \\
\text { their working life; they } \\
\text { wanted to make a } \\
\text { social contribution. } \\
\text { The majority of } \\
\text { participants reported } \\
\text { that they moved to } \\
\text { jobs such as teaching, } \\
\text { community } \\
\text { development, and } \\
\text { adult education. } \\
\text { Other participants } \\
\text { continued their } \\
\text { education journey to } \\
\text { Masters or PhD level. } \\
\text { Participants } \\
\text { expressed a great } \\
\text { value for the worth of } \\
\text { education; they had a } \\
\text { real pride in their } \\
\text { achievement and had } \\
\text { a desire to share their } \\
\text { knowledge with } \\
\text { others. }\end{array}$ & $\begin{array}{l}\cdot \cdot 54 \\
\cdot 55 \\
\bullet 56\end{array}$ & $\begin{array}{l}\text { While participants had } \\
\text { mixed motives for } \\
\text { returning to Higher } \\
\text { Education they } \\
\text { expressed a realistic } \\
\text { attitude towards post- } \\
\text { degree employment. } \\
\text { Participants valued their } \\
\text { degree and wanted to } \\
\text { utilise it to gain access } \\
\text { to the labour market. } \\
\text { Some participants } \\
\text { reported that they were } \\
\text { continuing the studies at } \\
\text { either Masters of PhD } \\
\text { level. }\end{array}$ & $\begin{array}{l}\cdot 57 \\
\qquad 58 \\
\bullet 559\end{array}$ & $\begin{array}{l}\text { Most participants reported } \\
\text { that they successfully } \\
\text { managed to either gain } \\
\text { promotion in their present } \\
\text { employment or change } \\
\text { career track into a more } \\
\text { senior position. } \\
\text { A few participants who } \\
\text { were self employed } \\
\text { reported that the degree } \\
\text { qualification increased the } \\
\text { marketing potential of the } \\
\text { service they provided. } \\
\text { All participants noted that } \\
\text { the degree programme } \\
\text { they undertook provided } \\
\text { them with the necessary } \\
\text { theoretical and practical } \\
\text { skill to engage actively in } \\
\text { the labour market. }\end{array}$ \\
\hline
\end{tabular}

Table 1: Comparative matrix based on data extracted from the interview samples from the three HEls. 


\section{Summary - Conclusion}

Mature students of all ages, and in particular women, are entering Higher Education in unprecedented numbers. A decade of economic boom, the changing nature of work in Irish society, the increased level of skills demanded in the economy, the feminisation of the workforce and the changing nature of Higher Education have all played a part in this. The research shows that for working class mature students, students with disabilities and ethnic minorities Higher Education is a highly valued transitional space which affords a greater level of career choice and also the opportunity to renegotiate aspects of their personal identities. In particular, large numbers are choosing to work in the educational sector or continue with their studies. The extent to which these opportunities were a function of general economic growth is unclear but this should be borne in mind. The research covered people who graduated in the seven years up to 2007 and it is highly likely that the current (2009) recession will impact on these graduates.

The labour market transitions effected by the graduates were all away from routine work often with low levels of autonomy, status and pay. The general profile of mature students at NUIM and these labour market transitions all appear to go against a more general trend in Irish Higher Education. In the most recent HEA report on Equity and Access in Higher Education (2008) it was noted that the only lower socio-economic group that has seen a drop in participation rates is the 'non-manual' group who work in retail, services, and administrative and clerical work. This group now accounts for one-fifth of Irish households. The fact that graduates used their degree to move away from such work and often chose careers that they perceive to be more meaningful and with greater security offers us an invaluable insight from the grassroots perspective of graduates and how they navigate a personal and career path through the knowledge economy. The graduates repositioned themselves in jobs in which they could envisage a future and that entailed greater levels of commitment and autonomy. Most notably graduates have chosen to work in the educational sector, very often in their own 
communities or to continue with their studies.

In general the monetary rewards for graduates are relatively modest and the 'learning society,' of which they are part, is based on a broad conception of the social and personal benefits of Higher Education. Their degree is understood first and foremost as a personal achievement that is seen as an important step in shaping a new type of life. Obtaining a degree undoubtedly strengthens their sense of being competent learners who can (and many do) return to formal learning in the future. For many graduates the journey through Higher Education marks the end of educational exclusion, a new phase of social inclusion and a commitment to a version of lifelong learning that is more rounded and complex than the instrumentalist version of public policy discourses.

Successfully completing a degree depends on a broad set of linked informal and formal contiguous spaces such as family, friends, workmates, adult learning centres, advice centres, access programmes and mature student programmes, all working together. It also depends on clear information and guaranteed state financial support. Family support is absolutely vital and measures that support a family member to engage in lifelong learning undoubtedly create the basis for durable learning webs amongst families and communities. Without most if not all these elements it is unlikely that working class mature students will continue to succeed in university. Through the research we were able to map a delicate ecosystem of horizontal and vertical supports that are vital to ensuring access for non-traditional students. By vertical we mean the state and institutional supports and by horizontal we mean the familial and peer support that is emphasised in the interviews with students. If we wish to maintain or improve the levels of participation of mature disadvantaged students, which by international standards is still quite low, both kinds of measures are required.

This is also true for those students who were doubly disadvantaged both in terms of socio-economic opportunities and disability or because they are immigrants. 
The timing of the entry of women into Higher Education was usually dependent on child rearing duties and done in anticipation of a family in the future after the degree or after the burden of responsibility had been lightened as the children grew older. The interviewees who studied with young children at home emphasised the importance of affordable childcare (not readily available in many cases).

Overall there is little evidence from any of the data that the most marginalised, impoverished and educationally challenged in Irish society are amongst the general body of mature students. While most of the interviewees had left school early, all of them had done the Junior Certificate or its equivalent. Similarly, while some of the participants had faced very serious material poverty in the past, or continued to live in disadvantaged areas, the majority had managed to establish a reasonable level of material security and most had worked, at least occasionally, or had a partner in work in the years before their degree. The journey through university was viewed as yet another step in moving away from the likelihood of poverty.

Most of the students, including those relying on social welfare payments, were not those deemed most at risk of poverty. However, poverty is a multidimensional issue in which cultural expectations, social participation and educational credentials all play a part. The research strongly supported Baumann's (1998, pp 37-38) contention that:

The phenomenon of poverty does not boil down, however, to material deprivation and bodily distress. Poverty is also a social and psychological condition: Poverty means being excluded from whatever passes for a 'normal life'. It means being 'not up to the mark'.

The graduates perceived that access to Higher Education in modern Ireland as part of normal life and was necessary both in personal terms and in terms of providing tools for citizenship and meaningful social participation. For several of 
the participants Higher Education was clearly understood and valued as a marker, a form of 'cultural capital' that would ensure that they were not left at the very margins of society. Thus Higher Education may allow more choices but on its own it does not explain the trajectory of the participants away from poverty.

While the involvement of mature students is relatively new in Ireland and the involvement of mature disadvantaged is even more recent, it is important to not only identify the progress already made, but to understand that the starting point for mature student involvement was from such a low base that any involvement becomes significant. In contrast to other countries with a history of mature and disadvantage mature student involvement in Higher Education we are really only beginning to deliver to adults the possibility of a university education. Levels of involvement are still low and not at all adequate to the task of addressing poverty through educational interventions. Poverty continues to impact on educational achievement and though progress is being made on increasing the number of secondary school graduates who progress to college, early school leaving continues to leave a significant number unable to progress in their normal school years to Leaving Certificate.

When research repeatedly identifies the same and similar problems, e.g. finance, crèche, etc., it underlines the slow nature of progress toward the public policy imperative of lifelong learning that is an essential part of economic development. But it is equally important to identify new understandings of the mature student experience of Higher Education. The strength of the family support, the power of the family background when the family does work ought to point to the importance of supporting families as one of the effective ways of addressing poverty. For those who are successful in Higher Education the family is the key to their success as it lays down foundations for access in early years, supports the student in college and in the following generation benefits from increased parental experiences of higher learning. 


\section{Recommendations}

The research findings have policy implications for the Higher Education Authority, the Department of Education and Science, Combat Poverty Agency, the Department of Social and Family Affairs and Higher Education Institutions.

For implementation by the Higher Education Authority and the Department of Education and Science:

1. Support for mature disadvantaged students in education should be sustained and enhanced, even in difficult economic times. Investment in education is a vital part of the economic and social infrastructure. The graduates in this research were emphatic about both the economic and the non-economic benefits of attending HE. Access measures developed over the past decade have encouraged many people from underrepresented groups into HE for the first time. To sustain this progress the increasing access agenda should be strongly supported at all levels of education. This means maintaining free fees and the other modest financial supports, such as county council grants, that are currently in place for mature disadvantaged students. One of the clearest findings of the research is that without such supports, attending Higher Education would have been either very difficult or impossible for many disadvantaged mature students.

2. For most graduates, access courses, adult basic education, and formal and informal community education initiatives were a vital part of accessing Higher Education. The relatively modest state financial support for Adult Education should be maintained and the work of career guidance and other supports in adult education should be further integrated in widening access strategies and practices.

3. The HEA through colleges and universities should gather and make 
available more detailed disaggregated data on the progress and experience of mature disadvantaged students in HE, including their postdegree destinations. Such data would be invaluable for evaluating progress on the targets that are set and would be enormously helpful for other policymakers, access offices in HEls and 'non-traditional students' themselves in evaluating the efficacy of widening access policies.

4. There continue to be inflexibilities in the HE system that impact on mature students. The HEA in cooperation with the HEls should re-examine the question of developing more flexible entry and progression routes into and in Higher Education. The vast majority of mature student graduates had studied in traditional full-time degree courses. Clearly, developing a greater range of options for accreditation would benefit mature students who are balancing study with other duties and major commitments. This also requires that students enrolling on recognised third level courses on a part-time basis are eligible for county council grants and other supports.

5. Any re-introduction of student fees will have a disproportionate impact on non-traditional students. Instead, financial support should be enhanced. Targeted financial support for maintenance costs is essential.

6. Learners are informed by a broader set of values than the dominant market fundamentalism of current state thinking. The benefits of supporting the wider range of motivations are significant as adults find it difficult to separate out and disconnect their career learning needs from the broader needs they have as members of families, communities and society. Lifelong learning is for workers and for citizens.

We propose for the CPA:

7. Continue to promote anti-poverty measures based on the understanding that to work against poverty is to ensure that the broad conditions for 
decent life are available. In a society in which attending Higher Education is increasingly seen as the norm this obviously includes improving access to education at all levels for those who, for various reasons, have been previously excluded from education. The paths from poverty are long, incremental and take time, with few guarantees that the journey will be successful. Graduates rightly perceive Higher Education as an important marker on this journey which facilitates a degree of social mobility. However, improving access to education alone will clearly not be sufficient to help individuals escape from poverty.

8. Working to eliminate poverty is a multifaceted process and interventions that enhance the ability of families to encourage, support and value learning from an early age are particularly crucial. This should include strong support for affordable crèche and childminding services.

We recommend that the Department of Social and Family Affairs:

9. Maintain and develop the Back to Education Allowance initiative. This support was vital for many of the students we interviewed in their decision to attend Higher Education. With this in mind it is commendable that money for BTEA was ring-fenced in the recent budget. However, given the large number of graduates interviewed and surveyed who felt that a postgraduate qualification was becoming 'necessary' for work in a credentialised society and the relatively small numbers of students in receipt of BTEA we propose that the decision in 2003 to limit the BTEA to primary degrees and teaching diplomas should be reconsidered.

10. Government departments and other responsible agencies should strive to disseminate more widely information about the available financial and social supports for mature students. Knowledge of such supports was uneven amongst graduates. 
11. The Department of Education and Science, in tandem with other government bodies, should develop measures that encourage and incentivise employers to support employees in education. Support from this sector was noticeably absent amongst the students who attended TCD and NUIM. Employers should be encouraged to support third level learning.

For the administrators, teachers, access officers and management of the HEls we advocate the following:

12. As noted earlier the HEA in cooperation with the HEIs should re-examine the question of developing more flexible entry and progression routes into Higher Education. Rationalise the access and interview system for mature students and give increased emphasis to non-academic skills and background experience (as workers, etc.) in assessing suitability for study.

13. The work of access offices in HEls is fundamental to ensuring the participation of non-traditional students. Repeatedly students referred to help, advice and support as being important to them. Individual mature students may or may not require help but many do and it is fundamental that such support is available and that it is offered without stigma or condescension. This means that the work of Access Offices is seen as central to HEIs. In particular, the initial interview and first few months of study are critical to non-traditional students and Access Offices have a central role in both providing services and alerting staff to the needs of students at that time.

14. HEls concerned with improving access for migrants and HEls with a high level of 'non-national' students should consider offering targeted short courses and advice on writing and using academic English.

15. The HEls should offer age-appropriate career advice before and after 
degree for mature students, based on their specific needs and aspirations.

16. There is a need for more affordable comprehensive crèche and childcare facilities for parents attending college.

17. The persistence of poverty and disadvantage in specific geographic areas in Ireland means that local education schemes within these areas that are linked or feed into Higher Education Institutions are of real significance. Universities and colleges should continue to develop 'satellite' courses in such areas that are linked to local needs and issues but use the resources and knowledge of the university to offer high-quality accredited courses.

18. Schedule courses in HE at times that are consistent with the multiple responsibilities of adult life (child minding, time to travel, etc.).

19. Services that enhance the learning of students with disabilities have been expanded in recent years and are hugely successful. However, the EU criteria and assessment process involved in achieving recognition as a disabled person is used to allocate ordinary facilities such as car park space. HEIs in allocating such facilities (e.g. car park spaces) are rigid and the procedures too onerous for students who may not meet all the criteria for full disability status but who require facilities that may be for a 'comparatively slight' or temporary disability (post-operation, or ill health due to coronary condition, etc).

20. Child minding supports and travel grants are essential and when provided are crucial to widening the participation by non-traditional groups.

21. Encourage lecturing staff in colleges and universities to be better informed about the learning needs of students with disabilities. 
22. Colleges and universities should keep accurate and accessible data on non-traditional and mature students' access and progression. 


\section{References}

Archer, L., Hutchings, M. and Ross, A. (2003) Higher Education and Social Class: Issues of Social Inclusion, London: Routledge Falmer.

Bauman, Z. (1998) Work, Consumerism and the New Poor, Buckingham: Open University Press.

Bauman, Z. (2000) Liquid Modernity, Cambridge: Polity Press.

Beck, U., Giddens, A. and Lash S. (1994) Reflexive Modernization: Politics, Tradition and Aesthetics in the Modern Social Order. Stanford: Stanford University Press.

Becker, G. (1994) Human Capital: A Theoretical and Empirical Analysis with special reference to Education (3rd Ed), Chicago, IL: University of Chicago Press.

Bell, D. (1974) The coming of Post-Industrial Society: A venture in social forecasting, New York: Basic Books.

Borg, C. and Mayo, P. (2005) The EU Memorandum on lifelong learning: Old wine in new bottles? Globalisation, Societies and Education, 3(2): 203-225.

Bourdieu, P. and Passeron, J. (1977) Reproduction in Education, Society and Culture, London: Sage.

Bourdieu, P. (1986) Forms of capital, in Richardson, J.G. (ed.), Handbook of Theory and Research for the Sociology of Education, Westport, CT: Greenwood.

Bourgeois, E., Duke, C., Guyot, J-L. and Merrill, B. (1999) The Adult University, Buckingham: SRHE/OUP.

Byrne, D., McCoy, S. and Watson, D. (2008) School Leavers Survey Report 2007, Dublin: ESRI.

(CSO) Central Statistics Office (2006) Census of population 2006, Cork: CSO.

Charmaz, K. (2006) Constructing grounded theory: A practical guide through qualitative analysis. London: Sage.

(CEC) Commission of the European Community (2000) Commission staff Working Paper: A Memorandum on Lifelong Learning, Brussels: European Commission.

Clancy, P. (1982) Participation in Higher Education, Dublin: Higher Education Authority. 
Clancy, P. (1988) Who goes to College? Dublin: Higher Education Authority.

Clancy, P. (1995) Access to College: Patterns of continuity and change, Dublin: Higher Education Authority.

Clancy, P. and Wall, J. (2000) Social background of Higher Education entrants, Dublin: Higher Education Authority.

Coffield, F. (1999) Breaking the consensus: Lifelong learning as social control. British Educational Research Journal, 25(4), 479-499.

Coleman, J. (1988) Social capital in the creation of human capital. The American Journal of Sociology, 94: S95-S120.

Darmody, M., Smyth, E., O'Connell, P., Williams, J. and Ryan, B. (2005)

Eurostudent Survey II: Irish Report on the Social and Living Conditions of Higher Education Students 2003/2004, Dublin: HEA.

Dempsey, N. (2004) Address by Noel Dempsey, T.D., Minister for Education \& Science at the Meeting of Directors General for Higher Education and Heads of Rector's Conference in Dublin Castle. Retrieved February 2, 2007 from http://www.eu2004.ie/templates/document file.asp?id=8421

(DES) Department of Education and Science (1995) Report on Action Group for Access to Higher Education, Dublin, Government Publications.

(DES) Department of Education and Science (2000) Learning for Life: White Paper on Adult Education, Dublin: The Stationery Office.

(DES) Department of Education and Science (2001) Report on Action Group for Access to Higher Education, Dublin: The Stationery Office.

European Universities Association (2006) Review of the Effectiveness of the Quality Assurance Procedures in Irish Universities: University Reports, Dublin: National Qualifications Authority of Ireland.

Expert Group on Future Skills (EGSFN) (2007) Towards a National Skills Strategy, Dublin: Forfás.

Finnegan, F. (2008) Neo-liberalism, Irish Society and adult education. The Adult Learner, pp 54-76.

Fleming, T. (in press, 2010). Models of lifelong learning: An overview, in M. London (Ed.). Oxford Handbook of Lifelong Learning. New York: Oxford University Press. 
Fleming, T. and Finnegan, F. (2009a) Honneth and Recognition as Sensitizing Concept for Narrative Analysis: An Irish suggestion. RANLHE Discussion Paper No. 2. http://www.ranlhe.dsw.edu.pl/files/Honneth and Recognition.pdf

Fleming, T. and Finnegan, F. (2009b) RANLHE EU Research on Access and Retention of Non-Traditional Learners in Higher Education. http://www.ranlhe.dsw.edu.pl/

Fleming, T. and Murphy, M. (1998) College Knowledge: Power, Policy and the Mature Student experience at University, Maynooth: MACE.

Fleming,T., Collins,T. and Coolahan, J.(1999) Higher Education: The Challenge of Lifelong Learning, Maynooth: Centre for Educational Policy Studies.

Fraser, N. and Honneth, A. (2003) Redistribution or recognition? A politicalphilosophical exchange. London: Verso.

Gash, V. and O'Connell, P.J. (2000) The Irish Graduate Labour Market: A six year follow up survey of third level graduates, Dublin: ESRI.

Glaser, B.G. (1992) Basics of grounded theory analysis, Mill Valley, CA: The Sociology Press.

Green, J. (2003) Understanding social programme through evaluation, in Denzin, N. and Linclon, Y. (pp 590-619) Collecting and Interpreting Qualitative Materials, London: Sage.

Habermas, J. (1979) Communication and the Evolution of Society, Boston, MA: Beacon Press.

Habermas, J. (1984) Theory of Communicative Action, Vol 1, Reason and the Rationalization of Society, Boston, MA: Beacon Press.

Habermas, J. (1987). Theory of Communicative Action, Vol 2, Lifeworld and System: A critique of functionalist reason, Boston, MA: Beacon Press.

Hardt, M. and Negri, A. (2000) Empire, Cambridge, MA: Harvard University Press.

Harvey, D. (1989) The condition of post-modernity: An Enquiry into the Origins of Cultural Change, Oxford: Blackwell.

HEA (2004) Towards a National Strategy: Initial Review of HEA Targeted Initiatives to Widen Access to Higher Education, Dublin: HEA.

HEA, (2008a) National Plan for Equity of Access to Higher Education, Dublin: HEA. 
HEA, (2008b) What do Graduates Do? The Class of 2006, Dublin: HEA.

Honneth, A. (1995) The struggle for recognition: The moral grammar of social conflicts. Cambridge: Polity Press.

Inglis, T. and Murphy, M. (1999) No Room for Adults? A Study of Mature Students in University College Dublin, Dublin: UCD.

Irish Government (1965) Investment in Education: Report of the survey team appointed by the Minister of Education in October 1962, Dublin: The Stationery Office.

Irish Government (2007) National Development Plan 2007-2013, Dublin: The Stationary Office.

Kelly, M. (2005) The effects of increasing numbers of mature students on the pedagogical practices of lecturers in the Institutes of Technology, Irish Educational Studies, 24(2-3): 207-221.

Loxley, A., and Seary, A. (2008) Some philosophical and other related issues of insider research, in Skies P. and Potis, A. Researching Education from the Inside (pp15-32), London: Routledge.

Lynch, K. (1997) A Profile of mature students in Higher Education and an analysis of equality issues, in Morris, R. (ed.) Mature Students in Higher Education (pp 79-116), Cork: Higher Education Equality Unit.

Lynch, K. (1999) Equality in Education, Dublin: Gill \& Macmillan.

Lynch, K. (2005) Neo-liberalism, Marketisation and Higher Education: Equality Considerations, in HEA, Report on Conference Proceedings: Achieving Equity of Access to Higher Education (pp 9-21), Dublin: HEA.

Lynch, K. and Baker, J. (2005) Equality in education: The importance of equality of condition, Theory and Research in Education, 3(2): 131-164.

McMahon F (2008) Mature student numbers in DIT, Presentation to the DIT Governing Body by the Director of Academic Affairs.

Mezirow, J. (2007). Adult education and empowerment for individual and community development, in Connolly, B., Fleming, T., McCormack, D. and Ryan, A. (eds.) Radical Learning for Liberation 2, Maynooth: MACE.

Morris, R. (ed.) (1997) Mature students in Higher Education. Proceedings of Conference in Athlone RTC, March 1996, Cork: Higher Education Equality Unit.

(NOEA) National Office for Equity of Access to Higher Education (2005) Toward the Best Education for All: An Evaluation of Access Programmes for Higher 
Education in Ireland, Dublin: HEA.

(NOEA) National Office for Equity of Access to HE (2007) Annual Report 2006 and Outline Plans 2007, Dublin: NOEA.

(NOEA) National Office for Equity of Access to Higher Education (2008) National Plan for Equity of Access to Higher Education 2008-2013, Dublin: HEA.

O'Connell, P.J., Clancy, D. and McCoy, S. (2006) Who went to college in 2004: A National Survey of New Entrants to Higher Education, Dublin: HEA.

OECD (2004) Review of National Policies for Education: Review of Higher Education in Ireland: Examiners report, Paris: OECD.

OECD (2008) Trends Shaping Education, Paris: OECD.

Osborne, R. and Leith, H. (2000) Evaluation of the Targeted Initiatives on Widening Access for Young People from Socio-Economically Disadvantaged Backgrounds, Dublin: HEA.

Risquez, A., Moore, S. amd Morley, M. (2007) Welcome to college? Developing a richer understanding of the transition process for adult first year students using reflective written journals. College Student Retention, 9(2): 183-204.

Sennett, R. and Cobb, J. (1977) The Hidden Injuries of Class, Cambridge: Cambridge University Press.

Shannon Consortium (2010) Gateways to learning. URL: http://www.ul.ie/shannonconsortium/index.php

Skilbeck, M. and Connell, H. (2000) Access and Equity in Higher Education: An International Perspective on Issues and Strategies. Dublin: HEA.

Tett, L. (2002) Community Education, Lifelong Learning and Social Inclusion, Edinburgh: Dunedin Academic Press.

Thomas, J. (1993) Doing Critical Ethnography, London: Sage.

Thomas, L. and Quinn, J. (2007) First Generation Entry into Higher Education: an International Study, Maidenhead: SRHE.

Thompson, J. (ed) (2000) Stretching the academy: The politics and practices of widening participation, Leicester: NIACE.

Trow, M. (1979) Elite and mass Higher Education: American models and European realities, in Trow, M. Research into Higher Education: Processes and Structures, Stockholm: National Board of Universities and Colleges. 
White, T. (2001) Investing in people: Higher Education in Ireland from 19602000, Dublin: IPA. 


\section{Appendix 1 Profile of research team}

\section{Dr Ted Fleming}

Dr Ted Fleming is Senior Lecturer at the Department of Adult and Community Education at the National University of Ireland Maynooth and is Director of the Centre for Research in Adult Learning and Education at Maynooth. He was awarded a Masters and Doctorate in Adult Education by Columbia University New York. His research interests include transformation theory; critical theory; mature students, access and Higher Education. Current research projects include an EU-funded longitudinal study of dropout and retention issues for nontraditional students in European universities (Fleming and Finnegan, 2009). He has recently co-edited (with M. Murphy) Habermas, Critical Theory and Education, New York: Routledge.

\section{Dr Andrew Loxley}

Dr Andrew Loxley is currently the Director of Research in the School of Education TCD and founding member of the School's Cultures, Academic Values in Education (CAVE) research group. A sociologist by trade and $\mathrm{PhD}$ graduate from the University of Bath, he has been involved in a number of small and large scale research projects both in Ireland and in the UK over the past 15 years and writes on the issue of social inclusion, as well as Higher Education policy and practice and research methodology. He has been in TCD since 2002 and before that was a lecturer in the School of Education at the University of Leeds.

\section{Aidan Kenny}

Aidan Kenny has been a lecturer in the DIT since 1997, working in the Faculty of the Built Environment. In 2006 he was appointed as the Project Manager of the Skills Research Initiative and the Co-ordinator of the UNESCO-UNEVOC National Centre for Ireland located in DIT. His research interests include the relationship between VET and HE, skills development, employability and forms of capital. He is also working on several EU-funded projects and an SIFII project. 


\section{Fergal Finnegan}

Fergal Finnegan is an adult education tutor and a Researcher at the Centre for Research in Adult Learning and Education at NUI Maynooth. He has a Masters degree in adult education and was a John and Pat Hume Scholar at Maynooth where he is studying working class students in Higher Education for PhD. His work is published in The Adult Learner (2009) and at the European Society for Research in the Education of Adults Conference. He is currently Government of Ireland Scholar at NUIM. 


\section{Appendix $2 \quad$ The Interview Schedule for Students}

Please note, that each interview was started by reiterating the purpose of the study and who it was for, the ethical parameters of the research, and the option to not record the interview. Additionally, the schedules were used in a semi-structured format to suit the particularly and institutional context.

1. Where Next? Mapping and Understanding the Post First Degree Destinations of Mature Disadvantaged Students in three Higher Education Institutions

2. Interview questions for critical stakeholders

3. In your opinion what kinds of ideas/thinking/concepts/philosophies underpin the rationale for opening up/encouraging access to HE for those adults deemed to be disadvantaged?

4. What do you see as being the key impediments to access for this group of adults?

5. What do you see/ or are/ or could be/ the kind of mechanisms used to facilitiate access for mature students?

6. What kind of third level programmes do you see as useful/necessary/significant for mature students?

7. Do you consider that Higher Education is an appropriate route into work for mature students?

8. How do you view the economic dimensions that are part of the lifelong learning agenda in relation to this group of students?

9. How do you view the social dimensions that are part of the lifelong learning agenda in relation to this group of students?

10. How do you view the relationship between these two dimensions?

11. How do you veiw the role of HE institutes in steering this fit between the percieved needs of the ecomony and the social dimension of Higher Education?

12. How do you percive the role of bodies outside of HE (DES, IBEC, ICTU, EGFSN, FAS, OECD etc) in steering HE institutes in the shaping of their programmes to meet the needs of mature students? 
NUIM, TCD, DIT Mature Student Research Project

Interview question schedule for Critical Stakeholders

November 2008

1. Why do you think (NUIM, TCD, DIT) is interested in attracting Mature Students?

2. From your knowledge why do you think Mature Students choose to enrol in (NUIM, TCD, DIT)? What degree programmes are most popular with Mature Students?

3. Are you aware of any barriers that stop Mature Students from considering and beginning the application process to enter (NUIM, TCD, DIT)? How is the Institute addressing these?

4. What polices has (NUIM, TCD, DIT) in place to facilitate Mature Student access? How will these be developed over the coming years?

5. How does (NUIM, TCD, DIT) promote Mature Student access? Do you consider this is effective?

6. What percentage of the current student body is enrolled as Mature Students? What is the projected target for 2010? How will this be achieved?

7. How does the (NUIM, TCD, DIT) Access programme work? What do Mature Students think about this programme?

8. What support services does (NUIM, TCD, DIT) offer to enrolled Mature Students? Are there any additional services that need to be developed?

9. Do you consider there are any barriers which inhibit Mature Students from engaging in the full range of general student body actives that are on offer in (NUIM, TCD, DIT)?

10. What follow-up services are in place for Mature Students who graduate? How will these services be developed in the future?

Any additional comments or observations? 
Appendix 3, Questionnaire

\section{MAPPING AND UNDERSTANDING THE POST DEGREE DESTINATIONS OF MATURE STUDENTS: QUESTIONNAIRE}

(C) NUIM 2008

Part 1: Personal Information 
1. Your gender Male $\square$ Female $\square$

2. Your age (at last birthday)

3. Nationality

4. Are you: Married $\square$ Single $\square$ Living with partner $\square$

5. Number of children

6. Your current occupation (please give exact title, eg secondary teacher instead of teacher, telesales for a software manufacturer rather than salesperson etc )

Part 2 : About your Degree

7. What type of degree were you awarded? BA $\square$ BSc $\square$ BEd $\square$ LLB $\square$

8. Did you study Part-time $\quad \square \quad$ Full-time

9. What year did you enroll?

9a. What year did you graduate?

10. What were your main subjects?

11. What was your main motivation for beginning the course?

Improve employment prospects: $\square \quad$ Personal interest

Other:

If 'Other' please give the reason here

12. Is your degree recognised by national agencies abroad? Yes $\square$ No $\square$ Do not know

13. Is your degree recognised by professional bodies abroad? Yes $\square$ No $\square$ Do not know

14. Are you familiar with the National Framework of Qualifications? Yes $\square$ No $\square$

15. Do you know where your degree fits within this framework? Yes $\square \quad$ No $\square$

16. Are you aware of the European Qualifications Framework? Yes $\square$ No $\square$ 
17. Do you know what level your degree is within the European framework? Yes $\square$ No $\square$

18. Is English one of your native languages?

Yes $\square \quad$ No $\square$

19. If English is not your first language, how significant an obstacle was this to you during your studies?

Very significant $\square$ Significant $\square$ Not significant $\square \quad$ Not an issue at all

20. If English is not your first language did the college offer support for your language needs?

Yes $\square \quad$ No $\square$

21. With the benefit of hindsight would you choose the same course again? Yes $\square$ NoD

Please give three main reasons for this:

1

2

3

Part 3: Financing your Studies

22. Did you have a job before college?

Yes $\square \quad \mathrm{No} \square$

23. If yes what job(s) did you do? (please give exact title eg secondary teacher instead of teacher, telesales for a software manufacturer rather than salesperson etc)

24. Was this job: Full-time $\square$ Part-time $\square$

25. Did you work while studying? Yes $\square$ No $\square$

26. If yes, what type of work did you do?

27. If you were in paid employment, on average how many hours a week did you work? 
28. Did you receive financial support from your employer for your studies?

Yes $\square$ No

If yes so please give details

29. Did you receive financial support from Social Welfare?

Yes $\square \quad$ No $\square$

If yes was this BTEI $\quad \square \quad$ Other $\square$ (If Other please specify)

30. How important was the availability of support from Social Welfare for the completion of your degree?

Not important $\quad \square$ Quite important $\quad \square$ Very important

31. Did you receive a grant while studying for your degree? Yes $\square$ No

32. Did you receive a scholarship? Yes $\square$ No $\square$

33. If 'yes' was this from the college where you were studying ? Yes $\square \quad$ No $\square$

Please specify the sponsoring department, institution, group or fund for the scholarship

34. As a student did this financial support cover:

All of your costs $\square$ Some of your costs

35. Did you receive financial support from a community group or partnership organisation?

Yes $\square \quad$ No $\square$ If yes please give details

36. As a student did this financial support cover:

All of your costs $\square$ Some of your costs

37. Did you build up debts as a consequence of studying for your degree?

Yes $\square \quad$ No $\square$

If yes please indicate approximately how much debt this entailed.

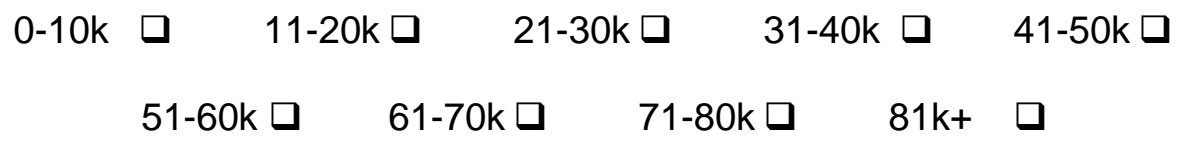

Part 4: Studying with a Disability

(if this part of the questionnaire does not apply to you please go to Part 5) 
38. If you have a disability (e.g. visual impairment, dysxlexia etc) did you find that the college took account of your needs and provided the necessary support and services?

$$
\text { Yes } \square \quad \text { No } \square \quad \text { Partially }
$$

39. In general, how would you rate the quality of the services and supports you had access to as a student with a disability? (Please circle the appropriate number with $0=$ very poor quality; 5 very high quality).

$$
\begin{array}{llllll}
0 & 1 & 2 & 3 & 4 & 5
\end{array}
$$

40. In general, to what extent did the services and supports meet your needs?

( 0 = not all; 5 =very good fit).

$\begin{array}{llllll}0 & 1 & 2 & 3 & 4 & 5\end{array}$

41. In general, how would you rate your experience of lecturers' attitude towards your disablity? ( $0=$ very negative; very positive).

$\begin{array}{llllll}0 & 1 & 2 & 3 & 4 & 5\end{array}$

42. In general, to what extent did the lecturers on your course meet your learning needs as a student with a disability? ( $0=$ not all; 5 = very good fit).

$$
\begin{array}{llllll}
0 & 1 & 2 & 3 & 4 & 5
\end{array}
$$

43. In general, how would you rate your experience of your fellow student's attitude towards your disablity? ( $0=$ very negative; very positive).

$\begin{array}{llllll}0 & 1 & 2 & 3 & 4 & 5\end{array}$




\section{Part 5: Your Experience of College and Study}

The following statements are concerned with your experience of higher education. After each one please tick the box that best represents your opinion.

\begin{tabular}{|c|c|c|c|c|c|}
\hline Statement & $\begin{array}{l}\text { Strongly } \\
\text { disagree }\end{array}$ & Disagree & $\begin{array}{l}\text { Neither } \\
\text { agree or } \\
\text { disagree }\end{array}$ & Agree & $\begin{array}{l}\text { Strongly } \\
\text { agree }\end{array}$ \\
\hline $\begin{array}{l}\text { In general the college was a } \\
\text { welcoming place }\end{array}$ & $\square$ & $\square$ & $\square$ & $\square$ & $\square$ \\
\hline $\begin{array}{l}\text { The approach(es) to teaching that I } \\
\text { experienced was well matched to } \\
\text { how adults learn }\end{array}$ & $\square$ & $\square$ & $\square$ & $\square$ & $\square$ \\
\hline $\begin{array}{l}\text { The criteria for academic evaluation } \\
\text { and assessment were clear }\end{array}$ & $\square$ & $\square$ & $\square$ & $\square$ & $\square$ \\
\hline $\begin{array}{l}\text { In general students on my course } \\
\text { were well supported by lecturers in } \\
\text { their academic work }\end{array}$ & $\square$ & $\square$ & $\square$ & $\square$ & $\square$ \\
\hline $\begin{array}{l}\text { The criteria for academic } \\
\text { progression on my course were } \\
\text { clear }\end{array}$ & $\square$ & $\square$ & $\square$ & $\square$ & $\square$ \\
\hline $\begin{array}{l}\text { My family members were supportive } \\
\text { of me whilst I was at college }\end{array}$ & $\square$ & $\square$ & $\square$ & $\square$ & $\square$ \\
\hline $\begin{array}{l}\text { My non-college friends were } \\
\text { supportive of me whilst I was at } \\
\text { college }\end{array}$ & $\square$ & $\square$ & $\square$ & $\square$ & $\square$ \\
\hline $\begin{array}{l}\text { I felt unprepared for studying at } \\
\text { degree level }\end{array}$ & $\square$ & $\square$ & $\square$ & $\square$ & $\square$ \\
\hline $\begin{array}{l}\text { I found other students on my course } \\
\text { supportive }\end{array}$ & $\square$ & $\square$ & $\square$ & $\square$ & $\square$ \\
\hline $\begin{array}{l}\text { I met a lot of students from a similar } \\
\text { background (e.g. age, social class } \\
\text { etc) as myself at college }\end{array}$ & $\square$ & $\square$ & $\square$ & $\square$ & $\square$ \\
\hline $\begin{array}{l}\text { Studying for a degree has changed } \\
\text { me personally }\end{array}$ & $\square$ & $\square$ & $\square$ & $\square$ & $\square$ \\
\hline $\begin{array}{l}\text { Studying for a degree negatively } \\
\text { affected my personal relationships }\end{array}$ & $\square$ & $\square$ & $\square$ & $\square$ & $\square$ \\
\hline $\begin{array}{l}\text { The type of and accessibility to } \\
\text { resources (library, ICT etc) were } \\
\text { adequate for my needs as a student }\end{array}$ & $\square$ & $\square$ & $\square$ & $\square$ & $\square$ \\
\hline
\end{tabular}


Studying on a degree course has changed the way I approach my job

I generally found my experience of college to be a negative one

\section{Statement}

My gender impacted on my experience of college

My family did not understand my reasons for going to college

It was difficult to interact with other students on my course who were younger than me

My age impacted on my experience of college

My life experience was an advantage to me

I developed lasting friendships at college

Balancing the demands of childcare with studying was very difficult

My socio-economic class had a negative impact on my experience of college

My life experience was viewed negatively by lecturers

The pacing and structure of the course was compatible with the other demands on my time

Studying meant I had to restrict my social activities

During my studies my quality time with my family was reduced

\section{Strongly}

disagree

Disagree

Neither

agree or

disagree

Agree

Strongly

agree

$\square$

$\square$

$\square$

$\square$

$\square$

$\square$

$\square$

$\square$

$\square$

$\square$ 


\section{Part 6: After your Degree: Work and Employment}

The following statements ask you about the relevance of your experience of third level education to work and your career

\section{STATEMENT}

I had a clear idea of the job I wanted when I chose my course

My career plans changed over the duration of the course.

My academic department(s) helped me to explore my career options.

The career advisory service at my college was a useful resource

I was overqualified for the job I had after my degree

Having a degree made a big difference to my short term career opportunities

Most of my work colleagues have degrees

It was necessary for me to have a degree for the type of job I wanted

I think a degree will make a big difference to my long term career opportunities

The content of my degree course was very useful to me in my job

On my college course I acquired skills that have helped me in my job

I am treated differently at work by my colleagues because I have a degree

My choice of college course was not about the kind of job I intended to do after graduation

I think a degree is necessary for a good job

My degree has opened up employment opportunities for me which I did not previously have
Strongly

Disagree

Disagree

Agree nor

Disagree

Agree

Strongly

Agree

$\begin{array}{ll}\square & \text { ㅁ } \\ \square & \\ \square & \end{array}$

$a$

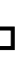

$\square$

$\square$

$\square$

$\square$

$\square$

$\square$

ㅁ

ㅁ

$\square$

$\square$

$\square$

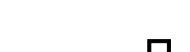

Agree

口

$\square$

$\square$


Having a degree makes me feel confident about my career prospects

My choice of degree course was vital for my career

\section{STATEMENT}

My college friends have helped me in my career

My degree will enable me to gain work in other countries

The time I invested gaining a degree was worthwhile

The financial investment I made in gaining a degree was worthwhile

Following my degree I now have a greater range of choice of jobs

\section{Strongly \\ Disagree}

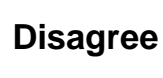

$\square$

$\square$

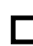

$\square$
Agree

Disagree
Strongly

Agree

44. Did you look for work immediately following graduation?

$$
\text { Yes } \square \quad \text { No }
$$

If 'no' were you: (please tick only one of the following boxes)

looking for another course $\square$

travelling (e.g. 'world tour')

doing volunteer work $\square$

doing unpaid work in the home

Other

If other please give details

45. Are you working at the moment? Yes $\square$ No

If yes are you working: $\quad$ Part-time $\quad \square \quad$ Full-time

46. What is your average gross annual income?

$$
\begin{aligned}
& \begin{array}{lllll}
0-10 k & \text { 11-20k } \square \quad 21-30 k \square & 31-40 k \square & 41-50 k
\end{array} \\
& \text { 51-60k } \square \quad 61-70 k \square \quad 71-80 k \square \quad 80 k+
\end{aligned}
$$


47. Have your post-degree earnings increased? Yes $\square \quad$ No $\square$

48. Did you expect your earning to increase? Yes $\square \quad$ No

49. Have you changed jobs since completing your degree? Yes $\square$ No

Please give details (title and when)

50. Have you been promoted within your present job? Yes $\square \quad$ No

Please give details (title and when)

51. Since being awarded your degree have you set up a company with college friends? Yes $\square \quad$ No $\square$

52. I now work (please tick only if applicable):

For a friend from college

For a relative of a college friend

With friends college

53. Have you had training at work? Yes $\square \quad$ No $\square$

If yes please give details

54. How useful has this training been?

Very useful

Of limited use $\square$

No use at all $\square$

55. Do you value the training you have had at work more than your degree?

Yes $\square \quad$ No $\square$

Please explain your response

56. Have you worked in another country since you graduated? Yes $\square$ No $\square$

57. If yes do you think your degree enabled you to get the job you wanted in that country? Yes $\square \quad$ No $\square$ 
58. Do you currently intend to stay and work in Ireland? Yes $\square$ No $\square$

59. What factors would be most likely to influence a decision to seek work abroad? (please tick the most relevant boxes)

Availability of work $\square$

Levels of pay $\square$

Accommodation

Cost of living $\square$

Work opportunities

Study opportunities $\square$

Social life

Cultural experience

Part 7: After your degree: Postgraduate study

60. Are you currently involved in or about to embark on postgraduate study?

Yes $\square$ No $\square$

If yes please indicate what type of course(s)? (Please note HDips are now called PGDips)

PostGrad Dipl/Higher Dipl

Masters Degree

Doctorate

Other

If started, date started

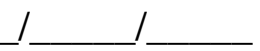

If other please give degree title

61. Have you completed a post-graduate degree? Yes $\square$ No $\square$

If yes, date graduated 1

62. If you have completed a postgraduate course what level was the degree?

MA $\square \quad$ PhD $\square \quad$ PGDip $\square \quad$ MEd $\square \quad$ MPhil $\square \quad$ MSc $\square \quad$ Other

If other please give degree title

63. Is/was your area of postgraduate study connected to what you did for your primary degree?

Yes $\square$ No $\square$ If 'no' why did you decide to change your areas of interest? 
64. What is/was the main factor in your decision to undertake postgraduate study?

To enhance employment prospects

$\square \quad$ Interest in the area

Other

If other please give details

65. If you have opted not to continue with your studies at this point in time, would you consider doing so in the future? Yes $\square \quad$ No $\square$

66. What do you imagine would be the main motivation for a return to third level?

To enhance employment prospects

Interest in the area

Other

67. If you do not intend to return to Higher Education what is the main reason?

Financial barriers

Job commitments

Family duties

I do not see the value of further study

Other

If other please specify

68. What advice would you offer someone in a similar position to yourself who is considering entering higher education?

69. If you have any other reflections or observations on the issues dealt with in the questionnaire please write them down here 
Many thanks for taking the time and effort to complete the questionnaire. Please send the questionnaire back to the Department of Adult and Community

Education in the prepaid and addressed envelope. Confidentiality is guaranteed.

As part of the next stage of the research project the team would like to talk to a number of our graduates. If you would be willing to participate in this study then please complete the section below.

I would like to participate in an interview

Name:

Address:

Telephone:

Email: 